Universidade de São Paulo

Instituto de Astronomia, Geofísica e Ciências Atmosféricas

Departamento de Ciências Atmosféricas

Camila da Cunha Lopes

\title{
Microfísica, Cinemática e Eletrificação em Tempestades Tropicais que geraram Granizo durante o Projeto SOS-CHUVA
}

São Paulo 



\section{Microfísica, Cinemática e Eletrificação em Tempestades Tropicais que geraram Granizo durante o Projeto SOS-CHUVA}

Dissertação apresentada ao Departamento de Ciências Atmosféricas do Instituto de Astronomia, Geofísica e Ciências Atmosféricas da Universidade de São Paulo como requisito parcial para a obtenção do título de Mestre em Ciências.

Área de Concentração: Meteorologia Orientadora: Prof ${ }^{\mathrm{a}}$ Dr $^{\mathrm{a}}$ Rachel Ifanger Albrecht

Versão Corrigida. O original encontrase disponível na Unidade.

São Paulo 



\section{Agradecimentos}

À minha orientadora, $\operatorname{Prof}^{\mathrm{a}} \mathrm{Dr}^{\mathrm{a}}$ Rachel Ifanger Albrecht, por todas as oportunidades dentro e fora da pesquisa, contribuindo imensamente para o meu crescimento pessoal e profissional.

À Fundação de Amparo à Pesquisa do Estado de São Paulo (FAPESP), sob o processo $n^{\circ}$ 2017/06075-3 (vinculado ao processo $n^{\circ} 2015 / 14497-0$ ) pelo apoio financeiro para a realização da pesquisa e apresentação em congresso internacional.

Ao Conselho Nacional de Desenvolvimento Científico e Tecnológico (CNPq), pelo apoio financeiro para a realização da pesquisa.

À Secretaria e Seção de Informática do Departamento de Ciências Atmosféricas (DCA-IAG) pela ajuda técnica e burocrática.

À toda equipe do Projeto SOS-CHUVA pela dedicação na instalação, manutenção, desenvolvimento e divulgação que permitiram que esse trabalho pudesse ser feito.

Ao Prof $^{o}$ Dr. Lawrence D. Carey, Msc. Sarah Stough e demais colegas do grupo de trabalho do Departamento de Ciências Atmosféricas da Universidade do Alabama em Huntsville (UAH) que me auxiliaram no processamento da recuperação de vento por Multi-Doppler durante a visita à universidade.

Aos amigos e colegas de departamento, especialmente Isabela Siqueira, Victória Peli e Alan Rosales, pela companhia e apoio, principalmente nas (muitas) horas difíceis.

E, acima de tudo, à minha família, Janice, Fernando e Yukio, por serem meu grande alicerce durante esses dois anos de tantas mudanças na minha vida. 

Weather Cat-O-mat
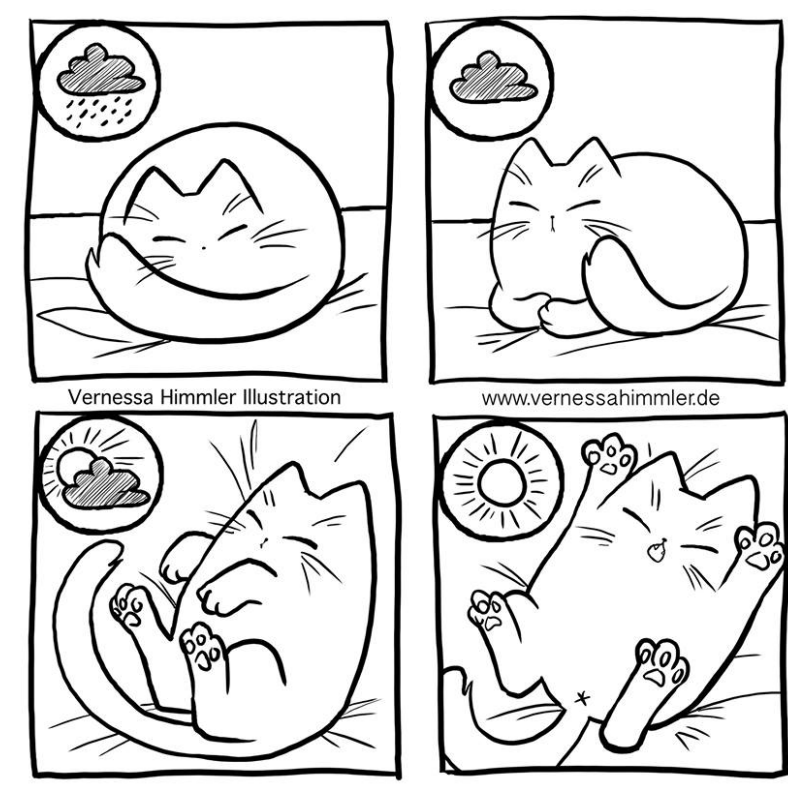

Fonte: Vernessa Himmler Illustration (2017). 



\section{Resumo}

Esta dissertação analisou tempestades que produziram granizo na Região Metropolitana de Campinas com o objetivo de identificar fatores determinantes para a produção e precipitação de granizo. De forma inédita, uma rede de detecção de granizo instalada na região permitiu a identificação e determinação das intensidades das tempestades entre 2016 e 2017. O ciclo de vida, estrutura microfísica e cinemática de casos específicos foram estudados usando três radares meteorológicos instalados no estado de São Paulo e uma rede de detecção de raios, com ferramentas como rastreamento de sistemas convectivos, identificação de hidrometeoros e recuperação de vento tridimensional por Multi-Doppler. Comparando com escalas de intensidade de granizo aplicadas ao continente europeu, os casos analisados apresentaram intensidade baixa, com granizo de no máximo 22, $4 \mathrm{~mm}$ de diâmetro. O caso de 2017-03-14 apresentou o tempo de vida mais longo (6,2 h), queda de granizo em duas localidades (com diâmetro máximo de 11,8 $\mathrm{mm}$ ) e atividade elétrica mais intensa (taxa máxima de 107 (31) flashes min $^{-1}$ IC (CG)), enquanto que o caso de 2017-11-15, com tempo de vida mais curto $(2,2 h)$, apresentou baixa atividade elétrica (total de 46 (20) flashes IC (CG)) porém com queda de granizo mais intensa (com diâmetro máximo de 22,4 mm). Todas as quedas de granizo dos casos específicos citados anteriormente estão associadas a uma extensa coluna de granizo identificada pelo radar polarimétrico e correntes ascendentes de até $30 \mathrm{~ms}^{-1}$ antes do evento; o granizo maior no caso de 2017-11-15 possivelmente tem contribuição da precipitação na forma líquida (associada à correntes descendentes mais intensas) que previne a diminuição de tamanho do granizo ao mesmo tempo que contribui para o seu crescimento mesmo abaixo da base da nuvem. Alguns fatores determinantes encontrados em ambos os casos foram o aumento da atividade elétrica antes ou depois da queda de granizo, a presença de granizo em uma camada extensa dentro da nuvem e a atuação da corrente ascendente dentro da região de fase mista contribuindo para a formação e crescimento do granizo.

Palavras-chave: Granizo. Microfísica de Nuvens. Multi-Doppler. São Paulo. 



\section{Abstract}

This dissertation analyzed hail producing storms on the Metropolitan Region of Campinas to identify key factors for hailfall occurrence. For the first time, a hail detection network installed in the region allowed the identification and determination of thunderstorm intensity in the 2016-2017 period. The life cycle, microphysical structure and kinematics of specific cases were studied using three meteorological radars installed in São Paulo state and a lightning detection network, with tools such as tracking of convective systems, hydrometeor identification and Multi-Doppler 3D wind retrieval. The analyzed cases had low hailfall intensity when compared with scales applied in Europe, with $22.4 \mathrm{~mm}$ maximum hail diameter. The 2017-03-14 case presented the longest lifetime $(6.2 h)$, hailfall in two locations (11.8 $\mathrm{mm}$ maximum hail diameter) and the most intense lightning activity (107 (31) flashes min $^{-1}$ IC (CG) maximum rate), while the 2017-11-15 case, with a shorter lifetime $(2.2 \mathrm{~h})$, presented low electrical activity (46 (20) flashes IC (CG) total) with the most intense hailfall (22.4 $\mathrm{mm}$ maximum hail diameter). All hailfall cases of the specific cases mentioned earlier are associated with a extensive hail column identified by the polarimetric radar and up to $30 \mathrm{~ms}^{-1}$ updrafts before the events; the bigger hail in the 2017-11-15 case possibly had the contribution of liquid precipitation (associated with larger downdrafts) which prevents hail size decrease as well as contributes to its growth below the cloud base. Some key factors found in both cases were the increase in electrical activity before or after hailfall, the presence of hail in a extensive layer within cloud and the updrafts within mixed phase layer contributing to hail formation and growth.

Keywords: Hail. Cloud Microphysics. Multi-Doppler. São Paulo. 



\section{Lista de figuras}

Figura 1 - Classificação dos processos primários de crescimento de hidrometeoros.

Figura 2 - Carga adquirida pelo graupel/granizo após a colisão com cristais de gelo em função do conteúdo de água líquida e temperatura. As linhas tracejadas delimitam os regimes de crescimento molhado (porção superior), crescimento seco por sublimação (porção central) e crescimento seco por deposição (porção inferior). . . . . . . . . . . . . . . . . . . . 27

Figura 3 - Esquema com as características de escala planetária e sinótica primárias encontradas na superfície no Atlântico Tropical em janeiro (a) e julho (b).

Figura 4 - Climatologia anual de granizo a partir do sensor AMSR-E para o sudeste da América do Sul. Os contornos em cinza indicam a elevação, com intervalos de $1 \mathrm{~km}$.

Figura 5 - Sistema de coordenadas cilíndricas usado para análise Dual-Doppler de dados de radar. Os radares estão localizados nos pontos 1 e 2 e $a_{r}, a_{s}$ e $a_{\alpha}$ são as normais unitárias definindo a direção das três componentes ortogonais da velocidade. O eixo cilíndrico está ao longo da linha conectando os radares (separados por uma distância $2 d$ ) e $r$ é a distância do eixo ao dado pontual. . . . . . . . . . . . . . . . . . . . . . .

Figura 6 - Ângulos teóricos de cruzamento do feixe com Dual-Doppler de $45^{\circ}$ (melhores dados de vento) e $30^{\circ}$ (dados de vento aceitáveis) para um par de radares Doppler. . . . . . . . . . . . . . . . . . . . . . . 34

Figura 7 - (a) Rede de hailpads instalada na Região Metropolitana de Campinas com a localização e cobertura de $80 \mathrm{~km}$ do radar XPOL. (b) Hailpad instalado na cidade de Indaiatuba, na localização indicada com a seta em $(\mathrm{a}) \ldots \ldots \ldots \ldots \ldots \ldots$. . . . . . . . . . . . . . . . . . . . .

Figura 8 - Placa R004 sensibilizada no sítio (a) e sem a cobertura de alumínio (b). 37

Figura 9 - Curva de calibração do hailpad obtida pelo LIM/CPTEC-INPE (THOMAZ JÚNIOR, 2016) . . . . . . . . . . . . . . . . . . . . . . 38

Figura 10 - Localização e cobertura dos radares da FCTH (laranja), de São Roque (azul) e o XPOL (verde). As linhas mais grossas representam a cobertura de 250 (80) km dos radares FCTH e São Roque (XPOL), enquanto que as linhas mais finas representam a cobertura de 100 (60) km dos mesmos radares. . . . . . . . . . . . . . . . . . . . . . . 40 
Figura 11 - Representação dos tipos de classificação do ForTraCC: continuidade (a), separação (b) e fusão (c). As formas com contorno tracejado representa o sistema no primeiro passo enquanto que as formas cinzas representam o sistema no passo seguinte, com as setas indicando o deslocamento. . .

Figura 12 - Estratégia de varredura volumétrica dos radares meteorológicos da FCTH (a), de São Roque (b) e o XPOL instalado na UNICAMP (c). As linhas tracejadas delimitam a distância de cada radar à rede de hailpads (Figura 7a). . . . . . . . . . . . . . . . . . 43

Figura 13 - Classificação de hidrometeoros de acordo com refletividade (a), refletividade diferencial (b), fase diferencial específica (c) e coeficiente de correlação (ou razão de correlação cruzada) (d) . . . . . . . . . . . . . .

Figura 14 - Ângulos de cruzamento do feixe com Dual-Doppler de $45^{\circ}$ (melhores dados de vento) e $30^{\circ}$ (dados de vento aceitáveis) para um par de radares Doppler, mais especificamente para as combinações dos radares FCTH e XPOL, São Roque (SR) e FCTH e SR e XPOL. Os contornos em cinza representam as cidades de São Paulo, Indaiatuba e Campinas, enquanto que as linhas pontilhadas indicam as distâncias entre os radares. 48

Figura 15 - Velocidade radial verdadeira vs medida de um alvo com uma velocidade de Nyquist de $10 \mathrm{~ms}^{-1}$ mostrando a ambiguidade para valores de velocidade verdadeira além do intervalo de -10 a $10 \mathrm{~ms}^{-1}$. . . . . . . . 49

Figura 16 - Histogramas de tempo entre strokes e entre flashes (a), número de strokes por flash (b) e distância latitude e longitudinal entre strokes em um flash (c). . . . . . . . . . . . . . . . . . . 52

Figura 17 - Plotagem violino com caixa das distribuições de diâmetro do granizo de diferentes medidas feitas por IAG (sendo que 1 e 2 foram medidas por uma pessoa e 3 por outra) e LIM separados por caso. . . . . . . . . 56

Figura 18 - Energia cinética do hailpad em função do diâmetro do granizo considerando as escalas ANELFA e TORRO, com os índices de A0 a A2 e de H0 a H2 (Tabela 3) indicados. . . . . . . . . . . . . . . . . . 57

Figura 19 - Evolução temporal da refletividade máxima em $3 \mathrm{~km}$ do radar de São Roque (a), tamanho do sistema (b) e taxa de flashes CG e IC (c). As linhas pontilhadas indicam o momento aproximado em que houve a queda de granizo medida no hailpad. . . . . . . . . . . . . . . . 58

Figura 20 - Campos da reanálise do ERA5 em 2017-03-14: Pressão ao nível médio do mar, espessura entre 1000 e $500 \mathrm{hPa}$ e velocidade do vento em $250 h P a$ às 1200 UTC (a); altura geopotencial em 850hPa, cisalhamento do vento entre 1000 e 500 hPa e CAPE em superfície às 1200 (b) e 1500 UTC, no domínio do estado de São Paulo (c) . . . . . . . . . . . . 60 
Figura 21 - Plotagem Skew-T Log-P da radiossondagem do Campo de Marte (SP) com hodógrafa do vento e índices CAPE e CIN em 2017-03-14 1200 UTC . . . . . . . . . . . . . . . . . . .

Figura 22 - Imagem de satélite do canal 13 do GOES-16 mostrando a temperatura de brilho do topo das nuvens no estado de São Paulo em 2017-03-14 1751 (a) e 1951 UTC (b). . . . . . . . . . . . . . . . . .

Figura 23 - Rastreamento (a) e localização dos flashes IC e CG (b) do sistema convectivo responsável pelas quedas de granizo em Cosmópolis e Indaiatuba em 2017-03-14. Os triângulos pretos indicam a localização dos hailpads. . . . . . . . . . . . . . . . . . . .

Figura 24 - Campos de refletividade (a) e flashes IC (b) e CG (c) acumulados em 10 minutos do sistema convectivo (delimitado pela linha preta) responsável pela queda de granizo em Cosmópolis em 2017-03-14. O triângulo preto indica a localização do hailpad. Linhas contínuas demarcam os limites dos municípios do Estado de São Paulo. . . . . . . . . . . . . .

Figura 25 - Campos de refletividade (CAPPI em $3 \mathrm{~km}$ do radar de São Roque) (a) e flashes IC (b) e CG (c) acumulados em 10 minutos do sistema convectivo (delimitado pela linha preta) responsável pela queda de granizo em Indaiatuba em 2017-03-14. O triângulo preto indica a localização do hailpad. Linhas contínuas demarcam os limites dos municípios do Estado de São Paulo. . . . . . . . . . . . . . . . . . . . . . . . .

Figura 26 - Corte horizontal em $3 \mathrm{~km}$ de altura e vertical entre os pontos A e B de campos do radar da FCTH em 2017-03-14 1827 UTC, no momento mais próximo da queda de granizo em Cosmópolis: Refletividade corrigida (a) e diferencial (b), fase diferencial específica (c) e coeficiente de correlação (d). O 'x' indica a localização do hailpad e as isotermas de 0 e $-40^{\circ} \mathrm{C}$ foram definidas a partir da radiossondagem de SBMT. Linhas contínuas demarcam os limites dos municípios do Estado de São Paulo. . . . . . . 66

Figura 27 - Corte horizontal em $3 \mathrm{~km}$ de altura e vertical entre os pontos A e B de campos derivados do radar da FCTH em 2017-03-14 1827 UTC, no momento mais próximo da queda de granizo em Cosmópolis: Identificação de hidrometeoros (a) e massas de água líquida (b) e gelo (c). $\mathrm{O}$ 'x' indica a localização do hailpad e as isotermas de 0 e $-40^{\circ} \mathrm{C}$ foram definidas a partir da radiossondagem de SBMT. Linhas contínuas demarcam os limites dos municípios do Estado de São Paulo. . . . . . . 
Figura 28 - Corte horizontal em $3 \mathrm{~km}$ de altura e vertical entre os pontos A e B de campos do radar da FCTH em 2017-03-14 1957 UTC, no momento mais próximo da queda de granizo em Indaiatuba: Refletividade corrigida (a) e diferencial (b), fase diferencial específica (c) e coeficiente de correlação (d). O 'x' indica a localização do hailpad e as isotermas de 0 e $-40^{\circ} \mathrm{C}$ foram definidas a partir da radiossondagem de SBMT. Linhas contínuas demarcam os limites dos municípios do Estado de São Paulo. . . . . . .

Figura 29 - Corte horizontal em $3 \mathrm{~km}$ de altura e vertical entre os pontos A e B de campos derivados do radar da FCTH em 2017-03-14 1957 UTC, no momento mais próximo da queda de granizo em Indaiatuba: Identificação de hidrometeoros (a) e massas de água líquida (b) e gelo (c). $\mathrm{O}$ ' $\mathrm{x}$ ' indica a localização do hailpad e as isotermas de 0 e $-40^{\circ} \mathrm{C}$ foram definidas a partir da radiossondagem de SBMT. Linhas contínuas demarcam os limites dos municípios do Estado de São Paulo. .... . 70

Figura 30 - Corte horizontal em $3 \mathrm{~km}$ de altura e vertical entre os pontos A e B de refletividade e velocidade do vento (correntes ascendentes e descendentes máximas no painel da esquerda, escoamento no painel da direita) derivado por Multi-Doppler em 2017-03-14 às 1820 (a) e 1830 UTC (b), no momento mais próximo da queda de granizo em Cosmópolis. O 'x' indica a localização do hailpad e as isotermas de 0 e $-40^{\circ} \mathrm{C}$ foram definidas a partir da radiossondagem de SBMT. Linhas contínuas demarcam os limites dos municípios do Estado de São Paulo. . . . . . 72

Figura 31 - Corte horizontal em $3 \mathrm{~km}$ de altura e vertical entre os pontos A e B de refletividade e velocidade do vento (correntes ascendentes e descendentes máximas no painel da esquerda, escoamento no painel da direita) derivado por Multi-Doppler em 2017-03-14 às 1950 (a) e 2000 UTC (b), no momento mais próximo da queda de granizo em Indaiatuba. $\mathrm{O}$ ' $\mathrm{x}$ ' indica a localização do hailpad e as isotermas de 0 e $-40^{\circ} \mathrm{C}$ foram definidas a partir da radiossondagem de SBMT. Linhas contínuas demarcam os limites dos municípios do Estado de São Paulo. . . . . 73

Figura 32 - Campos da reanálise do ERA5 em 2017-11-15: Pressão ao nível médio do mar, espessura entre 1000 e $500 \mathrm{hPa}$ e velocidade do vento em $250 h P a$ às 1200 UTC (a); altura geopotencial em 850hPa, cisalhamento do vento entre 1000 e $500 h P a$ e CAPE em superfície às 1200 UTC (b) e 1800 UTC, no domínio do estado de São Paulo (c). . . . . . . . . . . 74

Figura 33 - Plotagem Skew-T Log-P da radiossondagem do Campo de Marte (SP) com hodógrafa do vento e índices CAPE e CIN em 2017-11-15 1200 UTC. . . . . . . . . . . . . . . . . . . . . 75 
Figura 34 - Imagem de satélite do canal 13 do GOES-16 mostrando a temperatura de brilho do topo das nuvens no estado de São Paulo em 2017-11-15 1800 (a) e 2100 UTC (b). . . . . . . . . . . . . . . . . 75

Figura 35 - Rastreamento (a) e localização dos flashes IC e CG (b) do sistema convectivo responsável pela queda de granizo em Indaiatuba em 201711-15. Os triângulos pretos indicam a localização do hailpad. Linhas contínuas demarcam os limites dos municípios do Estado de São Paulo.

Figura 36 - Campos de refletividade (CAPPI em $3 \mathrm{~km}$ do radar de São Roque) (a) e flashes IC (b) e CG (c) acumulados em 10 minutos do sistema convectivo (delimitado pela linha preta) responsável pela queda de granizo em Indaiatuba em 2017-11-15. O triângulo preto indica a localização do hailpad. Linhas contínuas demarcam os limites dos municípios do Estado de São Paulo. . . . . . . . . . . . . . . . . . . . . . . . .

Figura 37 - Corte horizontal em $3 \mathrm{~km}$ de altura e vertical entre os pontos A e B de campos do radar da FCTH em 2017-11-15 2150 UTC, no momento mais próximo da queda de granizo em Indaiatuba: Refletividade corrigida (a) e diferencial (b), fase diferencial específica (c) e coeficiente de correlação (d). O 'x' indica a localização do hailpad e as isotermas de 0 e $-40^{\circ} \mathrm{C}$ foram definidas a partir da radiossondagem de SBMT. Linhas contínuas demarcam os limites dos municípios do Estado de São Paulo. . . . . . .

Figura 38 - Corte horizontal em $3 \mathrm{~km}$ de altura e vertical entre os pontos A e B de campos derivados do radar da FCTH em 2017-11-15 2150 UTC, no momento mais próximo da queda de granizo em Indaiatuba: Identificação de hidrometeoros (a) e massas de água líquida (b) e gelo (c). $\mathrm{O}$ ' $\mathrm{x}$ ' indica a localização do hailpad e as isotermas de 0 e $-40^{\circ} \mathrm{C}$ foram definidas a partir da radiossondagem de SBMT. Linhas contínuas demarcam os limites dos municípios do Estado de São Paulo. . . . . . . 80

Figura 39 - Corte horizontal em $3 \mathrm{~km}$ de altura e vertical entre os pontos A e B de refletividade e velocidade do vento (correntes ascendentes e descendentes máximas no painel da esquerda, escoamento no painel da direita) derivado por Multi-Doppler em 2017-11-15 às 2140 (a) e 2150 UTC (b), no momento mais próximo da queda de granizo em Cosmópolis. $\mathrm{O}$ 'x' indica a localização do hailpad e as isotermas de 0 e $-40^{\circ} \mathrm{C}$ foram definidas a partir da radiossondagem de SBMT. Linhas contínuas demarcam os limites dos municípios do Estado de São Paulo. .... 82

Figura 40 - Histogramas de tempo entre strokes e entre flashes (a), número de strokes por flash (b) e distância latitude e longitudinal entre strokes em um flash (c) para diferentes valores de $\epsilon_{\mathrm{spc}}$. . . . . . . . . . . . . . 104

Figura 40 - Continuação. . . . . . . . . . . . . . . . . . . 105 



\section{Lista de tabelas}

Tabela 1 - Descrição dos casos selecionados para análise. . . . . . . . . . . . 35

Tabela 2 - Descrição dos hailpads coletados para cada caso. . . . . . . . . . . 37

Tabela 3 - Descrição das escalas ANELFA e TORRO, com comparação entre o dano típico de cada escala. . . . . . . . . . . . . . . . . . . 39

Tabela 4 - Configuração dos radares nos casos em que a recuperação de vento por Multi-Doppler foi utilizada. . . . . . . . . . . . . . . . 4 47

Tabela 5 - Parâmetros de configuração do MultiDop para cálculos de Dual e MultiDoppler. . . . . . . . . . . . . . . . . . . 50 50

Tabela 6 - Resumo das principais características físicas e elétricas dos casos analisados. . . . . . . . . . . . . . . . . . . . . . 59 



\section{Lista de abreviaturas e siglas}

3DVAR 3 Variational Analysis

4DD Four-Dimensional Doppler Dealising Scheme

ABI Advanced Baseline Imager

AWS Amazon Web Services

ANELFA Association Nationale d'Etude et de Lutte contre les Fléaux Atmosphériques

BrasilDAT Sistema Brasileiro de Detecção de Descargas Elétricas

CAPE Convective Available Potential Energy

CAPPI Constant Altitude Plan Position Indicator

CCCS Copernicus Climate Change Service

CCST Centro de Ciência do Sistema Terrestre

CDS Climate Data Store

CG Cloud-to-Ground

CIN Convective Inibition

CPTEC Centro de Previsão de Tempo e Estudos Climáticos

DBSCAN Density-Based Spatial Clustering of Application with Noise

DCA Departamento de Ciências Atmosféricas

DECEA Departamento de Controle do Espaço Aéreo

ECMWF European Centre for Medium-Range Weather Forecasts

ELAT Grupo de Eletricidade Atmosférica

FCTH Fundação Centro Tecnológico de Hidráulica

ForTraCC Forecast and Tracking the Evolution of Cloud Clusters

GLM Geoestationary Lightning Mapper

HF High Frequency 
IAG Instituto de Astronomia, Geofísica e Ciências Atmosféricas

IC Intra-Cloud

INPE Instituto Nacional de Pesquisas Espaciais

IWC Ice Water Content

LF Low Frequency

LIM Laboratório de Instrumentação Meteorológica

LWC Liquid Water Content

NOAA National Oceanic and Atmospheric Administration

NWS National Weather Service

Py-ART Python ARM Radar Toolkit

RMC Região Metropolitana de Campinas

RMSP Região Metropolitana de São Paulo

SP São Paulo

SR São Roque (radar)

TORRO Tornado and Storm Research Organisation

UNICAMP Universidade Estadual de Campinas

USP Universidade de São Paulo

VAD Velocity-Azimuth Display

XPOL Radar polarimétrico Banda-X

ZCAS Zona de Convergência do Atlântico Sul 


\section{Sumário}

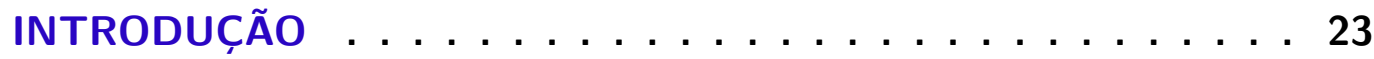

FUNDAMENTAÇÃO TEÓRICA . . . . . . . . . . . . . 25

2.1 Processos de Formação do Granizo e Eletrificação de Tempestades 25

2.2 Medindo Características de Tempestades de Granizo . . . . . . . . . 28

2.3 Tempestades de Granizo na América do Sul . . . . . . . . . . . . . 29

2.4 Usando Radares Meteorológicos para Estudar a Cinemática das Tempestades ....................... 31

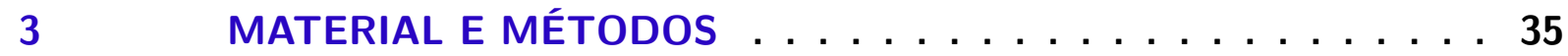

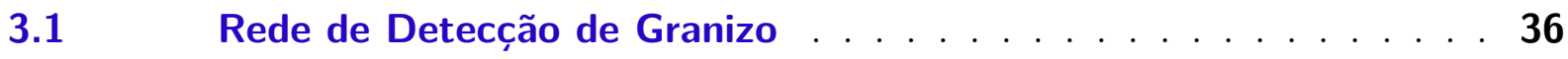

$3.2 \quad$ Radares Meteorológicos . . . . . . . . . . . . . . 40

3.2.1 Identificação de Hidrometeoros . . . . . . . . . . . . . . . . . . . . 42

3.2.2 Recuperação de Vento por Multi-Doppler . . . . . . . . . . . . . . 46

$3.3 \quad$ Rede de Detecção de Raios . . . . . . . . . . . . . . . . 50

3.3.1 Conversão Strokes-Flashes . . . . . . . . . . . . . . . . . . . . . 51

$3.4 \quad$ Reanálise . . . . . . . . . . . . . . . . . . 52

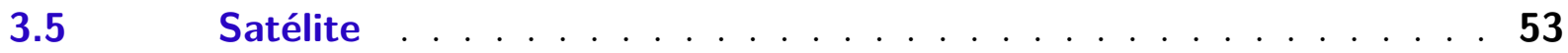

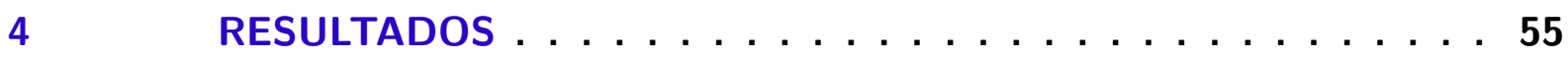

4.1 Intensidade das Tempestades que Geraram Granizo . . . . . . . 55

$4.2 \quad$ Estudos de Caso . . . . . . . . . . . . . . . . . . 59

$4.2 .1 \quad$ Caso de $2017-03-14 \ldots \ldots \ldots \ldots$

4.2.1.1 Ambiente Sinótico e Termodinâmico . . . . . . . . . . . . . . . . . . . 59

4.2.1.2 Eletrificação . . . . . . . . . . . . . . . . . . 62

4.2.1.3 Microfísica . . . . . . . . . . . . . . . . . . . . . . 64

4.2.1.4 Cinemática . . . . . . . . . . . . . . . . . . . . . 70

4.2.2 Caso de $2017-11-15 \ldots \ldots \ldots \ldots 73$

4.2.2.1 Ambiente Sinótico e Termodinâmico . . . . . . . . . . . . . . . . . 73

4.2.2.2 Eletrificação . . . . . . . . . . . . . . . . . . 76

4.2.2.3 Microfísica . . . . . . . . . . . . . . . . . . . . 77

$4.2 .2 .4 \quad$ Cinemática . . . . . . . . . . . . . . . . . . . . 80

$5 \quad$ CONCLUSÕES $\ldots \ldots \ldots \ldots$

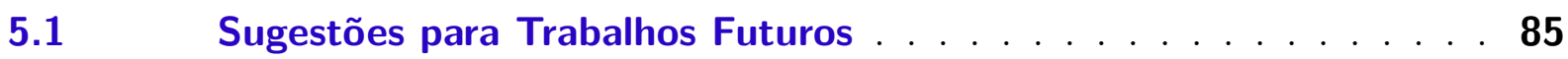


REFERÊNCIAS . . . . . . . . . . . . . . . . 87

$\begin{array}{ll}\text { ANEXOS } & 101\end{array}$

ANEXO A - CONVERSÃO STROKES-FLASHES: TESTE DE SEN-

SIBILIDADE DE $\epsilon_{s p c} \ldots \ldots \ldots \ldots \ldots$ 


\section{Introdução}

Tempestades de granizo, ou seja, que produzem granizo de tamanho suficiente para precipitar, são consideradas severas pelo Serviço Meteorológico Americano (National Weather Service, NWS) quando o granizo possui tamanho maior ou igual a $19 \mathrm{~mm}$ (MOLLER, 2001). Esse tipo de evento meteorológico causa prejuízos em diferentes escalas dependendo de sua intensidade, afetando principalmente o setor agrícola, o que motiva uma série de estudos sobre a frequência e distribuição espacial dessas tempestades ao redor do planeta (DESSENS; FRAILE, 1994; KNIGHT; KNIGHT, 2001a; ECCEL et al., 2012; BERTHET et al., 2013; BALDI et al., 2014; JIN et al., 2017; MARTINS et al., 2017) com o objetivo de melhorar sua previsibilidade. Por mais que trabalhos como Herman, Nielsen e Schumacher (2018) mostrem avanços na previsão de tempestades de granizo, a sua grande variabilidade em termos de estrutura microfísica, atividade elétrica e cinemática dificulta uma caracterização geral desse tipo de tempestade.

Os processos microfísicos de crescimento do granizo que permitem que ele precipite ainda como granizo são influenciados por outros aspectos inerentes à tempestade e o ambiente em que ela se desenvolve. Ambientes favoráveis para o desenvolvimento de tempestades de granizo são comumente encontrados em latitudes médias, principalmente quando são mais severas (COURT; GRIFFITHS, 1982). No entanto, é possível observar tempestades de granizo em regiões tropicais de maiores altitudes, que podem causar danos severos localmente (MORGAN; TOWERY, 1976).

No sudeste do Brasil, tempestades intensas com grandes acumulados de precipitação em geral são mais comuns do que tempestades severas - mesmo considerando definições melhor adaptadas para eventos severos no país como sugerido por Nascimento (2005) - afetando principalmente grandes centros urbanos vulneráveis como a Região Metropolitana de São Paulo (RMSP) (VEMADO; Pereira Filho, 2016). Ainda assim, tempestades que apresentam queda de granizo tem um alto impacto social e econômico: a partir de dados da Defesa Civil do estado de São Paulo entre 1991 e 2012, 23 casos de queda de granizo foram registrados, afetando mais de 38 mil pessoas e causando danos materiais principalmente em habitações (Ceped - Centro Universitário De Estudos E Pesquisas Sobre Desastres, 2013). Caracterizar estes eventos e melhorar sua previsibilidade é fundamental para estimar seu efeito na região e desenvolver políticas públicas de prevenção à este e outros desastres.

Como continuação do Projeto CHUVA no Vale do Paraíba (São Paulo) (MACHADO et al., 2014), o Projeto SOS-CHUVA (FAPESP 2015/14497-0) foi desenvolvido na Região Metropolitana de Campinas (RMC) entre 2016 e 2018, contemplando duas 
estações chuvosas, com foco na observação e desenvolvimento de pesquisa em previsão imediata de tempestades intensas. Além da instalação de um radar de dupla polarização e estações meteorológicas na região, uma rede de detecção de granizo foi instalada pela primeira vez no sudeste do Brasil, fornecendo medições in-situ de granizo. Ao combinar essas informações com dados volumétricos de radar e descargas elétricas, é possível estudar de forma inédita os processos físicos de tempestades que produzem granizo na região.

O restante da dissertação está organizado da seguinte forma: o Capítulo 2 apresenta uma breve revisão bibliográfica de diversos aspectos inerentes à tempestades de granizo, o Capítulo 3 descreve a base de dados e metodologia utilizada, o Capítulo 4 apresenta os resultados obtidos, incluindo dois estudos de caso, e o Capítulo 5 mostra uma discussão dos principais resultados e sugestões para trabalhos futuros.

\subsection{Objetivos}

O objetivo deste trabalho é explorar aspectos físicos de tempestades tropicais que geram granizo, de forma a caracterizar seus processos de formação e intensificação. A partir da cinemática convectiva e atividade elétrica, identificaremos fatores determinantes para que tempestades tropicais produzam granizo com tamanho suficiente para precipitar. 


\section{Fundamentação Teórica}

\subsection{Processos de Formação do Granizo e Eletrificação de Tempes- tades}

A Figura 1 apresenta os processos primários de crescimento de hidrometeoros dentro de uma nuvem fria através da colisão entre os mesmos. O granizo é formado a partir da acreção (coleta de água superresfriada ou cristais de gelo pequenos por uma partícula de gelo maior) em gotas de chuva congeladas ou graupel, sendo o último formado a partir do processo denominado riming (acreção de gotículas de água superresfriada em partículas de gelo em um depósito de baixa densidade) em cristais de gelo, neve ou gotas de chuva congeladas (REINKING, 1975). Esses processos são altamente influenciados pela quantidade e tamanho de gotas superresfriadas (ou conteúdo de água líquida) na região de fase mista da nuvem, intensidade da corrente ascendente e temperatura.

Figura 1 - Classificação dos processos primários de crescimento de hidrometeoros.

\section{Crescimento Primário dos Hidrometeoros}

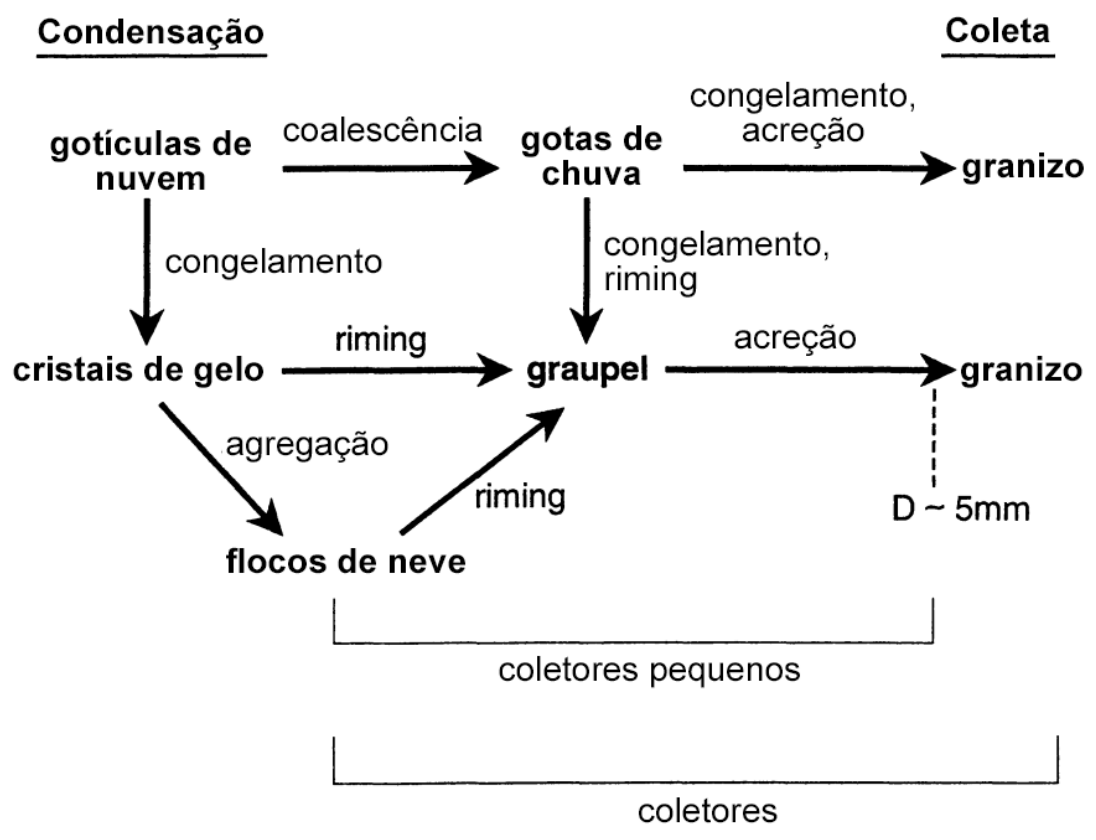

Fonte: Adaptado de Knight e Knight (2001a).

Dentro da região de fase mista da nuvem, a colisão entre hidrometeoros contribui não só para o crescimento mas também para a troca de cargas entre eles através da trans- 
ferência de massa. Considerando o momento de dipolo permanente da água, que expõe íons negativos na camada quase-líquida das partículas, a colisão entre dois hidrometeoros transfere íons negativos do hidrometeoro com maior camada para o com menor camada, deixando assim o primeiro positivamente carregado e o segundo negativamente carregado (BAKER et al., 1987; BAKER; DASH, 1994). Com a atuação da corrente ascendente, a distribuição de hidrometeoros carregados geram centros de cargas bem definidos dentro da nuvem, e é na interface entre centros de cargas opostas que ocorre a quebra de rigidez dielétrica que origina uma descarga elétrica. Assim, esse mecanismo, chamado de carregamento não-indutivo, é fundamental para a eletrificação de tempestades (SAUNDERS, 2008).

A espessura da camada quase-líquida de um hidrometeoro na região de fase mista depende do tipo e tamanho do hidrometeoro e também de fatores externos como conteúdo de água líquida e temperatura. A Figura 2 mostra o resultado obtido por Takahashi (1978) através de medidas em laboratório: após a colisão com cristais de gelo, o graupel fica carregado positivamente independentemente do conteúdo de água líquida em temperaturas mais altas que $-10^{\circ} \mathrm{C}$; em temperaturas mais baixas, o graupel fica positivamente carregado quando o conteúdo de água líquida é muito alto (acima de $2 \mathrm{gm}^{-3}$ ) ou muito baixo (abaixo de $0,2 \mathrm{gm}^{-3}$ ), enquanto que fica negativamente carregado quando o conteúdo de água líquida está entre $0,2 \mathrm{gm}^{-3}$ e $2 \mathrm{gm}^{-3}$. Williams, Zhang e Rydock (1991) indicam que o regime de crescimento do graupel/granizo também muda com o conteúdo de água líquida e temperatura (linhas tracejadas da Figura 2): o regime de crescimento é molhado quando o conteúdo de água líquida é muito alto e/ou a temperatura é próxima de $0^{\circ} C$, seco por deposição quando o conteúdo de água líquida e/ou a temperatura são muito baixos e seco por sublimação (coleta em um ambiente com baixa pressão de vapor) entre as duas porções anteriores. É importante ressaltar que não há um consenso em relação à esses valores, já que outros estudos feitos em laboratório (JAYARATNE; SAUNDERS; HALLETT, 1983; PEREYRA et al., 2000; SAUNDERS et al., 2006) não encontraram os mesmos resultados. Emersic e Saunders (2010), por exemplo, mostraram que o sinal de carregamento do graupel e temperaturas associadas em experimentos de laboratório é dependente da configuração experimental da câmera de nuvem, essencialmente do modo de nucleação dos cristais de gelo, isto é, crescer juntamente com ou separadamente da nuvem de gotículas superresfriadas, o que controla a espessura da camada quase-líquida e a taxa relativa de crescimento por difusão de vapor. Os fatores externos descritos aqui são altamente influenciados pela intensidade da corrente ascendente, já que correntes ascendentes mais intensas promovem maior transporte de água líquida para a região de fase mista da nuvem.

Simultaneamente à troca de cargas entre graupel/granizo e cristais de gelo, a corrente ascendente transporta e concentra esses hidrometeoros de acordo com a velocidade terminal de cada um: graupel e granizo tendem a entrar em equilíbrio com a corrente 
Figura 2 - Carga adquirida pelo graupel/granizo após a colisão com cristais de gelo em função do conteúdo de água líquida e temperatura. As linhas tracejadas delimitam os regimes de crescimento molhado (porção superior), crescimento seco por sublimação (porção central) e crescimento seco por deposição (porção inferior).

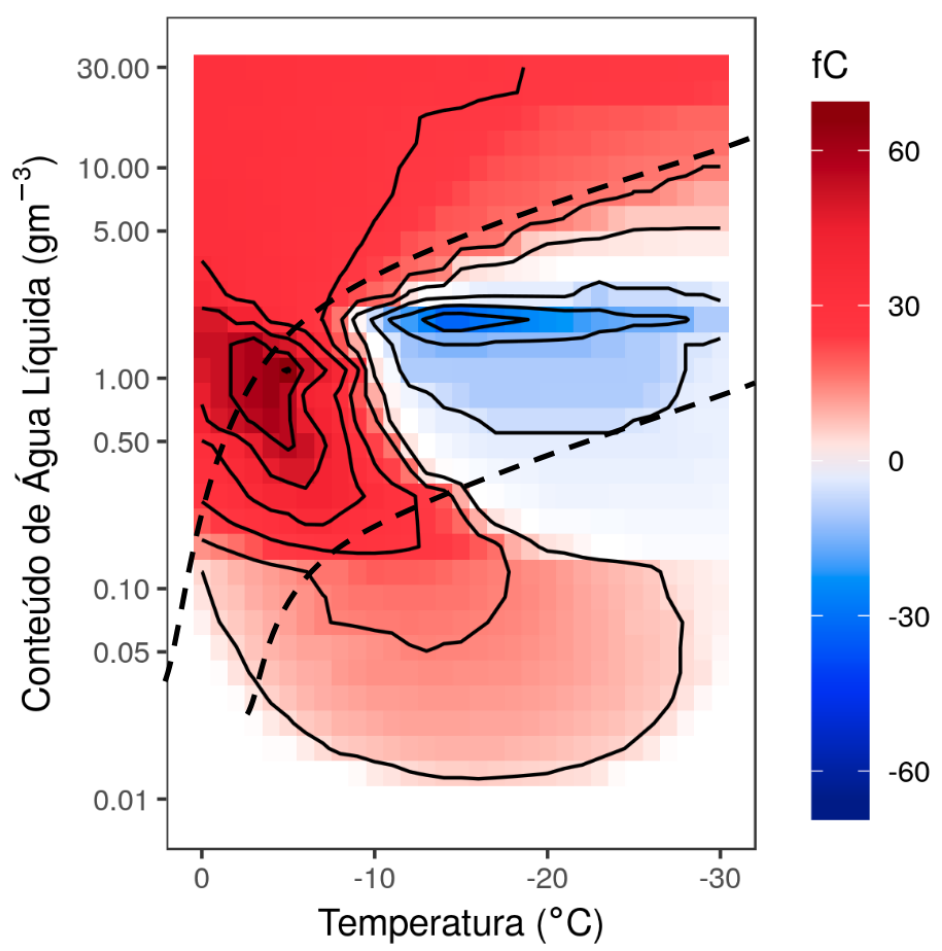

Fonte: Adaptado de Takahashi (1978) e Williams, Zhang e Rydock (1991).

ascendente ou descer para fora da região de fase mista, enquanto que os cristais de gelo são transportados para a porção superior ou acima da região de fase mista. Assim, centros de cargas elétricas são formados dentro da nuvem, e a distribuição desses centros depende da complexidade da cinemática da nuvem. Uma descrição simplificada de uma estrutura de cargas na forma de um dipolo foi feita por Wilson (1921), Simpson e Scrase (1937) e Simpson e Robinson (1941), mas Williams (1989) consolidou a estrutura de cargas tripolar como sendo a mais comumente encontrada na região de corrente ascendente em tempestades ao revisar diversos experimentos em laboratório e in-situ. Essa hipótese considera que o regime de crescimento preferencial do graupel/granizo é seco por deposição, o que significa que eles ficam negativamente carregados (região de carregamento negativo na Figura 2); com a atuação da corrente ascendente, um centro de cargas negativas principal é formado na região de fase mista, com dois centros de cargas positivas acima (com cristais de gelo) e abaixo (com hidrometeoros em tamanhos precipitáveis) dessa região, produzindo mais raios nuvem-solo (cloud-to-ground, CG) de polaridade negativa. Porém, diversos estudos in-situ (MACGORMAN; BURGESS, 1994; CAREY; RUTLEDGE, 1995; LYONS et al., 1998; CAREY; RUTLEDGE, 2003; CAREY; BUFFALO, 2007; PINEDA 
et al., 2016) mostram que tempestades severas produzem muito mais raios CG de polaridade positiva; dentre as hipóteses que procuram explicar esse fenômeno está a estrutura de tripolo invertido: a corrente ascendente mais intensa aumenta o conteúdo de água líquida na região de fase mista, promovendo o crescimento molhado e carregamento positivo do graupel/granizo (região de carregamento positivo em alto conteúdo de água líquida na Figura 2); assim, a estrutura simplificada é formada por um centro de cargas positivas na região de fase mista e dois centros de cargas negativas acima e abaixo dessa região, gerando maior quantidade de raios CG positivos. Além disso, tempestades severas também podem promover a formação de granizos gigantes através de ciclos de movimentos descendentes e ascendentes no flanco direito do núcleo de corrente ascendente (KNIGHT; KNIGHT, 1970; KNIGHT; KNIGHT, 2001b; KNIGHT; KNIGHT, 2005) e apresentar picos de atividade elétrica antes da ocorrência de tempo severo (lightning jump, salto de raios) (GOODMAN et al., 1988; WILLIAMS et al., 1999; SCHULTZ; PETERSEN; CAREY, 2009; GATLIN; GOODMAN, 2010; SCHULTZ; PETERSEN; CAREY, 2011).

\subsection{Medindo Características de Tempestades de Granizo}

O principal fenômeno que separa tempestades de granizo de tempestades nãoseveras é a queda de granizo na superfície, que pode causar danos quando o granizo possui tamanho grande ou gigante (diâmetro maior que $19 \mathrm{~mm}$ ). Por esse motivo, medidas de granizo são importantes para caracterizar e posteriormente prever a ocorrência e potencial destrutivo desse tipo de tempestade severa. Medidas in-situ usando hailpads - placas de isopor especial fixadas na superfície ou em suportes a uma certa altura que, através das cavidades formadas após o impacto dos granizos nas placas, geram distribuições de tamanho de granizo (SCHLEUSENER; JENNINGS, 1960; DECKER; CALVIN, 1961) - fornecem informações precisas sobre esse fenômeno em uma escala local, similar à representatividade de um pluviômetro na medida de precipitação. Diversas redes de hailpads instaladas em países da Europa (DESSENS, 1998; SVABIK, 1989; GIAIOTTI; NORDIO; STEL, 2003; POČAKAL; VEČENAJ; ŠTALEC, 2009; BERTHET; DESSENS; SANCHEZ, 2011) e na Argentina (SÁNCHEZ et al., 2009) permitiram uma caracterização das tempestades de granizo nessas regiões, inclusive em longos períodos (BERTHET et al., 2013). No Brasil, uma rede foi instalada no estado de Santa Catarina, em uma região rural, para estimar a eficiência de um sistema "anti-granizo"(ILIINE; MINUZZI; ROLIM, 2010). Diversos trabalhos utilizam medidas de hailpads como base de comparação com estimativas por sensoriamento remoto, principalmente radares meteorológicos (WALDVOGEL et al., 1978a; SCHMID; SCHIESSER; WALDVOGEL, 1992; SÁNCHEZ et al., 2013).

Uma grandeza ligada à distribuição de tamanho de granizo que estima o potencial destrutivo de uma tempestade de granizo é a energia cinética, equivalente ao trabalho 
mecânico que a superfície sofre ao ser atingida pelo granizo. Changnon Jr. (1971) e Morgan e Towery (1976) mostraram que essa grandeza possui maior relação com danos em plantações do que o tamanho ou quantidade de granizo. Além disso, a energia cinética do granizo pode ser estimada mais facilmente por radares já que a refletividade medida por eles tem a mesma ordem de grandeza do diâmetro do granizo (WALDVOGEL et al., 1978a), o que permite, por exemplo, que diversos trabalhos relacionem diretamente a energia cinética com danos em edificações (HOHL; SCHIESSER; ALLER, 2002; SCHUSTER; BLONG; MCANENEY, 2006).

\subsection{Tempestades de Granizo na América do Sul}

Diferentemente de tempestades em latitudes médias, tempestades tropicais raramente são intensas o suficiente para gerar queda de granizo ou graupel no solo, com exceção da África Central (COURT; GRIFFITHS, 1982; HAND; CAPPELLUTI, 2011; CECIL; BLANKENSHIP, 2012). Como mostrado na Figura 3, a porção central e norte da América do Sul não apresenta condições sinóticas que favoreçam a formação de convecção organizada e sistemas convectivos de mesoescala (por ser um ambiente barotrópico, com baixos gradientes de temperatura e cisalhamento vertical), apenas tempestades isoladas principalmente durante o verão (Figura 3a); essas tempestades costumam ter pouco tempo de vida e correntes ascendentes insuficientes para transportar grandes quantidades de água líquida para a região de fase mista e promover o crescimento de granizo. Já mais ao sul, tempestades de granizo destrutivas têm sido relatadas na Argentina subtropical e na região sul do Brasil (COURT; GRIFFITHS, 1982; MARTINS et al., 2017); satélite, modelagem e climatologias mostram que essa área pode chegar a $15^{\circ} \mathrm{S}$ de latitude (HAND; CAPPELLUTI, 2011; CECIL; BLANKENSHIP, 2012; ALBRECHT et al., 2016).

A Figura 4 mostra uma climatologia de tempestades de granizo severas (ou seja, com queda de granizos grandes ou gigantes) no sudeste da América do Sul usando uma série temporal de 8 anos de dados do sensor passivo em microondas AMSR-E (Advanced Microwave Scanning Radiometer for Earth Observing System, Radiômetro Avançado de Escaneamento em Microondas para o Sistema de Observação Terrestre) a bordo do satélite de órbita sincronizada com o Sol Aqua. O pico de frequência de tempestades de granizo está centrado no norte da Argentina, se estendendo ao Paraguai, Uruguai e partes de Brasil e Bolívia (CECIL; BLANKENSHIP, 2012). Barnes (2001) (em sua Figura 10.31) mostra que o ciclo anual de eventos de granizo no Brasil (entre 18 e $22^{\circ} \mathrm{S}$ ) é sazonal, com maior frequência na primavera e verão. Sperling (2018) também mostra maior frequência de granizo durante a primavera considerando eventos no sul do Brasil, que são produzidos por tempestades isoladas de grande extensão vertical antes de se juntarem a sistemas convectivos de mesoescala formados ao longo do jato sul-americano de baixos níveis em situações pré-frontais. Essas tempestades são formadas por pequenas células convectivas 
Figura 3 - Esquema com as características de escala planetária e sinótica primárias encontradas na superfície no Atlântico Tropical em janeiro (a) e julho (b).

\section{January}

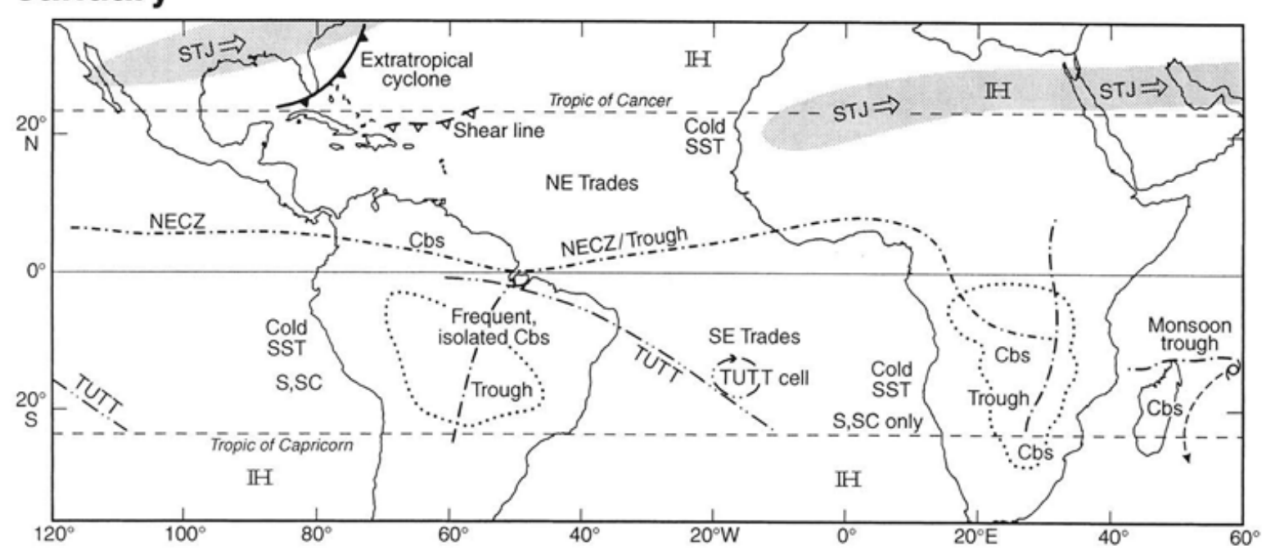

(a)

\section{July}

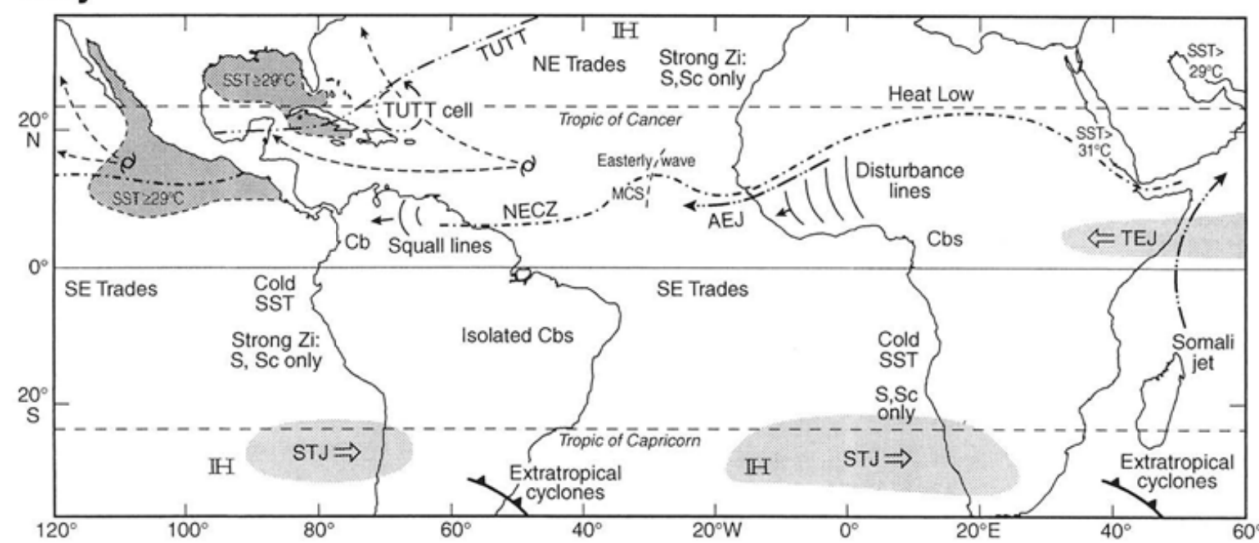

(b)

Fonte: Barnes (2001).

explosivas que rapidamente (até 30 minutos) desenvolvem uma região de fase mista com refletividade acima de $50 \mathrm{dBZ}$ até $18 \mathrm{~km}$ de altura; entre 10 e 20 minutos depois do crescimento explosivo das células e aumento da massa de gelo, há um distinto salto na taxa de raios totais, produzindo granizo com mais de $6 \mathrm{~cm}$ de diâmetro observado no solo. No sudeste do Brasil, incluindo a região de estudo desta dissertação, a frequência e tamanho do granizo são menores que no sul do Brasil, mas também produzidos por pequenas células convectivas em situações pré-frontais (PUIG, 2017). 
Figura 4 - Climatologia anual de granizo a partir do sensor AMSR-E para o sudeste da América do Sul. Os contornos em cinza indicam a elevação, com intervalos de $1 \mathrm{~km}$.

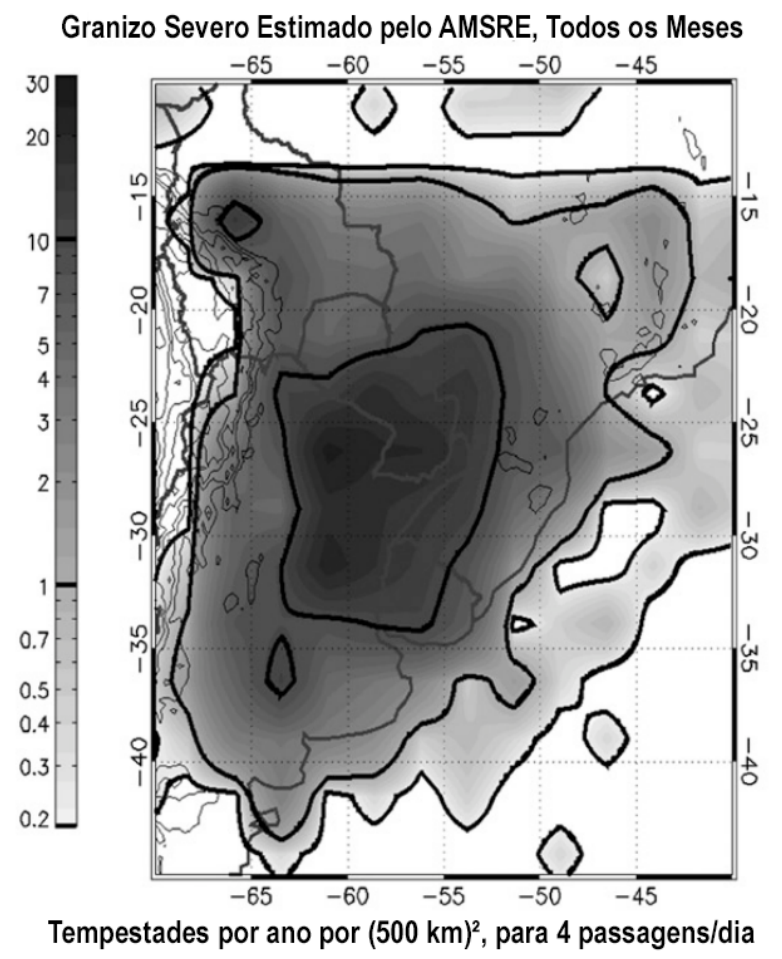

Fonte: Adaptado de Cecil e Blankenship (2012).

\subsection{Usando Radares Meteorológicos para Estudar a Cinemática das Tempestades}

Radares Doppler possuem a capacidade de medir a velocidade dos alvos que estão em seu volume observado, gerando essa importante informação sobre as nuvens com alta resolução espacial. A partir da velocidade desses alvos, é possível derivar não só o deslocamento da nuvem em si como também o escoamento dentro da nuvem, inferindo assim as propriedades cinemáticas da nuvem e sua importância para o ciclo de vida. É possível extrair informações relacionadas ao campo de vento a partir da recuperação das componentes do vento com um (display de velocidade-azimute (VAD, velocity-azimuth display); para mais informações, ver seção 11.5 de Rauber e Nesbitt (2018)) ou mais radares (Dual ou Multi-Doppler; gera um campo tridimensional do vento). Para tempestades de granizo, por exemplo, Morgan e Summers (1986) afirmam que técnicas Dual ou Multi-Doppler oferecem a descrição mais realista do ambiente relacionado ao granizo, pois permite observar efeitos de advecção com alto grau de detalhamento.

Desde a primeira formulação do método de recuperação de vento tridimensional (ARMIJO, 1969), diversos trabalhos usaram este método para entender a cinemática de 
tempestades. Estudos pioneiros descrevem a estrutura de tempestades severas (BRANDES, 1977; RAY et al., 1980), frentes de rajada (WEAVER; NELSON, 1982), tempestades não-severas usando Multi-Doppler (RAY et al., 1978) e microexplosões (WILSON et al., 1984) nos Estados Unidos, além do estudo de uma linha de instabilidade tropical no oeste da África (CHONG et al., 1987). O desenvolvimento de métodos e ferramentas mais sofisticadas permitiu estudos detalhados de tempestades que causaram grandes volumes de precipitação (PETERSEN et al., 1999; CALHOUN et al., 2013) e supercélulas (POTVIN et al., 2012; POTVIN; SHAPIRO; XUE, 2012), incluindo um caso com sucessivas tornadogêneses (WURMAN et al., 2007); Hubbert et al. (1998) usou o método DualDoppler para auxiliar na identificação dos processos microfísicos associados à assinaturas nas variáveis polarimétricas em um caso com queda de granizos gigantes. Outros estudos buscaram estudar a estrutura de diversos tipos de tempestades para descrever as principais diferenças na cinemática convectiva entre tempestades severas e não-severas (LANG; RUTLEDGE, 2002; DEIERLING et al., 2008). No Brasil, o experimento TRMM-LBA (Tropical Rainfall Measuring Mission Large Scale Biosphere-Atmosphere Experiment in Amazonia, Experimento de Larga Escala Biosfera-Atmosfera na Amazônia da Missão de Medidas de Precipitação Tropical) gerou diversos estudos da cinemática de tempestades tropicais na Amazônia durante o período chuvoso, mostrando que as tempestades que se desenvolvem em um escoamento de leste em baixos níveis apresentam extensão vertical maior e correntes ascendentes mais intensas comparando com as que se desenvolvem em um escoamento de oeste (RUTLEDGE et al., 2000; CIFELLI et al., 2002; CIFELLI et al., 2004).

A base teórica do método de recuperação de vento tridimensional consiste em determinar 3 componentes da velocidade do vento em coordenadas cartesianas: $u, v$ e $w$ nas coordenadas $x, y$ e $z$, além de $w_{t}$, definida como a velocidade terminal da precipitação (RINEHART, 1997). Dois radares Doppler vendo a mesma tempestade de ângulos diferentes fornecem duas medidas distintas de velocidade radial $\left(v_{r_{1}}\right.$ e $\left.v_{r_{2}}\right)$, como mostra a Figura 5 , e $w_{t}$ pode ser estimada em função da refletividade (usando uma distribuição de Marshall-Palmer, por exemplo). Assim, $u$ e $v$ podem ser descritos como:

$$
\begin{aligned}
& u=\frac{1}{\sin \left(\theta_{1}-\theta_{2}\right)}\left(\frac{v_{r_{1}} \cos \theta_{2}}{\sin \alpha_{1}}-\frac{v_{r_{2}} \cos \theta_{2}}{\sin \alpha_{2}}\right) \\
& v=\frac{1}{\sin \left(\theta_{1}-\theta_{2}\right)}\left(\frac{v_{r_{2}} \cos \theta_{1}}{\sin \alpha_{2}}-\frac{v_{r_{1}} \cos \theta_{1}}{\sin \alpha_{1}}\right)
\end{aligned}
$$

onde $\theta_{1}$ e $\theta_{2}$ são os ângulos azimutais dos radares 1 e 2 , respectivamente, e $\alpha_{1}$ e $\alpha_{2}$ são os ângulos de elevação dos mesmos.

Para calcular a componente vertical da velocidade, a equação de continuidade de massa na forma anelástica é usada, assumindo como condições de contorno que a 
Figura 5 - Sistema de coordenadas cilíndricas usado para análise Dual-Doppler de dados de radar. Os radares estão localizados nos pontos 1 e 2 e $a_{r}, a_{s}$ e $a_{\alpha}$ são as normais unitárias definindo a direção das três componentes ortogonais da velocidade. O eixo cilíndrico está ao longo da linha conectando os radares (separados por uma distância $2 d$ ) e $r$ é a distância do eixo ao dado pontual.

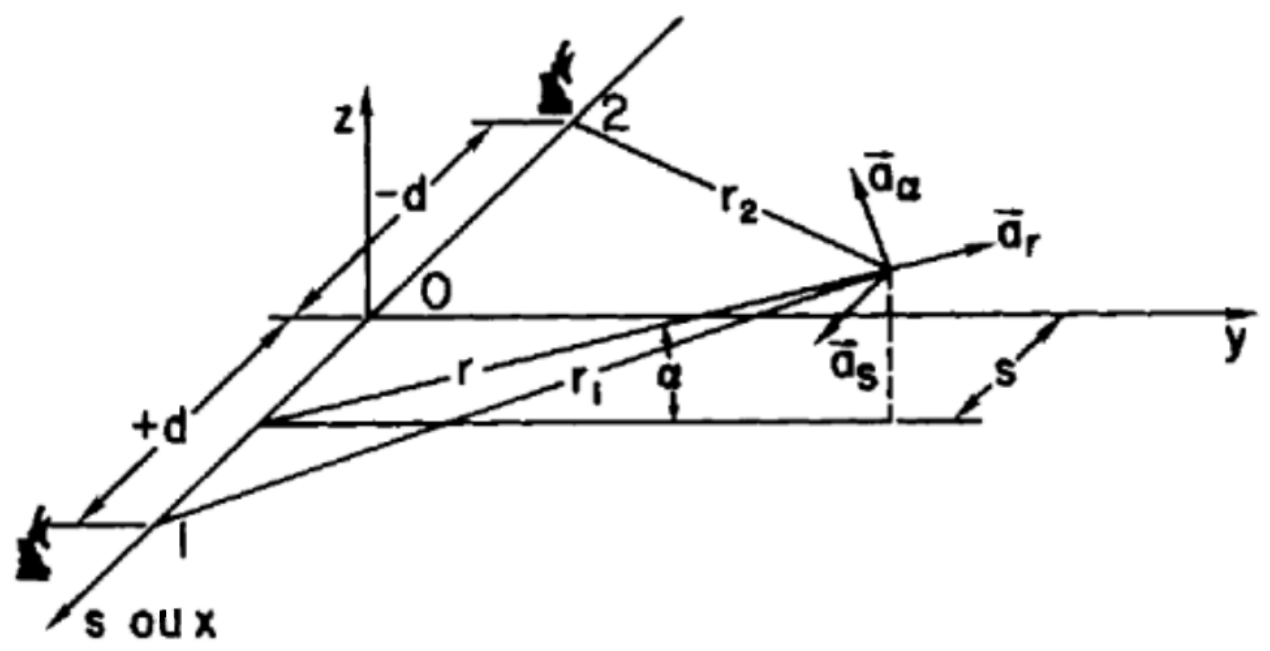

Fonte: Adaptado de Doviak e Zrnic (1993).

velocidade na superfície e no topo da tempestade são nulas, ou seja:

$$
\begin{gathered}
\frac{\partial(\rho w)}{\partial z}=-\rho\left(\frac{\partial u}{\partial x}+\frac{\partial v}{\partial y}\right) \\
w=w_{T}-w_{t}
\end{gathered}
$$

onde $\rho$ é a densidade do ar atmosférico e $w_{T}$ é a velocidade vertical total. Quando três radares são usados, é possível calcular o campo tridimensional sem usar a Equação 2.3.

Ao combinar radares Doppler para a recuperação do vento, a área de cobertura e erros característicos (altura do feixe e resolução espacial) devem ser considerados (DOLAN; RUTLEDGE, 2007). Se a distância da linha de base entre os dois radares for longa, a área de cobertura será maior mas a resolução espacial será prejudicada. Além disso, se o ângulo de cruzamento do feixe é pequeno (mais paralelo), as duas medidas serão mais similares e as variâncias dos erros de velocidade nas estimativas Dual-Doppler $-\sigma_{u}^{2}$ e $\sigma_{v}^{2}$ - serão menores. De acordo com Davies-Jones (1979), $\sigma_{u}^{2}$ e $\sigma_{v}^{2}$ estão relacionadas com as variâncias dos erros de velocidade Doppler de cada radar, $\sigma_{1}^{2}$ e $\sigma_{2}^{2}$, da seguinte forma:

$$
\frac{\sigma_{u}^{2}+\sigma_{v}^{2}}{\sigma_{1}^{2}+\sigma_{2}^{2}}=\csc ^{2} \beta
$$


onde $\beta$ é o ângulo de cruzamento do feixe entre os dois radares. Para $\beta<30^{\circ}, \sigma_{u}^{2}$ e $\sigma_{v}^{2}$ crescem rapidamente (DOVIAK et al., 1976; DAVIES-JONES, 1979; DOVIAK; ZRNIC, 1993).

A Figura 6 mostra teoricamente as áreas aceitáveis para estimativa de velocidade do vento considerando dois valores de $\beta$ : $30^{\circ}$ e $45^{\circ}$. Quanto maior o valor de $\beta$, melhor é a estimativa Dual-Doppler, mas menor será a área de cobertura dessa estimativa.

Figura 6 - Ângulos teóricos de cruzamento do feixe com Dual-Doppler de $45^{\circ}$ (melhores dados de vento) e $30^{\circ}$ (dados de vento aceitáveis) para um par de radares Doppler.

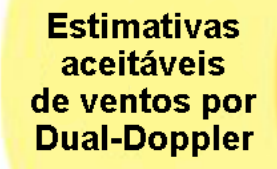

Melhor estimativa de ventos por Dual-Doppler

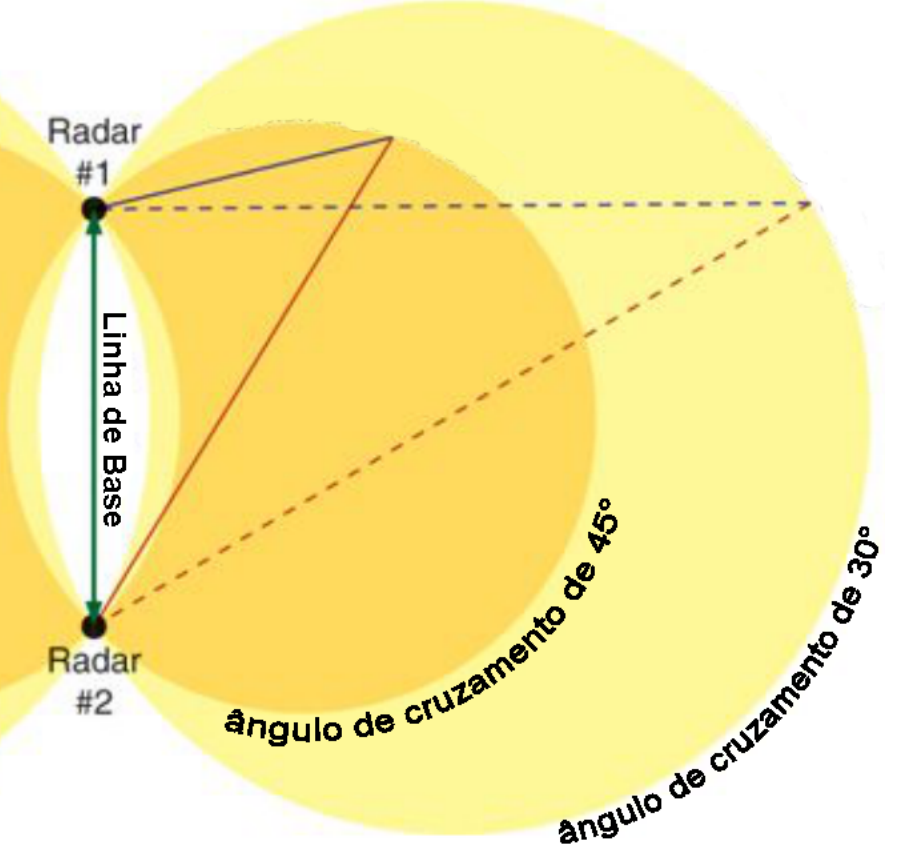

Fonte: Adaptado do original fornecido pelo Dr. Matthew D. Eastin, UNC. 


\section{Material e Métodos}

Para alcançar o objetivo de explorar os aspectos físicos de tempestades tropicais que geram granizo, cinco casos de queda de granizo durante o Projeto SOS-CHUVA foram selecionados. A escolha destes casos foi baseada nas medidas obtidas pela rede de detecção de granizo (seção 3.1). A Tabela 1 mostra uma breve descrição de cada caso.

Tabela 1 - Descrição dos casos selecionados para análise.

\begin{tabular}{|c|c|c|c|}
\hline Caso & Descrição & Regiões Afetadas & Tipo de Severidade \\
\hline $2016-12-25$ & $\begin{array}{l}\text { Condições instáveis na } \\
\text { região levou à formação de } \\
\text { diversos sistemas } \\
\text { convectivos }\end{array}$ & $\begin{array}{l}\text { Campinas, Vale do } \\
\text { Paraíba, São Carlos }\end{array}$ & Rajadas de vento, granizo \\
\hline 2017-01-31 & $\begin{array}{l}\text { Tempestade associada à } \\
\text { uma Linha de Instabilidade } \\
\text { formada a partir de } \\
\text { condições de calor e } \\
\text { umidade favoráveis }\end{array}$ & Sorocaba, Itu, Araraquara & Granizo \\
\hline $2017-03-14$ & $\begin{array}{l}\text { Aquecimento da superfície } \\
\text { e convergência de umidade } \\
\text { associada a uma frente fria } \\
\text { no oceano favoreceu a } \\
\text { formação de sistemas } \\
\text { convectivos no centro do } \\
\text { estado }\end{array}$ & $\begin{array}{c}\text { Campinas, Indaiatuba, } \\
\text { Jacareí }\end{array}$ & Granizo \\
\hline $2017-11-15$ & $\begin{array}{l}\text { Condições localmente } \\
\text { favoráveis levaram à } \\
\text { formação de sistemas } \\
\text { convectivos isolados no } \\
\text { centro do estado de SP }\end{array}$ & Indaiatuba, Bebedouro & Granizo \\
\hline 2017-11-16 & $\begin{array}{c}\text { Escoamento do Jato de } \\
\text { Baixos Níveis no centro-sul } \\
\text { do país possibilitou } \\
\text { condições de calor e } \\
\text { umidade favoráveis para a } \\
\text { formação de sistemas } \\
\text { convectivos em todo o } \\
\text { estado }\end{array}$ & $\begin{array}{c}\text { Lorena, Ribeirão Preto, } \\
\text { Campinas, São Paulo, } \\
\text { Itapeva }\end{array}$ & Rajadas de vento, granizo \\
\hline
\end{tabular}

$\overline{\text { Fonte - Adaptado de <https://topicssoschuva.blogspot.com.br/2017/03/summary-of-case-studies. }}$ html>.

As linguagens R (R CORE TEAM, 2018) e Python (PYTHON CORE TEAM, 2018) foram utilizadas no processamento dos dados. Os códigos desenvolvidos estão disponíveis no repositório <https://github.com/cclopes/soschuva_hail>. 


\subsection{Rede de Detecção de Granizo}

Como parte do Projeto SOS-CHUVA, uma rede de detecção de granizo através de hailpads foi instalada na Região Metropolitana de Campinas, dentro da cobertura do radar meteorológico Banda-X instalado na UNICAMP (XPOL). Como mostrado na Figura 7a, a rede foi composta por 24 localidades, com maior densidade de pontos nas cidades de Campinas e Indaiatuba. O hailpad utilizado é composto por uma placa de isopor (espuma de poliestireno) usado para isolamento coberta por uma folha de alumínio e fixada em um suporte de ferro aproximadamente 1,5 m acima da superfície (THOMAZ JÚNIOR, 2016). Na Figura 7b é possível observar uma placa instalada em Indaiatuba.

Figura 7 - (a) Rede de hailpads instalada na Região Metropolitana de Campinas com a localização e cobertura de $80 \mathrm{~km}$ do radar XPOL. (b) Hailpad instalado na cidade de Indaiatuba, na localização indicada com a seta em (a).

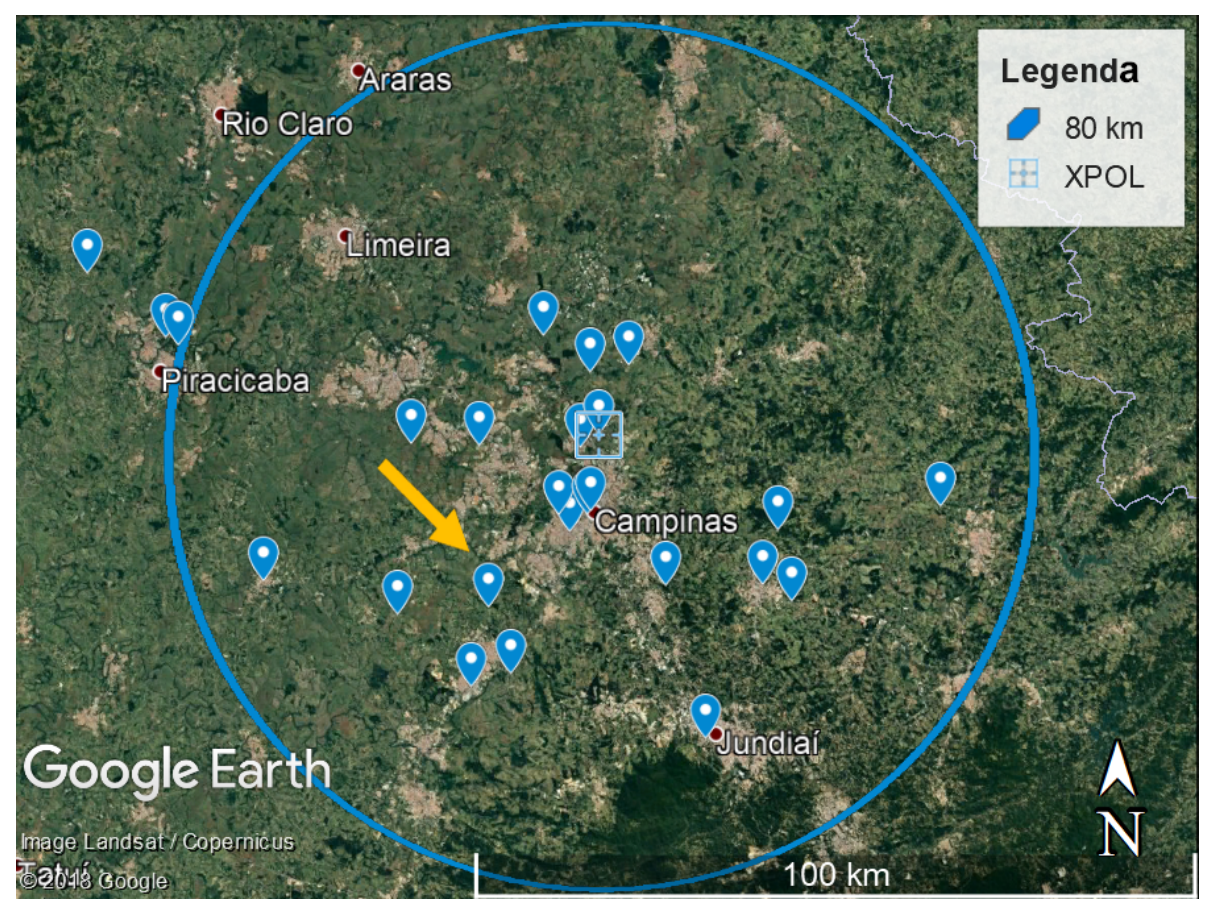

(a)

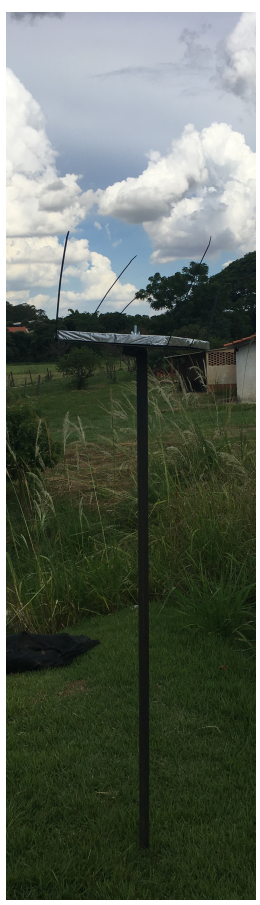

(b)

Fonte: Produzido pela autora.

Os casos descritos na Tabela 1 foram selecionados com base nos registros dos hailpads dentro da rede. A Tabela 2 mostra a localização das placas e os grupos que mediram a distribuição de tamanho de granizo, sendo eles: Departamento de Ciências Atmosféricas (DCA/IAG-USP) e Laboratório de Instrumentação Meteorológica (LIM/CPTEC-INPE). O horário aproximado foi baseado nas imagens do radar da FCTH (seção 3.2). Não houve registro da localização exata da placa C004.

A partir de um hailpad é possível derivar diversas grandezas relacionadas à tem- 
Tabela 2 - Descrição dos hailpads coletados para cada caso.

\begin{tabular}{ccccc}
\hline $\begin{array}{c}\text { Data do } \\
\text { evento }\end{array}$ & $\begin{array}{c}\text { Horário } \\
\text { aproximado (UTC) }\end{array}$ & $\begin{array}{c}\text { Código do } \\
\text { hailpad coletado }\end{array}$ & Localização & Medido por \\
\hline $2016-12-25$ & 1945 & C002 & Campinas & IAG, LIM \\
\hline $2017-01-31$ & 1929 & C003 & Campinas & IAG, LIM \\
& & C004 & Arredores de Campinas & IAG, LIM \\
\hline $2017-03-14$ & 1827 & C001 & Cosmópolis & IAG \\
& $19 \mathrm{~h} 57$ & R002 & Indaiatuba & IAG \\
\hline $2017-11-15$ & 2150 & R004 & Indaiatuba & IAG \\
\hline $2017-11-16$ & 1820 & R038 & Campinas & IAG \\
\hline
\end{tabular}

Fonte - Produzido pela autora.

pestade que gerou a queda de granizo. A principal delas é a distribuição de tamanho de granizo, medindo as cavidades na placa sensibilizada (Figura 8). Essa grandeza foi obtida através de uma série de medições manuais dos diâmetros das cavidades com um paquímetro e ajustando os dados com a curva de calibração desse tipo de isopor, realizada pelo LIM e exibida na Figura 9 (THOMAZ JÚNIOR, 2016). Com essa distribuição, pode-se calcular a energia cinética do granizo (quando diversas placas mediram um mesmo evento) ou do hailpad (quando poucas ou uma única placa mediram um evento). Ambas grandezas são equivalentes ao trabalho mecânico sofrido pela superfície onde caiu o granizo, indicando então o dano causado por ele na superfície.

Figura 8 - Placa R004 sensibilizada no sítio (a) e sem a cobertura de alumínio (b).

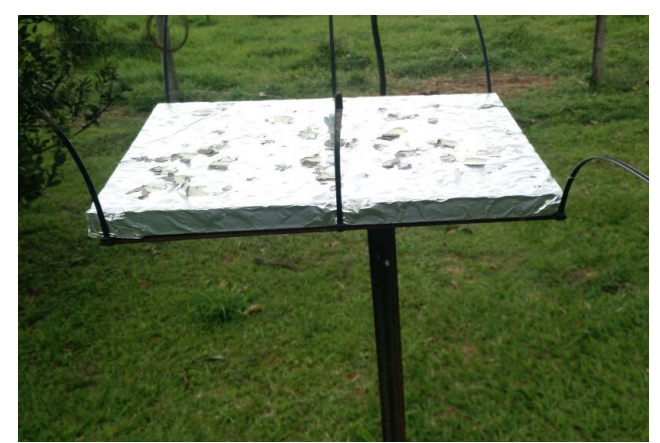

(a)

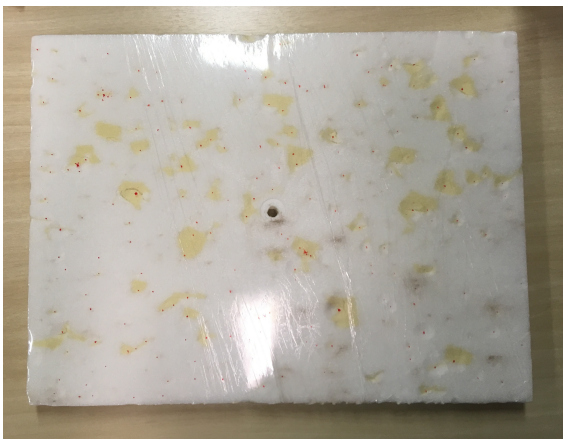

(b)

Fonte: A autora.

Como houve no máximo 2 placas sensibilizadas em todos os casos (quantidade insuficiente para inferir a energia cinética do granizo), calculou-se a energia cinética do hailpad $E_{t}\left(J^{-2}\right)$, definida por Waldvogel et al. (1978b) como:

$$
E_{t}=4,58 e^{-6} \sum_{i=1}^{k} n_{i} d_{i}^{4}
$$


Figura 9 - Curva de calibração do hailpad obtida pelo LIM/CPTEC-INPE (THOMAZ JÚNIOR, 2016).

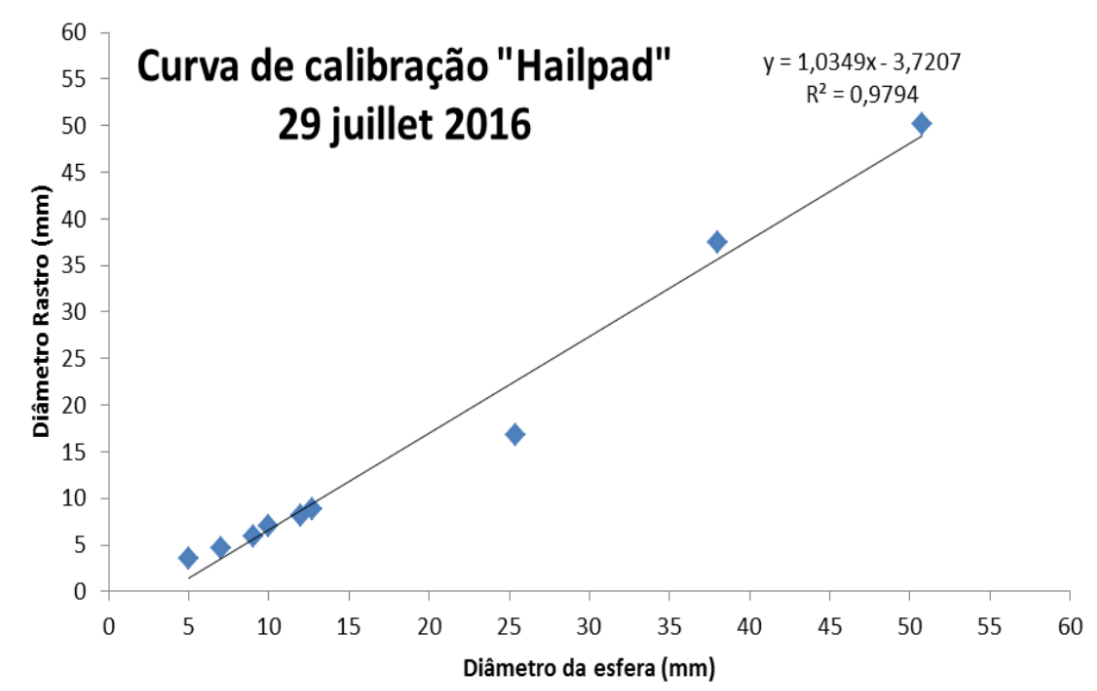

Fonte: Thomaz Júnior et al. (2015).

sendo $n_{i}$ a quantidade de pontos por $m^{2}$ em um dado diâmetro médio $d_{i}(m m)$ de um intervalo $\Delta d$. $k$ é o numero de intervalos, igual a 9 nesse caso já que $\Delta d$ variou entre $2 \mathrm{e}$ $22 \mathrm{~mm}$ com espaçamento de $1 \mathrm{~mm}$. Foram consideradas incertezas nas medidas propagando o desvio-padrão da distribuição média entre as diferentes medidas de uma mesma placa.

Com os valores de diâmetro do granizo e energia cinética do hailpad, duas escalas que definem a intensidade de tempestades de granizo foram comparadas entre si. A Tabela 3 descreve as escalas ANELFA e TORRO, comparando-as de acordo com o descrito por Dessens, Berthet e Sanchez (2007). A escala ANELFA, referente à organização que a desenvolveu (Association Nationale d'Etude et de Lutte contre les Fléaux Atmosphériques, Associação para Suprimir Pragas Atmosféricas), foi desenvolvida na França usando uma série de 16 anos de dados de hailpads e compara o diâmetro máximo do granizo com a energia cinética do hailpad, indicando possíveis danos (principalmente a plantações) que um evento com dado tamanho de granizo pode causar (DESSENS; BERTHET; SANCHEZ, 2007). O índice varia entre A0 (onde ocorre danos à folhas de árvores) e A5 (onde o evento é extremamente perigoso e pode causar mortes). A escala TORRO de intensidade de queda de granizo, também referente à organização que a desenvolveu (Tornado and Storm Research Organisation, Organização de Pesquisa em Tornado e Tempestade), foi desenvolvida na Grã-Bretanha e compara o diâmetro típico (interpretado aqui como a mediana da distribuição) do granizo com a energia cinética e também indica possíveis danos que o evento pode causar (WEBB; ELSOM; MEADEN, 1986). Este índice varia entre H0 (onde não há danos) e H10 (onde há extensivos danos estruturais). 
Tabela 3 - Descrição das escalas ANELFA e TORRO, com comparação entre o dano típico de cada escala.

\begin{tabular}{|c|c|c|c|c|}
\hline & \multicolumn{2}{|r|}{ ANELFA } & \multicolumn{2}{|r|}{ TORRO } \\
\hline $\begin{array}{l}\text { Objeto Equivalente ao } \\
\text { Tamanho do Granizo }\end{array}$ & Escala & Dano Típico & Escala & Dano Típico \\
\hline Ervilha & A0 & $\begin{array}{l}\text { Acidentes de trânsito, } \\
\text { danos a folhas de árvores }\end{array}$ & $\mathrm{H} 0$ & Sem danos \\
\hline Naftalina & A1 & $\begin{array}{c}\text { Danos a vinhas, pomares, } \\
\text { tabaco }\end{array}$ & $\mathrm{H} 1$ & $\begin{array}{l}\text { Danos gerais leves a } \\
\text { plantas e plantações }\end{array}$ \\
\hline Bola de Gude, Uva & $\mathrm{A} 2$ & $\begin{array}{c}\text { Danos sérios a cereais, } \\
\text { vegetais, árvores }\end{array}$ & $\mathrm{H} 2$ & $\begin{array}{c}\text { Danos significativos a } \\
\text { frutas, plantações e } \\
\text { vegetações }\end{array}$ \\
\hline $\mathrm{Noz}$ & A3 & $\begin{array}{c}\text { Danos totais a todas as } \\
\text { plantações, vidros } \\
\text { quebrados, carros } \\
\text { danificados }\end{array}$ & H3 & $\begin{array}{c}\text { Danos severos a frutas e } \\
\text { plantações, danos a } \\
\text { estruturas de vidro e } \\
\text { plástico, pinturas em } \\
\text { madeiras }\end{array}$ \\
\hline $\begin{array}{c}\text { Ovo de Pombo a Bola de } \\
\text { Squash }\end{array}$ & $\mathrm{A} 4$ & $\begin{array}{c}\text { Paisagem de inverno, } \\
\text { mortes de animais, } \\
\text { pessoas feridas, danos a } \\
\text { aviões pousados }\end{array}$ & $\mathrm{H} 4$ & $\begin{array}{l}\text { Danos difundidos em } \\
\text { vidros, danos em } \\
\text { carrocerias de veículos }\end{array}$ \\
\hline $\begin{array}{c}\text { Bola de Golfe a Ovo de } \\
\text { Franga }\end{array}$ & & & H5 & $\begin{array}{l}\text { Destruição total de } \\
\text { vidros, danos a telhados } \\
\text { de azulejo, riscos } \\
\text { significativos de } \\
\text { ferimentos }\end{array}$ \\
\hline Ovo de Galinha & A5 & $\begin{array}{l}\text { Evento extremamente } \\
\text { perigoso, morte de } \\
\text { pessoas desprotegidas }\end{array}$ & $\mathrm{H} 6$ & $\begin{array}{l}\text { Carrocerias de aeronaves } \\
\text { pousadas amassadas, } \\
\text { paredes de tijolos furadas }\end{array}$ \\
\hline $\begin{array}{c}\text { Bola de Tênis a Bola de } \\
\text { Cricket }\end{array}$ & & & $\mathrm{H} 7$ & $\begin{array}{l}\text { Danos severos a telhados, } \\
\text { risco de ferimentos sérios }\end{array}$ \\
\hline $\begin{array}{c}\text { Laranja Grande a Bola } \\
\text { de Softball }\end{array}$ & & & H8 & $\begin{array}{c}\text { (Evento mais severo } \\
\text { registrado nas Ilhas } \\
\text { Britânicas) Danos severos } \\
\text { a aeronaves }\end{array}$ \\
\hline Toranja & & & H9 & $\begin{array}{c}\text { Danos estruturais } \\
\text { extensivos; Risco de } \\
\text { ferimentos severos ou até } \\
\text { fatais em pessoas a céu } \\
\text { aberto }\end{array}$ \\
\hline Melão & & & H10 & $\begin{array}{c}\text { Danos estruturais } \\
\text { extensivos; Risco de } \\
\text { ferimentos severos ou até } \\
\text { fatais em pessoas a céu } \\
\text { aberto }\end{array}$ \\
\hline
\end{tabular}

Fonte - Adaptado de Dessens, Berthet e Sanchez (2007) e <http://www.torro.org.uk/hscale.php $>$. 


\subsection{Radares Meteorológicos}

A Figura 10 mostra a localização e cobertura espacial dos radares utilizados neste trabalho. A Figura 12 mostra a estratégia de varredura de cada radar.

Figura 10 - Localização e cobertura dos radares da FCTH (laranja), de São Roque (azul) e o XPOL (verde). As linhas mais grossas representam a cobertura de 250 (80) $\mathrm{km}$ dos radares FCTH e São Roque (XPOL), enquanto que as linhas mais finas representam a cobertura de 100 (60) $\mathrm{km}$ dos mesmos radares.

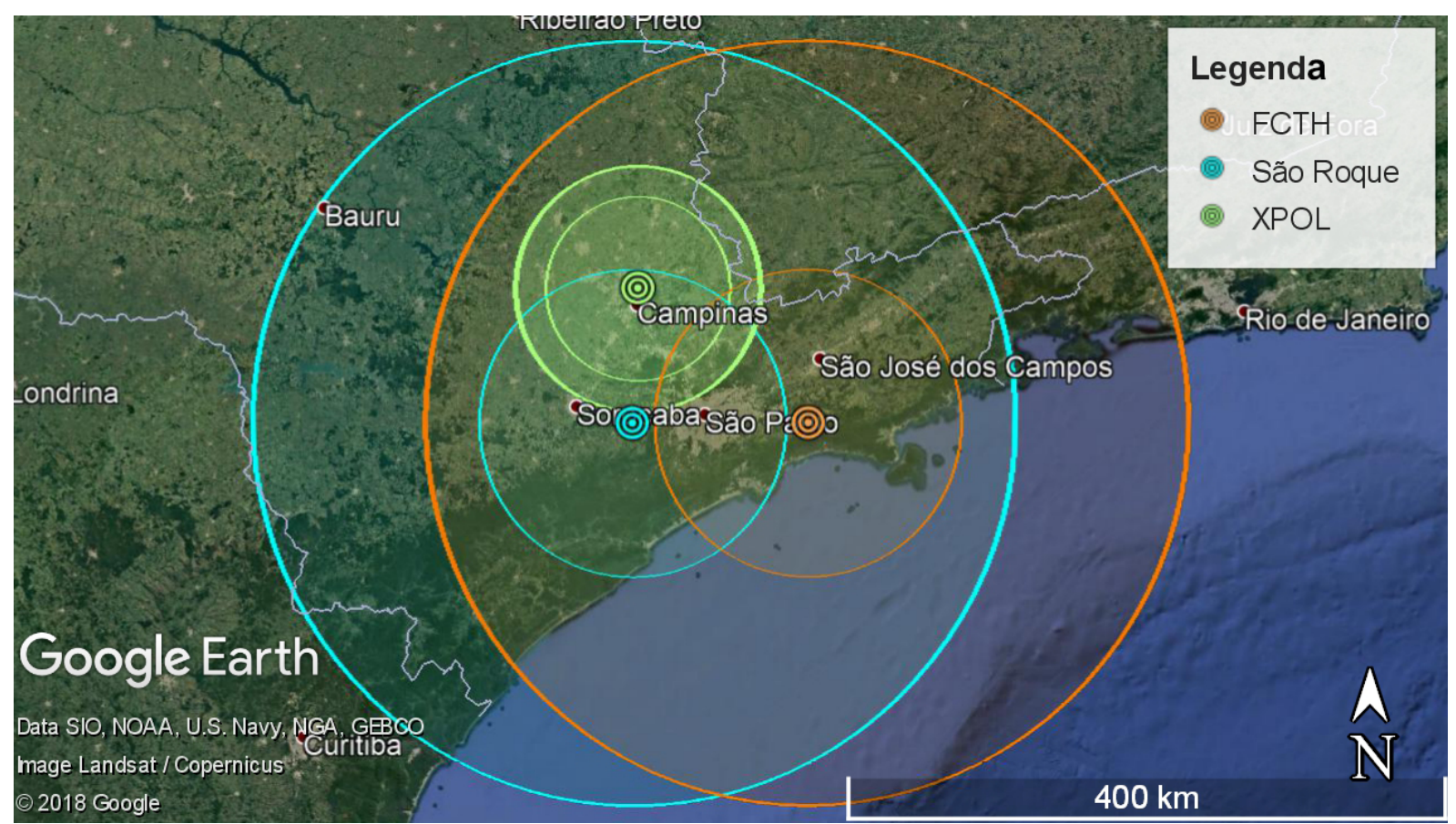

Fonte: Produzido pela autora.

O radar Doppler Banda-S de dupla polarização operado pela Fundação Centro Tecnológico de Hidráulica (FCTH) é localizado na barragem de Ponte Nova, município de Biritiba Mirim (23 $36^{\prime} \mathrm{S}, 45^{\circ} 58^{\prime} 20^{\prime \prime} \mathrm{W}, 916 \mathrm{~m}$ de altitude). Este radar faz uma varredura volumétrica a cada 5 minutos em uma cobertura de até $250 \mathrm{~km}$, com 8 elevações $\left(1^{\circ}, 1,6^{\circ}\right.$, $2,4^{\circ}, 3,2^{\circ}, 4,2^{\circ}, 5,5^{\circ}, 6,9^{\circ}$ e $8,6^{\circ}$ ) de $1^{\circ}$ de abertura do feixe, como mostra a Figura 12a. A velocidade de Nyquist (valor máximo (mínimo no caso negativo) de velocidade radial medido) deste radar é de $16,27 \mathrm{~ms}^{-1}$. Os dados volumétricos foram convertidos em uma grade de $1 \times 1 \times 1 \mathrm{~km}$ usando o pacote Py-ART (Python ARM Radar Toolkit, Conjunto de Ferramentas de Radar em Python do ARM) (HELMUS; COLLIS, 2016) e perfis horizontais (em $3 \mathrm{~km}$ de altura) e verticais (cortes entre dois pontos com coordenadas latitudinais e longitudinais) foram analisados. Além da variável refletividade do radar (medida em $d B Z$ ), três variáveis polarimétricas foram analisadas e relacionadas com diferentes tipos de hidrometeoros seguindo a classificação de Straka, Zrnić e Ryzhkov (2000) descrita na subseção 3.2.1: 
a) Refletividade Diferencial $(d B)$ : Razão entre os fatores de refletividade horizontal e verticalmente polarizados; diferencia a forma das partículas em um dado volume medido;

b) Fase Diferencial Específica $\left({ }^{\circ} \mathrm{km}^{-1}\right)$ : Calculada a partir das matrizes de espalhamento vertical e horizontal, é fortemente influenciada pela concentração numérica e massa de gotículas de nuvem, permitindo a derivação da distribuição de tamanho das mesmas;

c) Coeficiente de Correlação (adimensional): Razão entre as amplitudes das matrizes de espalhamento; destaca misturas de formas e tamanhos das partículas (RAUBER; NESBITT, 2018).

O radar Doppler Banda-S operado pelo DECEA (Departamento de Controle do Espaço Aéreo) instalado em São Roque ( $23^{\circ} 35^{\prime} 56^{\prime \prime} \mathrm{S}, 47^{\circ} 5^{\prime} 52^{\prime \prime} \mathrm{W}, 1147,54 \mathrm{~m}$ de altitude) faz varreduras a cada 10 minutos em uma cobertura de até $250 \mathrm{~km}$, com 15 elevações $\left(0,5^{\circ}\right.$, $1^{\circ}, 2^{\circ}, 3^{\circ}, 4^{\circ}, 5^{\circ}, 6^{\circ}, 7^{\circ}, 8^{\circ}, 9^{\circ}, 10^{\circ}, 12^{\circ}, 14^{\circ}, 16^{\circ}$ e $18^{\circ}$ ) de $2^{\circ}$ de abertura do feixe, como mostra a Figura 12b. A velocidade de Nyquist deste radar é de 14,63 $\mathrm{ms}^{-1}$. Os perfis horizontais de CAPPIs (Constant Altitude Plan Position Indicator, Indicador Plano de Posição em Altitude Constante) em $3 \mathrm{~km}$ de altura serviram como dados de entrada para o algoritmo ForTraCC (Forecast and Tracking the Evolution of Cloud Clusters, Prevendo e Rastreando a Evolução de Aglomerados de Nuvens) (VILA et al., 2008) adaptado para radares meteorológicos (ForTraCC-Radar). Este algoritmo identifica os sistemas convectivos usando um limiar de refletividade - $35 \mathrm{dBZ}$ neste trabalho - e os classifica usando imagens subsequentes: sistema novo, em continuidade, em fusão ou em separação - a Figura 11 mostra uma ilustração dessas situações.

O ciclo de vida da tempestade associada a cada caso da Tabela 1 foi definido a partir do sistema convectivo com maior intensidade na posição do hailpad, considerando o horário aproximado da queda de granizo. A partir desse sistema, a família - definição do algoritmo para um conjunto de sistemas próximos uns aos outros com mesmo deslocamento - associada a ele foi extraída e corrigida manualmente caso houvesse necessidade. A partir de cada rastreamento, variáveis como refletividade máxima e tamanho do sistema foram analisadas, além de servirem como base para a seleção de descargas elétricas associadas aos sistemas.

O radar Doppler Banda-X de dupla polarização XPOL foi operado pelo Projeto SOS-CHUVA na UNICAMP, cidade de Campinas $\left(22^{\circ} 48^{\prime} 50^{\prime \prime} \mathrm{S}, 47^{\circ} 3^{\prime} 22^{\prime \prime} \mathrm{W}, 680 m\right.$ de altitude). Ele fez varreduras volumétricas a cada 10 minutos em uma cobertura de até $80 \mathrm{~km}$, com 17 elevações $\left(0,5^{\circ}, 1,8^{\circ}, 3,1^{\circ}, 4,4^{\circ}, 5,7^{\circ}, 7^{\circ}, 8,3^{\circ}, 9,6^{\circ}, 10,9^{\circ}, 13^{\circ}, 15^{\circ}, 18^{\circ}, 22^{\circ}\right.$, $26^{\circ}, 32^{\circ}, 40^{\circ}$ e $55^{\circ}$ ) de $1,3^{\circ}$ de abertura do feixe, como mostra a Figura 12c. Por ser de uma banda de frequência mais alta, a velocidade de Nyquist deste radar é menor do que a dos 
Figura 11 - Representação dos tipos de classificação do ForTraCC: continuidade (a), separação (b) e fusão (c). As formas com contorno tracejado representa o sistema no primeiro passo enquanto que as formas cinzas representam o sistema no passo seguinte, com as setas indicando o deslocamento.

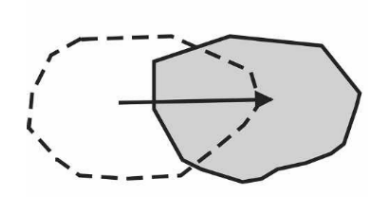

(a)

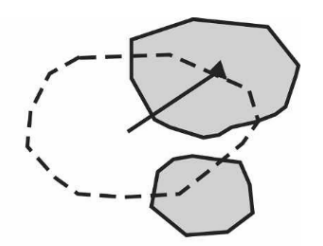

(b)

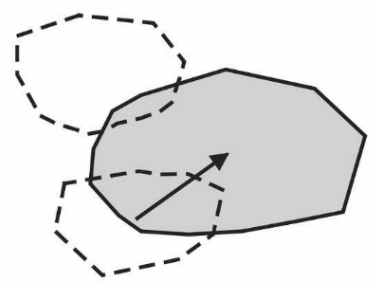

(c)

Fonte: Vila et al. (2008).

radares Banda-S: 9, $6 \mathrm{~ms}^{-1}$. Os dados volumétricos também foram convertidos em uma grade de $1 \times 1 \times 1 \mathrm{~km}$ usando o pacote Py-ART (HELMUS; COLLIS, 2016) e as variáveis refletividade do radar e velocidade radial foram utilizadas. Devido à falta de dados em muitos dos casos de tempestade de granizo selecionados, este radar foi usado apenas como entrada no algoritmo de recuperação de vento por Multi-Doppler (subseção 3.2.2) juntamente com os demais radares.

\subsubsection{Identificação de Hidrometeoros}

Para definir de forma mais acurada a presença de granizo nas medidas de radar, o método de classificação de hidrometeoros usando Lógica Fuzzy foi aplicado. Presente no pacote CSU_RadarTools (LANG; DOLAN; GUY, 2017) através de uma função chamada Fuzzy Hydrometeor Classificator (Classificador Fuzzy de Hidrometeoros), o método implementado é dividido em três passos (LIU; CHANDRASEKAR, 2000):

a) A fuzzificação usa funções beta, que indicam a probabilidade de um dado valor de variável polarimétrica representar um dado tipo de hidrometeoro, com pesos específicos para cada variável (refletividade e temperatura apresentam o maior peso) para classificar os dados polarimétricos de entrada em cada ponto de grade;

b) A inferência calcula uma pontuação para cada tipo de hidrometeoro somando as classificações de cada variável e; 
Figura 12 - Estratégia de varredura volumétrica dos radares meteorológicos da FCTH (a), de São Roque (b) e o XPOL instalado na UNICAMP (c). As linhas tracejadas delimitam a distância de cada radar à rede de hailpads (Figura 7a).

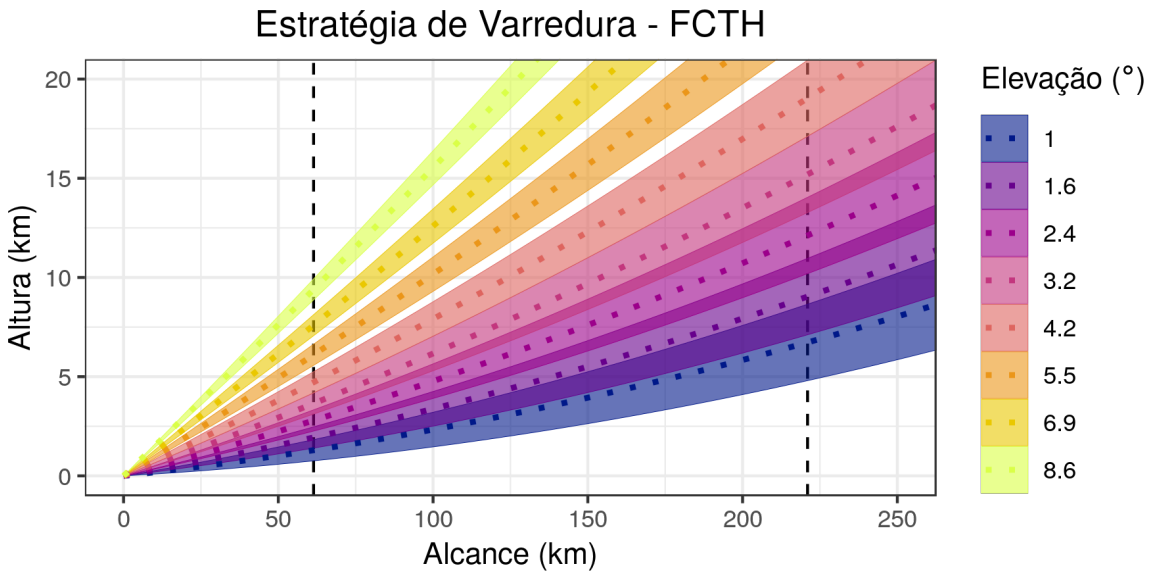

(a)

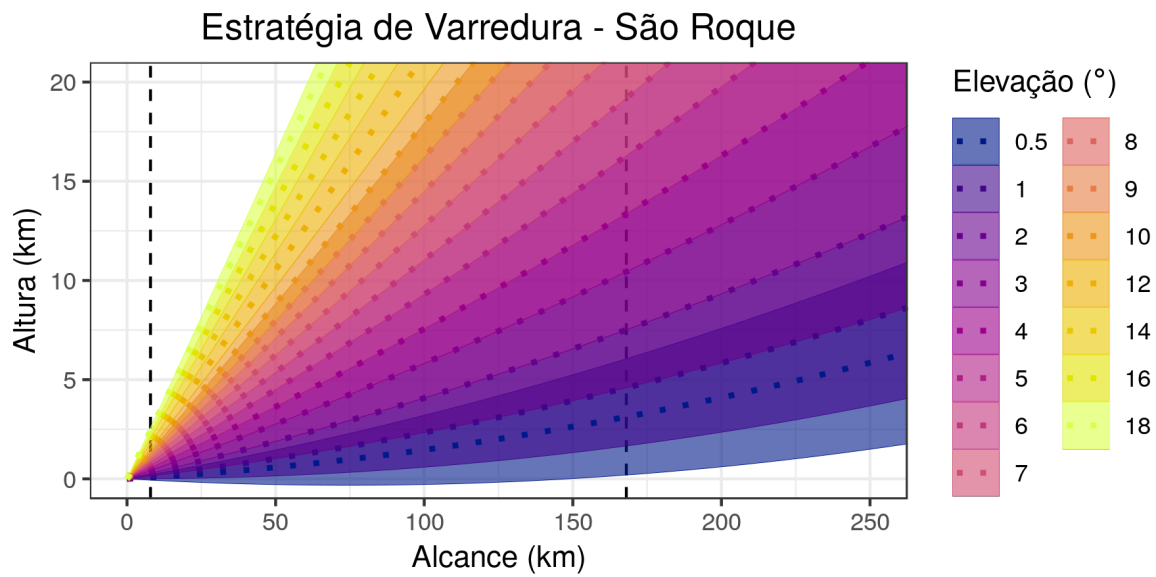

(b)

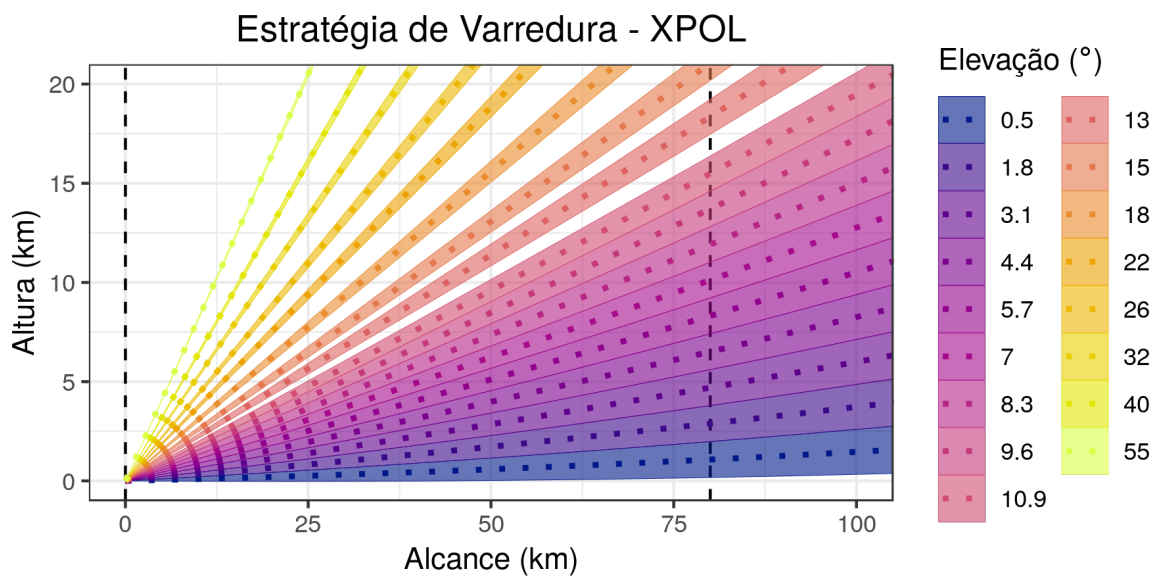

(c)

Fonte: Produzido pela autora. 
c) A agregação escolhe a pontuação máxima para cada ponto e indica o hidrometeoro correspondente a ela.

Este Classificador Fuzzy de Hidrometeoros leva em consideração intervalos de valores de variáveis polarimétricas nas funções beta com aquelas características de tempestades de verão e diferencia 10 tipos de hidrometeoros (LANG; DOLAN; GUY, 2017):
a) Chuvisco (Drizzle)
b) Chuva (Rain)
c) Cristais de Gelo (Ice Crystals)
d) Agregados (Aggregates)
e) Neve Molhada (Wet Snow)
f) Gelo Vertical (Vertical Ice)
g) Graupel de Densidade Baixa (Low-Density Graupel)
h) Graupel de Densidade Alta (High-Density Graupel)
i) Granizo (Hail)
j) Gotas Grandes (Big Drops)

O classificador utiliza como entrada os campos de refletividade, refletividade diferencial, fase diferencial específica e coeficiente de correlação, além de um perfil de temperatura obtido a partir de uma radiossondagem. O método de ponderação desta função (chamado de híbrido) multiplica a soma dos pesos das variáveis polarimétricas ao valor verdadeiro dos campos de refletividade e perfil de temperatura (dando assim maior peso à essas variáveis; por exemplo, se quatro variáveis polarimétricas forem usadas, cada um com peso igual a 0,5 , temperatura e refletividade teriam peso igual a 2); os pesos de refletividade diferencial, fase diferencial específica e coeficiente de correlação foram subjetivamente definidos como 1 pois não foi possível determinar a confiabilidade dessas variáveis. As funções beta de cada variável estão descritas em Carey e Rutledge (1998), Liu e Chandrasekar (2000) e Dolan e Rutledge (2009). As radiossondagens aplicadas foram coletadas no Campo de Marte (Estação SBMT, São Paulo) em datas próximas aos eventos.

Para verificar subjetivamente a performance do método de classificação de hidrometeoros, os campos de variáveis polarimétricas foram analisados e relacionados com os mesmos tipos de hidrometeoros do método a partir da classificação de Straka, Zrnić e 
Ryzhkov (2000). A Figura 13 mostra os intervalos de valores de cada variável correspondente a cada tipo de hidrometeoro, incluindo também a mistura de chuva com granizo $($ rain + hail $)$.

Figura 13 - Classificação de hidrometeoros de acordo com refletividade (a), refletividade diferencial (b), fase diferencial específica (c) e coeficiente de correlação (ou razão de correlação cruzada) (d).

a

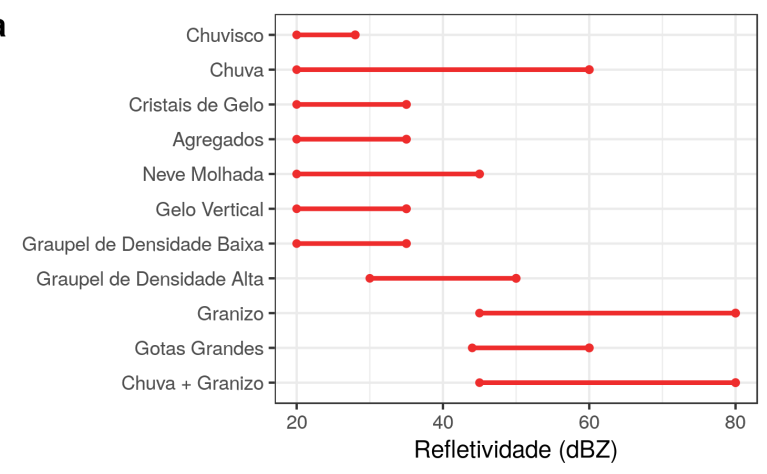

c

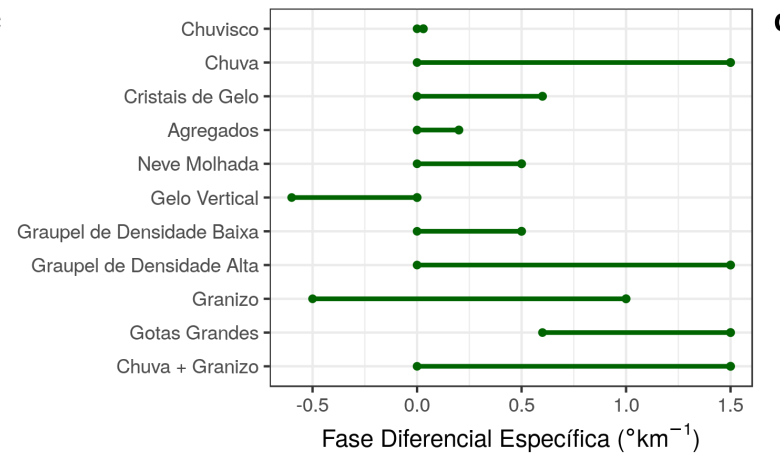

b

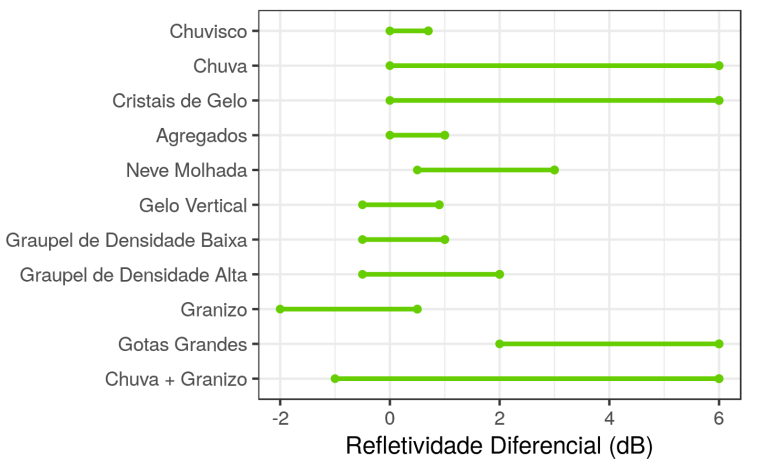

d

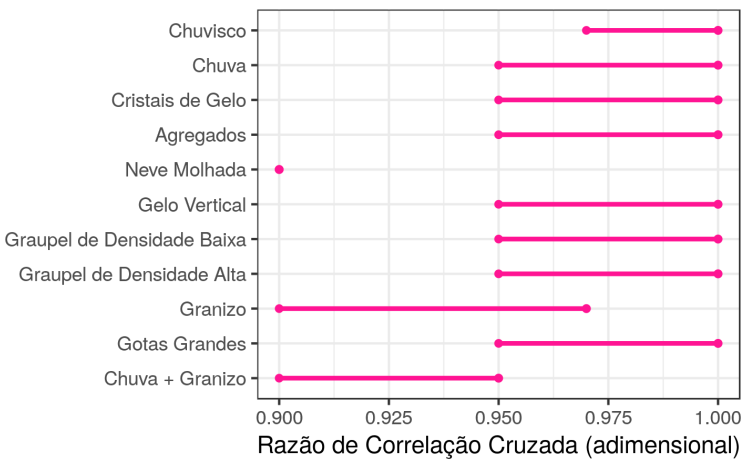

Fonte: Produzido pela autora a partir de Straka, Zrnić e Ryzhkov (2000).

A partir das variáveis polarimétricas, é possível também estimar as massas $(M)$ dos hidrometeoros, separando em água líquida e gelo: com a refletividade $(Z)$, por exemplo, usa-se uma relação Z-M da forma $M=a Z^{b}$ (SASSEN, 1987). Essas grandezas são importantes para determinar fluxos de massa (especialmente de gelo) dentro da nuvem e relacioná-las com outras características, como por exemplo a atividade elétrica (DEIERLING et al., 2005; DEIERLING et al., 2008). Uma metodologia mais robusta, descrita por Carey e Rutledge (2000) e Cifelli et al. (2002), usa a refletividade diferencial $\left(Z_{d p}\right.$, dB) (GOLESTANI; CHANDRASEKAR; BRINGI, 1989) para determinar a contribuição da água e do gelo para a refletividade horizontal $\left(Z_{h}, d B Z\right)$ da seguinte forma:

$$
\begin{gathered}
Z_{h}=Z_{h}^{\text {chuva }}+Z_{h}^{\text {gelo }} \\
Z_{h}^{\text {chuva }}=0,77 Z_{d p}+14
\end{gathered}
$$


As massas de água líquida e gelo são calculadas a partir das seguintes situações (CIFELLI et al., 2002):

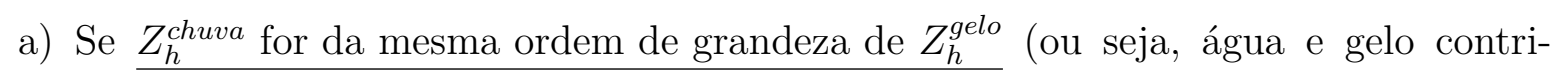
buem da mesma forma para a refletividade), as massas de água líquida $\left(M_{l}, \mathrm{gm}^{-3}\right)$ e gelo $\left(M_{g}, g m^{-3}\right)$ serão:

$$
M_{l}=3,44 \times 10^{-3}\left(Z_{h}^{\text {chuva }}\right)^{4 / 7}
$$

onde $Z_{h}^{\text {chuva }}$ está em $m m^{6} m^{-3}($ RYZHKOV; ZRNIC, 1995) e

$$
M_{g}=1000 \pi \rho_{i} N_{0}^{3 / 7}\left(\frac{5,28 \times 10^{-18} Z_{h}^{\text {gelo }}}{720}\right)^{4 / 7}
$$

onde $Z_{h}^{\text {gelo }}$ está em $\mathrm{mm}^{6} \mathrm{~m}^{-3}, \rho_{i}$ é a densidade do gelo $\left(0,917 \mathrm{~kg} \mathrm{~m}^{-3}\right)$ e $N_{0}(4 \times$ $\left.10^{6} \mathrm{~m}^{-4}\right)$ é o parâmetro de interceptação de uma distribuição exponencial inversa assumida para o gelo (CAREY; RUTLEDGE, 2000);

b) Se $Z_{h}^{\text {chuva }}$ for muito maior do que $Z_{h}^{\text {gelo }}$ (ou seja, a água tem a maior contribuição para a refletividade), a massa de água líquida $\left(M_{l}, \mathrm{gm}^{-3}\right)$ será:

$$
M_{l}=0,70 \times 10^{-3} Z_{h}^{0,886} \varsigma^{-4,159}
$$

onde $Z_{h}\left(Z_{v}\right)$ é a refletividade horizontal (vertical) em $m m^{6} m^{-3}$ e (BRINGI; CHANDRASEKAR, 2001)

$$
\varsigma=\frac{Z_{h}}{Z_{v}}=10^{Z_{d r} / 10}
$$

onde $Z_{d r}$ é a refletividade diferencial em $d B$;

c) Se $Z_{h}^{\text {chuva }}$ for muito menor do que $Z_{h}^{\text {gelo }}$ (ou seja, o gelo tem a maior contribuição para a refletividade), a massa de gelo $\left(M_{g}, \mathrm{gm}^{-3}\right)$ será igual a Equação $3.5 \mathrm{com}$ $Z_{h}^{\text {gelo }}=Z_{h}$.

Nesta dissertação, a função Liquid/Ice Water Mass Calculations (Cálculos de Massas de Água Líquida e Gelo) do pacote CSU_RadarTools (LANG; DOLAN; GUY, 2017) foi utilizada. A partir dos campos de refletividade e refletividade diferencial, ela calcula as massas de água líquida e gelo usando o método descrito acima.

\subsubsection{Recuperação de Vento por Multi-Doppler}

A área de estudo (RMC dentro da cobertura da rede de hailpads) possui cobertura de pelo menos dois radares - três se considerar a cobertura máxima dos radares (Figura 10) - capazes de medir velocidade radial (Doppler) quase simultaneamente (Tabela 4). Isso permite a aplicação de métodos que convertem os campos tridimensionais de refletividade 
Tabela 4 - Configuração dos radares nos casos em que a recuperação de vento por Multi-Doppler foi utilizada.

\begin{tabular}{cccccc}
\hline Caso & \multicolumn{2}{c}{$2017-03-14$} & \multicolumn{3}{c}{$2017-11-15$} \\
\hline Radares disponíveis & FCTH & SR & FCTH & SR & XPOL \\
\hline Resolução temporal $(s)$ & 300 & 600 & 300 & 600 & 600 \\
\hline $\begin{array}{c}\text { Diferença mínima entre os horários de } \\
\text { começo da varredura dos radares }(s)\end{array}$ & 172 & & 19 & \\
\hline $\begin{array}{c}\text { Diferença máxima entre os horários de } \\
\text { começo da varredura dos radares }(s)\end{array}$ & 174 & & 20 & \\
\hline Fonte - Produzido pela autora. & & & & & \\
\hline
\end{tabular}

e velocidade radial de múltiplas perspectivas em um campo tridimensional de velocidade do vento com alto grau de detalhamento.

A Figura 14 mostra o mesmo da Figura 6, mas para combinações entre os três radares usados neste trabalho. Considerando a combinação FCTH/XPOL (painel superior), a distância entre os radares e a localização do XPOL dentro da cidade de Campinas limita as estimativas boas $\left(\beta \geq 45^{\circ}\right)$ ou aceitáveis $\left(30^{\circ} \leq \beta<45^{\circ}\right)$ em boa parte da região de estudo, com exceção da cidade de Indaiatuba e à oeste dela. Considerando a combinação SR/FCTH (painel central), a estimativa Dual-Doppler tem erros menores (ou seja, $\beta=45^{\circ}$ ) em Campinas e Indaiatuba (cidades com mais casos de queda de granizo, Tabela 1) e à leste, mas estimativas aceitáveis (ou seja, $\beta=30^{\circ}$ ) estão disponíveis para toda a RMC. Considerando a combinação SR/XPOL (painel inferior), os ventos à nordeste e sudeste da RMC não podem ser estimados devido ao alinhamento na direção norte-sul desses radares: não é possível estimar o campo tridimensional do vento na linha de base que alinham os radares pois nessa região eles observam o alvo exatamente na mesma direção (apenas em sentidos opostos), medindo assim a mesma componente de velocidade. A partir dessas considerações e da disponibilidade de dados para cada caso (Tabela 4), as combinações SR/FCTH e SR/FCTH/XPOL são as que apresentam melhores estimativas (menores erros) do campo tridimensional do vento e serão usadas para os estudos de caso dos dias 2017-03-14 e 2017-11-15, respectivamente.

Uma metodologia desenvolvida recentemente de recuperação de vento tridimensional por Dual e Multi-Doppler é baseada em 3DVAR (3D Variational Analysis, Análise Variacional em 3D) (SHAPIRO; POTVIN; GAO, 2009; POTVIN; SHAPIRO; XUE, 2012). Nela, as componentes cartesianas do vento $u, v$ e $w$ são calculadas minimizando uma função custo total $J$ que quantifica erros nas restrições relacionadas aos dados $\left(J_{O}\right)$, às equações de conservação de massa $\left(J_{M}\right)$ e vorticidade $\left(J_{V}\right)$ e à suavização $\left(J_{S}\right)$ :

$$
J=J_{O}+J_{M}+J_{V}+J_{S}
$$


Figura 14 - Ângulos de cruzamento do feixe com Dual-Doppler de $45^{\circ}$ (melhores dados de vento) e $30^{\circ}$ (dados de vento aceitáveis) para um par de radares Doppler, mais especificamente para as combinações dos radares FCTH e XPOL, São Roque (SR) e FCTH e SR e XPOL. Os contornos em cinza representam as cidades de São Paulo, Indaiatuba e Campinas, enquanto que as linhas pontilhadas indicam as distâncias entre os radares.

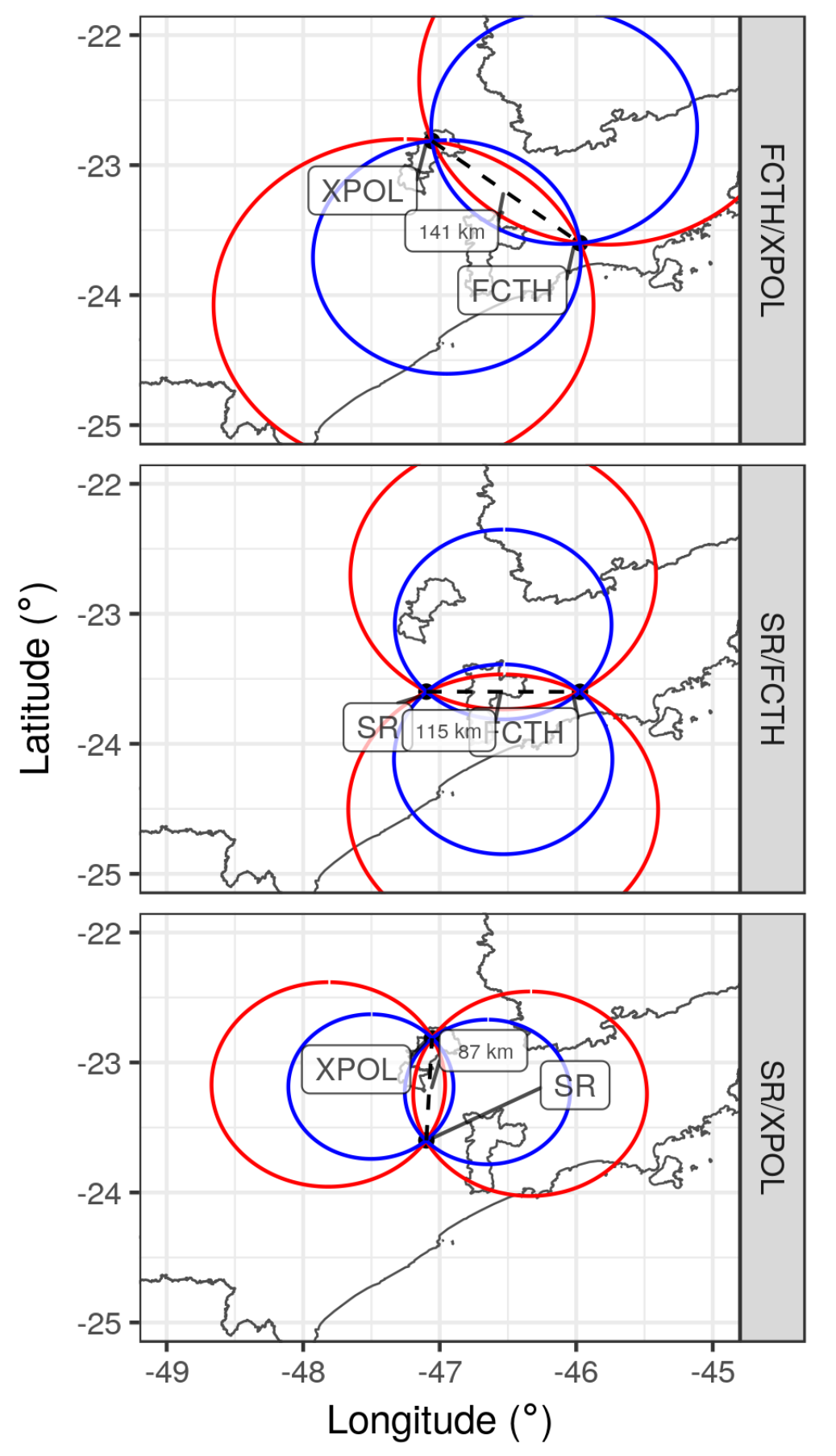

Ângulo de Cruzamento do Feixe $\left(^{\circ}\right)-30$

Fonte: Produzido pela autora. 
Cada função custo é equivalente ao erro multiplicado por um coeficiente de ajuste $C$, que define o peso que esse erro terá no valor final de velocidade do vento (POTVIN; SHAPIRO; XUE, 2012).

A metodologia acima foi usada nesta dissertação através do pacote MultiDop $<$ https://github.com/nasa/MultiDop>. Desenvolvido em Python e C e compatível com o pacote Py-ART (HELMUS; COLLIS, 2016), este pacote extrai o campo tridimensional de velocidade do vento a partir de uma combinação de 2 ou 3 radares e permite que os coeficientes de ajuste sejam definidos pelo usuário. A Tabela 5 mostra os parâmetros de configuração do MultiDop escolhidos para as análises; os coeficientes de ajuste são similares a Potvin, Shapiro e Xue (2012).

Como mostrado na Tabela 5, os dados de radar foram convertidos para uma grade de $1 \times 1 \times 1 \mathrm{~km}$. Além disso, problemas de ambiguidade da velocidade radial - quando a velocidade radial é maior do que a velocidade de Nyquist (Figura 15) - foram corrigidos usando algoritmos baseado na região (analisa os dados por região de velocidades parecidas) e baseado em um esquema em quatro dimensões (4DD, Four-Dimensional Doppler Dealising Scheme) (JAMES; HOUZE, 2001), ambos presentes no pacote Py-ART; no caso do algoritmo 4DD, uma radiossondagem (novamente da estação do Campo de Marte) foi utilizada como condição inicial. Como forma de complementar as correções automáticas, correções manuais dos dados de velocidade radial foram feitas usando o software Solo3 $<$ https://www.eol.ucar.edu/software/solo3>.

Figura 15 - Velocidade radial verdadeira vs medida de um alvo com uma velocidade de Nyquist de $10 \mathrm{~ms}^{-1}$ mostrando a ambiguidade para valores de velocidade verdadeira além do intervalo de -10 a $10 \mathrm{~ms}^{-1}$.

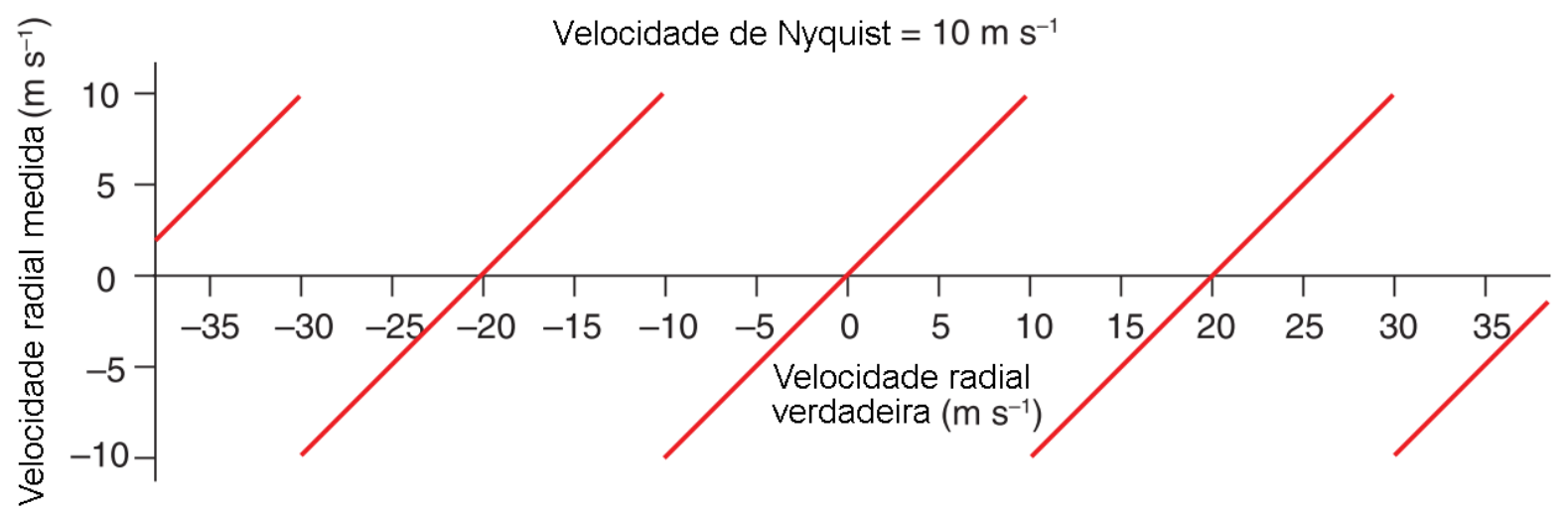

Fonte: Adaptado de Rauber e Nesbitt (2018). 
Tabela 5 - Parâmetros de configuração do MultiDop para cálculos de Dual e MultiDoppler.

\begin{tabular}{|c|c|}
\hline Resolução da grade & $1 \times 1 \times 1 \mathrm{~km}$ \\
\hline Restrição da conservação de massa & Aproximação anelástica \\
\hline Restrição de suavização & Derivadas de segunda ordem \\
\hline Pesos na restrição de dados & Pesos iguais para todas as observações \\
\hline $\begin{array}{c}\text { Condição inicial da tempestade (deslocamento } \\
\text { constante) }\end{array}$ & $U_{t}=V_{t}=-10 \mathrm{~ms}^{-1}$ \\
\hline Impor $w=0$ no topo & Sim \\
\hline Coeficiente da restrição dos dados & 1 \\
\hline $\begin{array}{l}\text { Coeficiente da restrição da equação de } \\
\text { continuidade de massa }\end{array}$ & 30 \\
\hline $\begin{array}{c}\text { Coeficiente da restrição da equação de } \\
\text { vorticidade }\end{array}$ & $1 e^{-3}$ \\
\hline Coeficiente de suavização horizontal & $1 e^{-2}$ \\
\hline Coeficiente de suavização vertical & $1 e^{-2}$ \\
\hline Coeficiente da restrição da sondagem & 0 \\
\hline Todos os pesos constantes & $\operatorname{Sim}$ \\
\hline Filtros & Nenhum \\
\hline $\begin{array}{l}\text { Estatísticas de verificação computadas apenas } \\
\text { dentro do domínio de } 2+\text { radares Doppler }\end{array}$ & $\operatorname{Sim}$ \\
\hline Critério do domínio & 10 pontos \\
\hline Altura de corte & $0 \mathrm{~km}$ \\
\hline $\begin{array}{l}\text { Matrizes de cobertura de fundo para ângulos de } \\
\text { cruzamento de feixe ótimos para dois radares }\end{array}$ & Sim para todas as combinações \\
\hline $\begin{array}{l}\text { Matrizes de cobertura de fundo para ângulos de } \\
\text { cruzamento de feixe aceitáveis para dois radares }\end{array}$ & Sim para todas as combinações \\
\hline $\begin{array}{c}\text { Matrizes de cobertura de fundo para um radar } \\
\text { individual }\end{array}$ & Não para todos \\
\hline $\begin{array}{l}\text { Multiplicador do peso dos dados quando todos os } \\
\text { radares tem bons ângulos de cruzamento do feixe }\end{array}$ & $S R=1 e^{-3}, F C T H=X P O L=1$ \\
\hline
\end{tabular}

Fonte - Produzido pela autora.

\subsection{Rede de Detecção de Raios}

A atividade elétrica dos casos selecionados foi analisada através dos dados do Sistema Brasileiro de Deteç̧ão de Descargas Elétricas (BrasilDAT) (NACCARATO et al., 2014). Essa rede opera entre as faixas de frequência LF (Low Frequency, Baixa Frequência) e HF (High Frequency, Alta Frequência), detectando pulsos eletromagnéticos - chamados de strokes neste trabalho - emitidos pelas descargas elétricas através da técnica do tempo de chegada (LEWIS; HARVEY; RASMUSSEN, 1960). Devido à larga banda de frequência, é possível diferenciar descargas de retorno de raios CG e pulsos de raios intranuvem (intra- 
cloud, IC), além de estimar a polaridade dos raios nuvem-solo através do sinal do pico de corrente. A eficiência de detecção estimada da rede na RMC é de 60 a $70 \%$ para raios IC e de $95 \%$ para raios CG (Dr. Kleber Naccarato, ELAT-CCST-INPE, comunicação pessoal, 2018). Os dados (data, latitude e longitude, polaridade e tipo - IC ou CG) dessa rede foram fornecidos pelo Grupo de Eletricidade Atmosférica (ELAT) do INPE para o Projeto SOS-CHUVA e agrupados em flashes neste trabalho (subseção 3.3.1).

\subsubsection{Conversão Strokes-Flashes}

Devido ao fato de que strokes estão associados a descargas de retorno e pulsos que não necessariamente representam raios distintos (um raio nuvem-solo, por exemplo, pode ser constituído de diversas descargas de retorno), esses dados foram convertidos em flashes, que representam todo o evento de uma descarga elétrica (MACGORMAN; RUST, 1998). De acordo com Cummins et al. (1998) e Murphy e Nag (2015), strokes devem ser agrupados em flashes seguindo as seguintes considerações:

a) Strokes devem ser agrupados em um período total de $1 \mathrm{~s}$, com intervalo entre strokes de até $500 \mathrm{~ms}$;

b) Strokes subsequentes devem estar em um raio de até $10 \mathrm{~km}$ a partir do primeiro; pode-se considerar strokes subsequentes em um raio de até $50 \mathrm{~km}$, desde que esteja dentro do intervalo de $500 \mathrm{~ms}$;

c) A multiplicidade de um flash (quantidade de strokes em um único flash) pode ser de até 63 (1023) strokes CG (IC).

Para fazer o agrupamento seguindo as orientações acima, o algoritmo DBSCAN (Density-Based Spatial Clustering of Application with Noise, Agrupamento Espacial Baseado em Densidade de Aplicação com Ruído) de agrupamento de dados foi utilizado. Ele usa a distância entre pontos $\epsilon$ e a quantidade mínima de pontos min $_{\text {pts }}$ para agrupar qualquer matriz de dados n-dimensional (ESTER et al., 1996; KRIEGEL et al., 2011). Hutchins, Holzworth e Brundell (2014) e Hutchins e Holzworth (2014) usaram este método para agrupar strokes em flashes e em conjuntos de tempestades com raios, e a mesma abordagem foi adotada neste trabalho.

Como o algoritmo DBSCAN usa apenas dois parâmetros ( $\epsilon$ e $\left.\min _{p t s}\right)$, enquanto que o agrupamento de strokes em flashes precisa de três (distância entre pontos $\epsilon_{s p c}$, distância temporal $\epsilon_{t}$ e quantidade mínima de pontos $\min _{p t s}$ ), duas etapas são necessárias: agrupar os dados em função do tempo (usando $\epsilon_{t}$ ) e depois agrupar em função do espaço bidimensional (usando $\epsilon_{\mathrm{spc}}$ em latitude e longitude). A partir das orientações de Cummins et al. (1998) e Murphy e Nag (2015) e após alguns testes com valores distintos de $\epsilon_{s p c}$ 
(vide Anexo A), definiu-se que $\min _{p t s}=1, \epsilon_{t}=0,5 s$ e $\epsilon_{s p c}=2,5 \mathrm{~km}$. O algoritmo foi implementado e adaptado usando a linguagem R (R CORE TEAM, 2018).

A Figura 16 mostra as características dos dados de flashes gerados usando as especificações acima. É possível observar que a distribuição de tempos entre strokes e entre flashes (Figura 16a) apresentam picos em aproximadamente 0,1 e $1 \mathrm{~s}$, respectivamente; o tempo máximo entre strokes é de aproximadamente $500 \mathrm{~ms}$, compatível com Cummins et al. (1998). A maioria dos dados apresentou um stroke por flash (Figura 16b), com registros de até 17 strokes por flash, compatível com Murphy e Nag (2015). A distribuição espacial de distância entre strokes em um flash (Figura 16c) possui maior concentração de dados dentro do intervalo de 0 a $2,5 \mathrm{~km}$ de latitude e longitude, com distâncias de até $7 \mathrm{~km}$, também compatível com Cummins et al. (1998). Assim, pode-se dizer que o algoritmo de agrupamento de strokes em flashes usando o método DBSCAN foi bem sucedido em agrupar os dados dentro das orientações citadas.

Figura 16 - Histogramas de tempo entre strokes e entre flashes (a), número de strokes por flash (b) e distância latitude e longitudinal entre strokes em um flash (c).
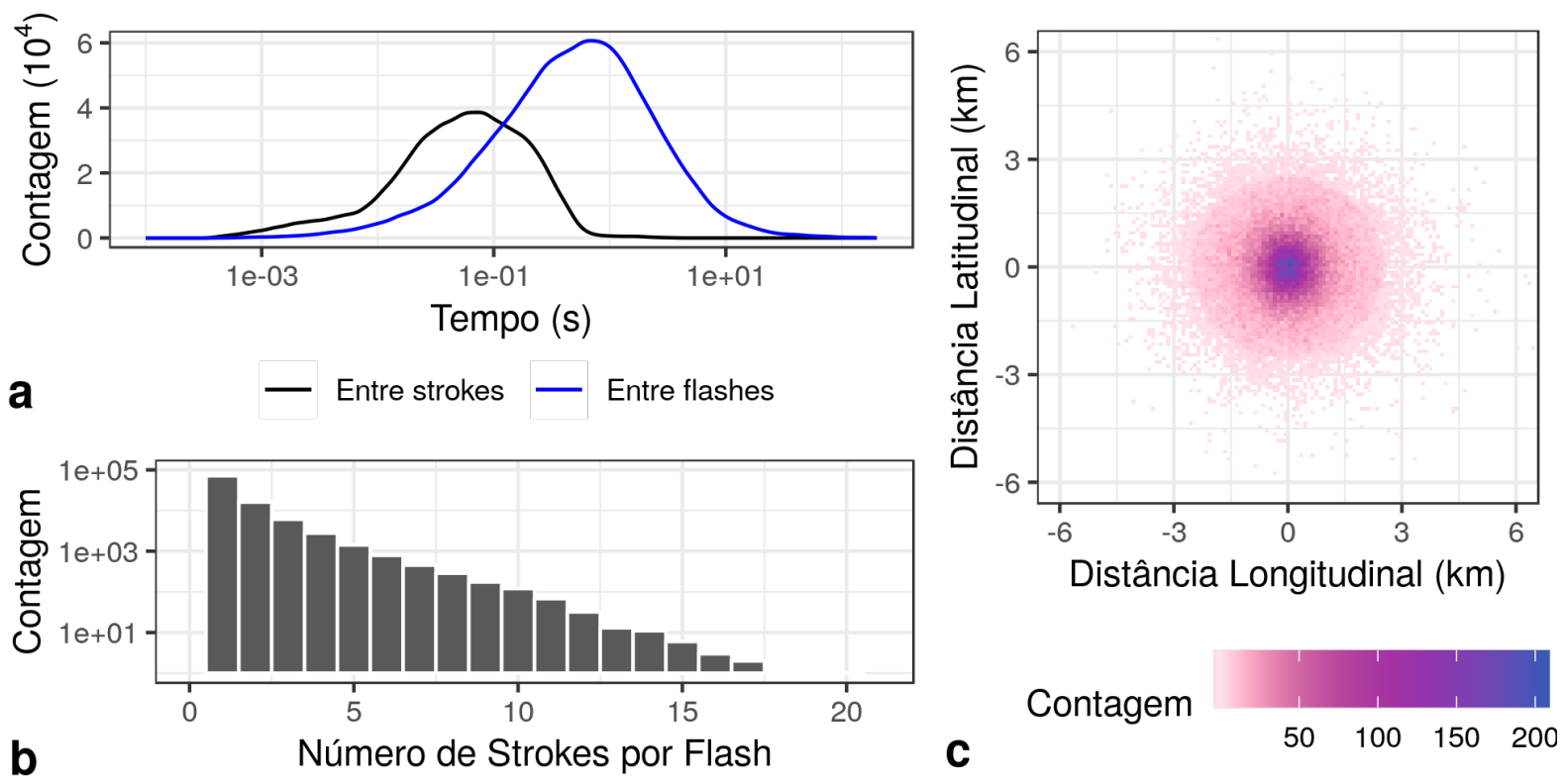

Fonte: Produzido pela autora.

\subsection{Reanálise}

Para analisar o ambiente sinótico associado a cada caso, o conjunto de dados de reanálise ERA5 (COPERNICUS CLIMATE CHANGE SERVICE, 2017) foi utilizado. Desenvolvido pelo ECMWF (European Centre for Medium-Range Weather Forecasts, Centro Europeu para Previsões de Tempo de Médio Alcance), estes dados estão disponíveis publicamente para o período de 1979 a 2-3 meses antes do presente. Este modelo eventualmente 
substituirá o conjunto de reanálise mais antigo ERA-Interim. A resolução espacial destes dados é de $30 \mathrm{~km}$ de cobertura global e 137 níveis verticais, da superfície até $80 \mathrm{~km}$ de altura; a resolução temporal é de $1 h$. Foram usados campos de pressão em superfície, geopotencial, vento e CAPE em diferentes níveis de pressão. Os dados foram obtidos a partir do Armazenamento de Dados Climáticos (Climate Data Store, CDS) do Serviço de Mudanças Climáticas Copernicus (Copernicus Climate Change Service, CCCS) do ECMWF e processados usando a linguagem Python (PYTHON CORE TEAM, 2018).

\subsection{Satélite}

Para auxiliar na análise do ambiente sinótico associado a cada caso, os dados do satélite GOES-16 foram utilizados. Ele foi lançado em novembro de 2016 e está operacional desde 18 de dezembro de 2017. Ele possui 16 canais no principal sensor (ABI - Advanced Baseline Imager, Imageador Avançado de Base), além de sensores de raios (GLM - Geostationary Lightning Mapper, Mapeador Geoestacionário de Raios) e que medem atividade solar. O modo de escaneamento Full Disk (Disco Inteiro) gera uma imagem que inclui a América do Sul continuamente com uma resolução temporal de 5 a 15 minutos e espacial de 0,5 a $2 \mathrm{~km}$. Considerando o período de estudo (Tabela 1), 3 dos 5 casos foram analisados com estes dados, usando o canal 13 do ABI, que corresponde à janela "limpa"do infravermelho de onda longa, para identificar os sistemas mais intensos e profundos (menor temperatura de brilho). Os dados de nível 2 (convertidos em uma grade latitude-longitudinal e que servem como base para os cálculos de produtos derivados de combinação dos canais) foram obtidos do repositório da NOAA (National Oceanic and Atmospheric Administration, Administração Nacional Oceânica e Atmosférica) na AWS (Amazon Web Services, Serviços Web da Amazon) <https://docs.opendata.aws/noaa-goes16/cics-readme.html> e processados usando a linguagem Python (PYTHON CORE TEAM, 2018). 



\section{Resultados}

Os resultados desta dissertação estão organizados da seguinte forma: uma visão geral de cada caso (Tabela 1) é apresentada através da intensidade da queda de granizo, ciclo de vida e atividade elétrica; dois casos são analisados mais profundamente, incluindo a microfísica e cinemática do sistema convectivo que gerou a queda de granizo.

\subsection{Intensidade das Tempestades que Geraram Granizo}

A Figura 17 mostra as diferentes distribuições de tamanho de granizo medidas por IAG e LIM (vide seção 3.1) para cada placa separados por caso (Tabela 1). As plotagens violino (úteis para comparar também os formatos das distribuições) mostram diferenças significativas entre medidas para uma mesma placa além das diferenças entre placas, possivelmente causadas pela subjetividade envolvida na forma em que as cavidades do hailpad foram medidas: não houve consenso em relação à definição do diâmetro (eixo maior ou menor, aproximação para um formato esférico, entre outros). Comparando os casos, é possível observar que o caso de 2017-03-14 mostrou menor diversidade de tamanhos de granizo (entre 6 e $12 \mathrm{~mm}$ ), enquanto que o caso de 2017-11-15 mostrou a maior diversidade considerando os extremos, sendo que este caso teve o maior diâmetro máximo, 22, $4 \mathrm{~mm}$, com 6,5 $\mathrm{mm}$ de diâmetro mínimo.

Para os casos com medidas dos dois grupos (2016-12-25 e 2017-01-31), o IAG tende a medir diâmetros maiores que o LIM, o qual mede mais valores extremos principalmente no caso de 2016-12-25 (os diâmetros máximos de IAG 1, LIM 1 e LIM 2 são aproximadamente iguais). Já comparando as placas para um mesmo caso (2017-01-31 e 2017-03-14), as distribuições entre o primeiro e terceiro quartil são similares: no caso de 2017-01-31, por exemplo, as distribuições variaram entre 7 e $10 \mathrm{~mm}$ em todas as medidas do IAG nas duas placas, o que indica que o sistema convectivo que gerou a queda de granizo em um ponto não sofreu mudanças significativas quando gerou a queda de granizo no outro ponto.

A Figura 18 mostra a energia cinética de cada hailpad em função do diâmetro do granizo para as escalas ANELFA e TORRO. As barras de erros mais largas em relação ao diâmetro são causadas pelo desvio-padrão maior em placas com maiores diferenças entre cada conjunto de medidas (Figura 17). As duas escalas mostram resultados similares entre si, com a maioria das placas relacionadas a casos minimamente intensos porém defasados em relação aos índices mínimos: os diâmetros (máximos ou típicos) são equivalentes a um índice acima da energia cinética correspondente. Isso pode estar relacionado à Equação 3.1, derivada a partir de medições de tempestades na Europa, assim como às próprias 
Figura 17 - Plotagem violino com caixa das distribuições de diâmetro do granizo de diferentes medidas feitas por IAG (sendo que 1 e 2 foram medidas por uma pessoa e 3 por outra) e LIM separados por caso.
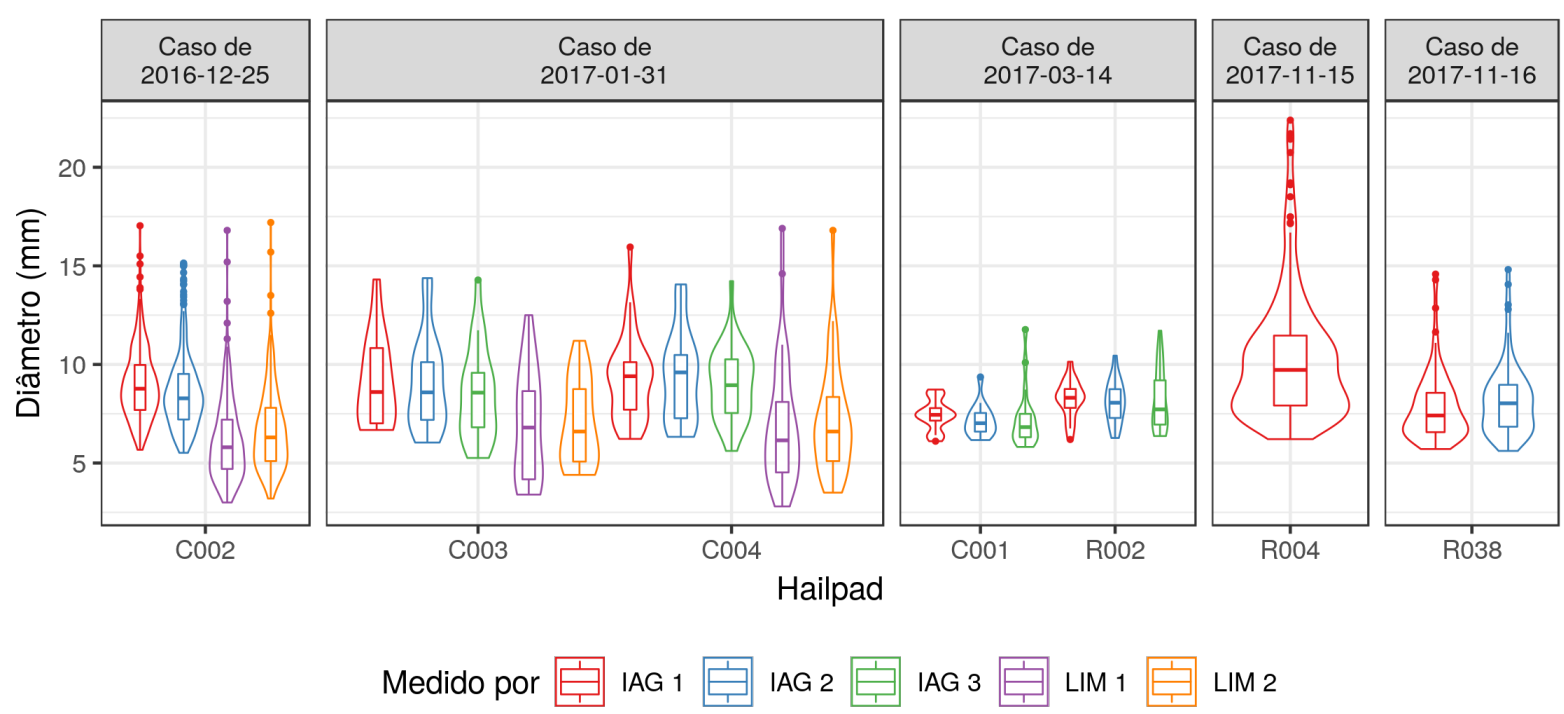

Fonte: Produzido pela autora.

escalas que também foram estabelecidas a partir de tempestades no continente europeu: condições locais e sinóticas dessa região são distintas das condições da região de estudo, principalmente comparando sistemas de latitudes médias com tropicais, e essas condições são importantes na formação de granizo (seção 2.1). Sánchez et al. (2009), ao comparar distribuições de tamanho de granizo em três países com redes de hailpads, mostram que podem ocorrer diferenças nos parâmetros característicos mesmo em localidades geograficamente próximas, diferença que pode ser propagada facilmente na estimativa da energia cinética dos hailpads.

Dentro da escala ANELFA (painel esquerdo da Figura 18), o caso de 2017-11-15 foi considerado o mais intenso, dentro do índice A2 (danos sérios a vegetais e árvores foram reportados danos à plantações próximas da localização do hailpad em Indaiatuba), com o caso de 2016-12-25 sendo o segundo mais intenso, dentro do índice A1 (danos à vinhas e pomares). No caso de 2017-03-14, com mais de um hailpad, a queda de granizo em Indaiatuba (placa R002) foi ligeiramente mais intensa do que em Cosmópolis (placa C004) (diferença de $1 \mathrm{~mm}$ no diâmetro máximo e de cerca de $2 \mathrm{Jm}^{-2}$ de energia cinética). Dentro da escala TORRO (painel direito da Figura 18) os resultados foram similares, com o caso de 2017-11-15 sendo o mais intenso também mas ligeiramente fora do índice H2 (tempestade significante) e o caso de 2016-12-25 sendo o segundo mais intenso, dentro do índice H1 (tempestade potencialmente prejudicial). A queda de granizo em Indaiatuba no caso de 2017-03-14 também foi ligeiramente mais intensa do que em Cosmópolis. 
Figura 18 - Energia cinética do hailpad em função do diâmetro do granizo considerando as escalas ANELFA e TORRO, com os índices de A0 a A2 e de H0 a H2 (Tabela 3) indicados.

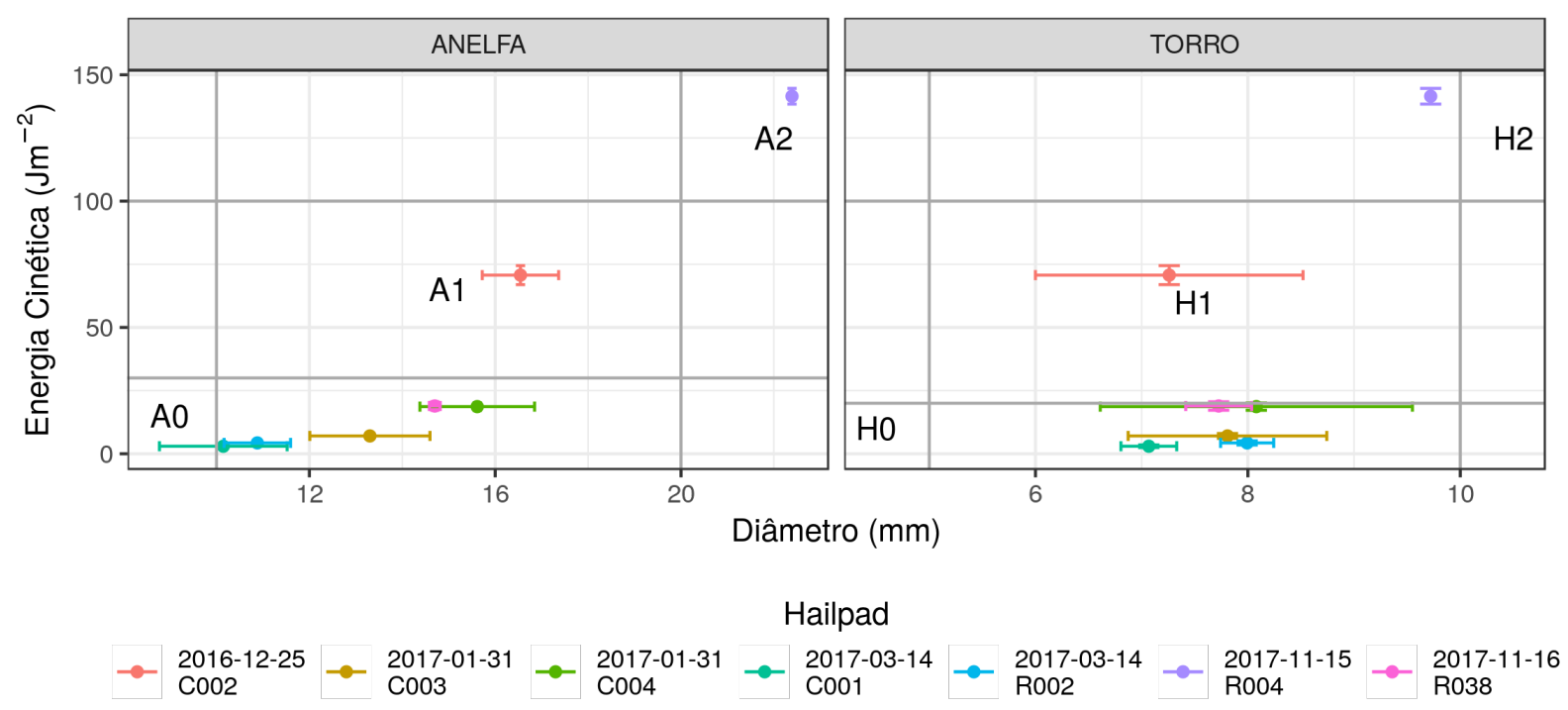

Fonte: Produzido pela autora.

Nota - A escala ANELFA leva em conta o diâmetro máximo medido no hailpad, enquanto que a escala TORRO leva em conta o diâmetro típico da distribuição medida no hailpad.

A Figura 19 mostra a evolução temporal da refletividade máxima em $3 k m$ de altura (a), tamanho do sistema convectivo (b) e taxa de raios (c), enquanto que a Tabela 6 mostra um panorama geral das características físicas relacionadas ao ciclo de vida dos casos em análise, rastreados usando o algoritmo ForTraCC-Radar (seção 3.2). De forma geral, a queda de granizo ocorreu dentro da fase de maturação dos sistemas convectivos, com refletividade acima de $60 \mathrm{dBZ}$, área em relativo crescimento e intensa atividade elétrica. O caso de 2017-01-31 foi o com menor tempo de vida $(0,5 \mathrm{~h})$, área máxima $\left(69 \mathrm{~km}^{2}\right)$ e quantidade de raios (3 flashes), mas não teve o menor tamanho de granizo: o caso de 2016-12-25 teve o menor granizo médio, enquanto que o caso de 2017-03-14 teve o menor granizo máximo (e granizo médio ligeiramente maior). O mesmo caso de 2017-0314 foi o com maior tempo de vida $(6,2 h)$, refletividade máxima (70 dBZ) e quantidade e taxa máxima de raios (10525 (2576) flashes IC (CG), com taxa máxima de 107 (31) flashes min $^{-1}$ IC (CG)). Outro caso a ser destacado é o de 2017-11-15, com tempo de vida curto $(2,2 \mathrm{~h})$, área máxima pequena $\left(253 \mathrm{~m}^{2}\right)$ e pouca quantidade de raios (menos

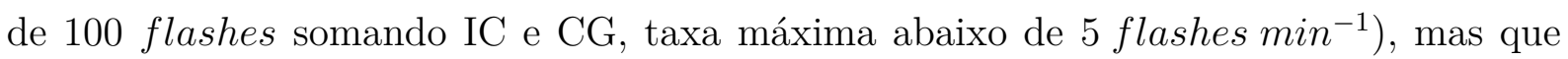
mostrou granizos acima de $10 \mathrm{~mm}$ em média e granizo máximo de 22, $4 \mathrm{~mm}$. Considerando o papel do granizo na formação de raios (seção 2.1), é de se esperar uma relação direta entre mudança da atividade elétrica e queda de granizo (Figura 19c), porém ela não foi consistente em todos os casos: em 2016-12-25, 2017-03-14 e 2017-11-15 há um ligeiro 
aumento da atividade elétrica (principalmente raios IC) até 30 minutos antes da queda de granizo, enquanto que em 2017-01-31 não há raios suficientes para determinar aumento ou diminuição da atividade elétrica, e em 2017-11-16 há um aumento da atividade elétrica depois da queda de granizo.

Figura 19 - Evolução temporal da refletividade máxima em $3 \mathrm{~km}$ do radar de São Roque (a), tamanho do sistema (b) e taxa de flashes CG e IC (c). As linhas pontilhadas indicam o momento aproximado em que houve a queda de granizo medida no hailpad.

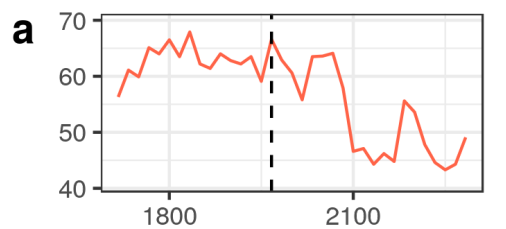

b
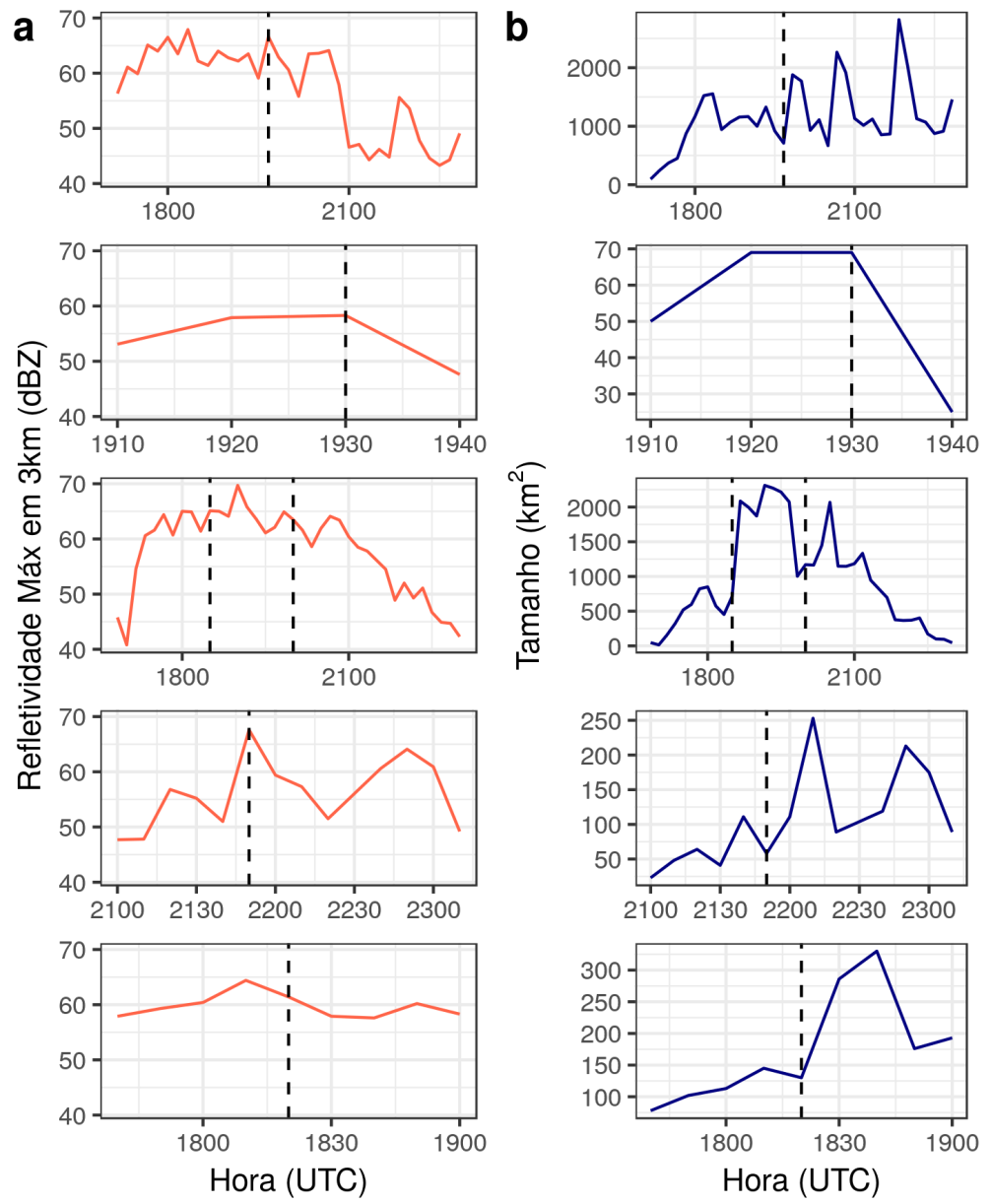

Hora (UTC)

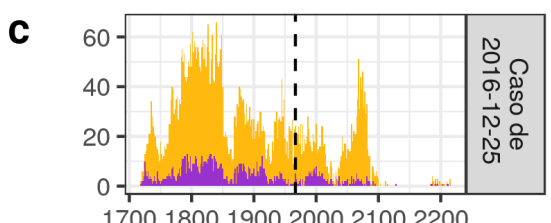

170018001900200021002200
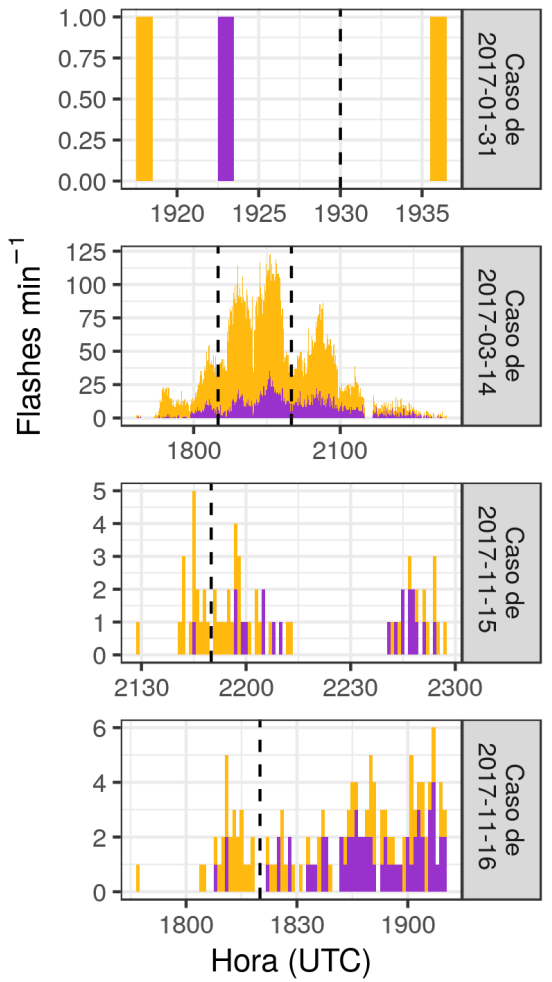

Tipo $\square$ IC $\square$ CG

Fonte: Produzido pela autora.

A partir dos resultados descritos nesta seção, dois casos foram escolhidos para uma análise mais detalhada:

a) 2017-03-14: Classificado como tempestade com queda de granizo de baixa intensidade, este caso teve alta atividade elétrica durante seu longo ciclo de vida, gerando queda de granizo em dois pontos diferentes. Os dois momentos em que houve queda de granizo serão comparados em relação à estrutura e cinemática da nuvem; 
Tabela 6 - Resumo das principais características físicas e elétricas dos casos analisados.

\begin{tabular}{ccccccccccc}
\hline Caso & $\begin{array}{c}\text { Tempo } \\
\text { de } \\
\text { Vida } \\
(h)\end{array}$ & $\begin{array}{c}\text { Máximo } \\
\text { em } 3 \mathrm{~km} \\
(d B Z)\end{array}$ & $\begin{array}{c}\text { Área } \\
\left(\mathrm{km}^{2}\right)\end{array}$ & $\begin{array}{c}\text { Granizo } \\
\text { Médio } \\
(\mathrm{mm})\end{array}$ & $\begin{array}{c}\text { Granizo } \\
\text { Máximo } \\
(\mathrm{mm})\end{array}$ & $\begin{array}{c}\text { Total de } \\
\text { Raios } \\
(\text { flashes })\end{array}$ & $\begin{array}{c}\text { Taxa } \\
\text { Máxima de } \\
\text { Raios } \\
\left(\text { flashes min }^{-1}\right)\end{array}$ \\
\hline $2016-12-25$ & 5,7 & 67,9 & 2822 & 7,6 & 17,2 & 4943 & 1037 & 61 & 16 \\
\hline $2017-01-31$ & 0,5 & 58,3 & 69 & 8,2 & 16,9 & 2 & 1 & 1 & 1 \\
\hline $2017-03-14$ & 6,2 & 69,7 & 2312 & 7,8 & 11,8 & 10525 & 2576 & 107 & 31 \\
\hline $2017-11-15$ & 2,2 & 67,6 & 253 & 10,3 & 22,4 & 46 & 20 & 3 & 2 \\
\hline $2017-11-16$ & 1,3 & 64,4 & 330 & 8 & 14,8 & 73 & 63 & 4 & 4 \\
\hline
\end{tabular}

Fonte - Produzido pela autora.

b) 2017-11-15: Classificado com tempestade com queda de granizo de intensidade ligeiramente mais intensa, este caso teve baixa atividade elétrica, o que não é esperado em uma tempestade com produção de granizo suficiente para cair no solo com tamanho considerável. A microfísica e cinemática desta tempestade com ciclo de vida mais curto ajudará a explicar esse comportamento.

\subsection{Estudos de Caso}

Os estudos dos casos de 2017-03-14 e 2017-11-15 estão descritos a seguir, focando: no ambiente sinótico e termodinâmico em que os sistemas convectivos se formaram; na atividade elétrica ao longo dos ciclos de vida; na microfísica através da estrutura vertical da convecção quando houve queda de granizo e; na cinemática, observando os campos de vento derivado por Multi-Doppler antes e durante a queda de granizo.

\subsubsection{Caso de 2017-03-14}

\subsubsection{Ambiente Sinótico e Termodinâmico}

A influência de uma frente fria no litoral de São Paulo e do Rio de Janeiro durante a madrugada foi determinante para o disparo de sistemas convectivos no estado de São Paulo durante a tarde. O sistema frontal em si se deslocou para o Oceano Atlântico ao longo do dia - às 1200 UTC (Figura 20a), o sistema está à leste de $30^{\circ} \mathrm{W}$ - mas favoreceu a convergência de umidade na região de estudo (não mostrado). Às 1200 UTC, a radiossondagem (Figura 21) mostra uma camada úmida entre a superfície e $600 h P a$, mas com CAPE (Convective Available Potential Energy, Energia Potencial Disponível para Convecção) nulo e pouco cisalhamento (mesma condição no resto do estado, como mostra a Figura 20b). Já às 1500 UTC (Figura 20c), o potencial para convecção (CAPE entre 
500 e $1500 \mathrm{~J} \mathrm{~kg}^{-1}$ ) e o cisalhamento (de até 10 nós) aumentaram e sistemas convectivos se formaram no centro do estado de São Paulo. As imagens de satélite da Figura 22 mostram a propagação e intensificação de sistemas convectivos com topos de até $-75^{\circ} \mathrm{C}$ de temperatura de brilho em alguns pontos na região de estudo aproximadamente às 1800 (a) e 2000 UTC (b), o que inclui o sistema que causou queda de granizo em Cosmópolis e Indaiatuba.

Figura 20 - Campos da reanálise do ERA5 em 2017-03-14: Pressão ao nível médio do mar, espessura entre 1000 e $500 h P a$ e velocidade do vento em $250 h P a$ às 1200 UTC (a); altura geopotencial em $850 h P a$, cisalhamento do vento entre 1000 e $500 h P a$ e CAPE em superfície às 1200 (b) e 1500 UTC, no domínio do estado de São Paulo (c).

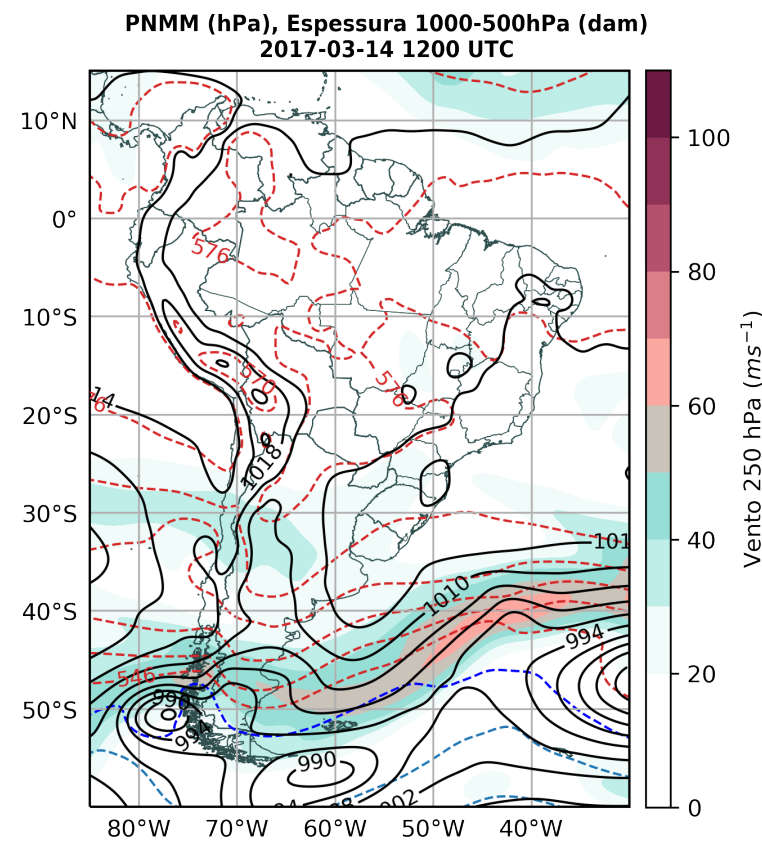

(a)

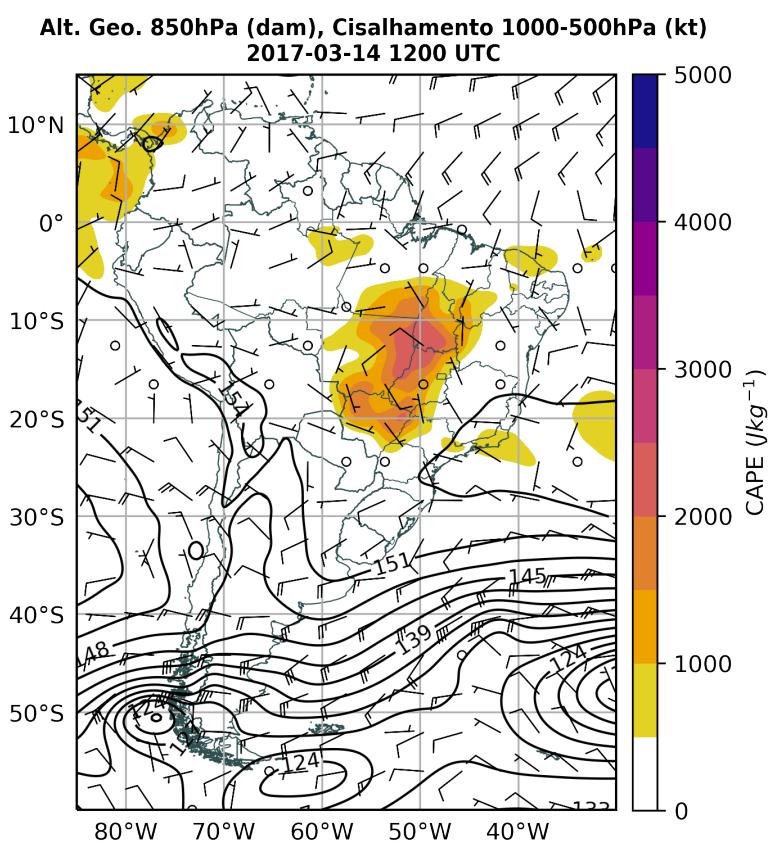

(b)

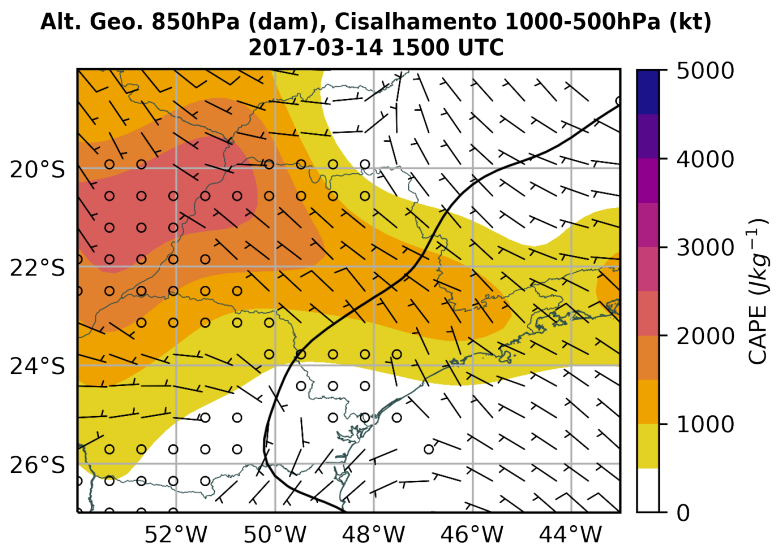

(c)

Fonte: Produzido pela autora. 
Figura 21 - Plotagem Skew-T Log-P da radiossondagem do Campo de Marte (SP) com hodógrafa do vento e índices CAPE e CIN em 2017-03-14 1200 UTC.

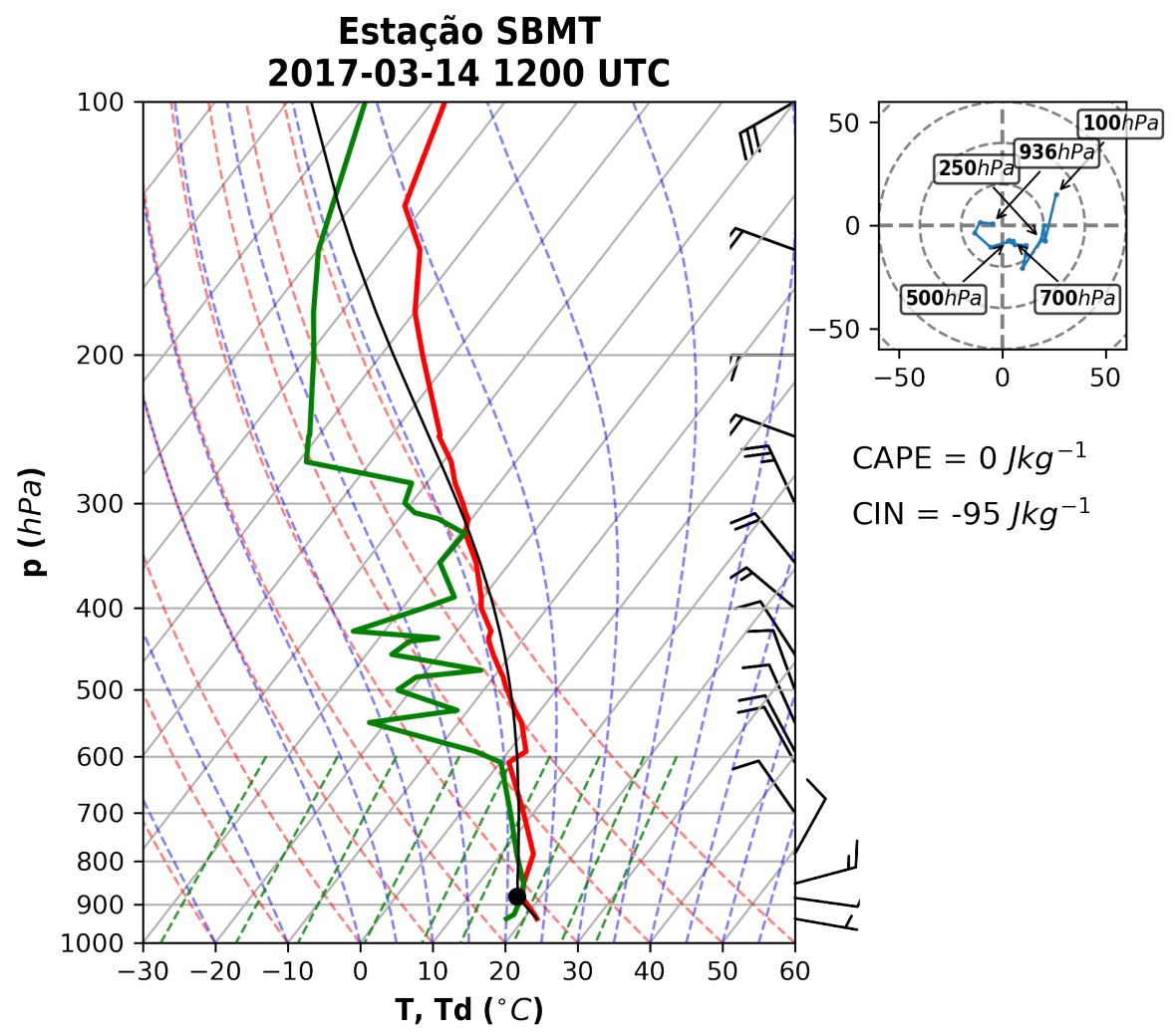

Fonte: Produzido pela autora.

Figura 22 - Imagem de satélite do canal 13 do GOES-16 mostrando a temperatura de brilho do topo das nuvens no estado de São Paulo em 2017-03-14 1751 (a) e 1951 UTC (b).

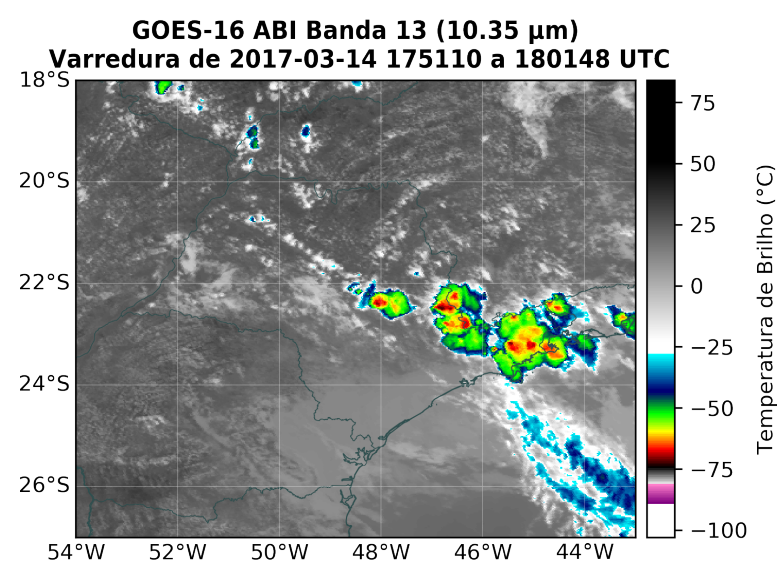

(a)

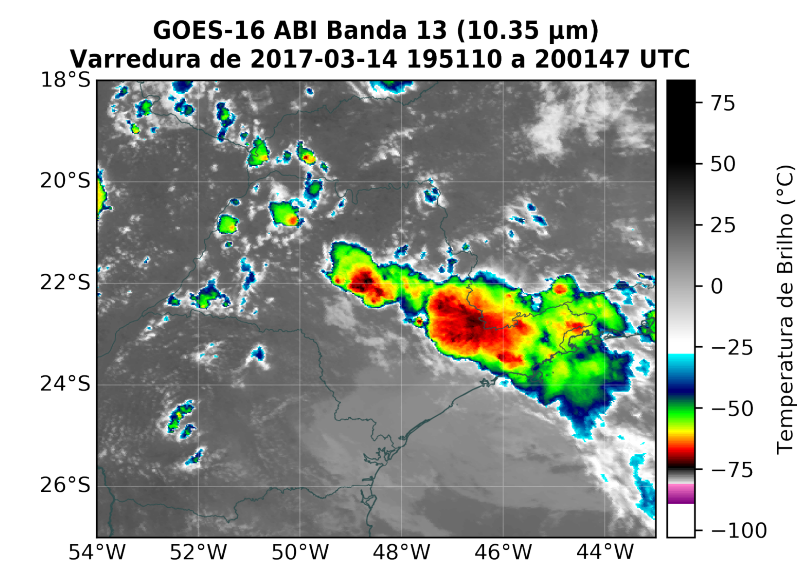

(b)

Fonte: Produzido pela autora. 


\subsubsection{Eletrificação}

A Figura 23 mostra a localização do sistema ao longo do ciclo de vida e dos flashes associados a ele. Como já mostrado (Figura 19, Tabela 1), este caso teve um longo ciclo de vida com intensa atividade elétrica - a taxa de flashes chega a um máximo (107 (31) flashesmin $^{-1} \mathrm{IC}(\mathrm{CG})$ ) após a queda de granizo em Cosmópolis e diminui antes do evento em Indaiatuba. O sistema convectivo se deslocou por toda a RMC e regiões vizinhas na direção sudoeste, com fusões e separações com sistemas menores. Os flashes IC e CG ocorreram principalmente dentro da RMC durante todo o ciclo de vida, com cerca de 5 vezes mais flashes IC (10525) do que CG (2576).

Figura 23 - Rastreamento (a) e localização dos flashes IC e CG (b) do sistema convectivo responsável pelas quedas de granizo em Cosmópolis e Indaiatuba em 2017-0314. Os triângulos pretos indicam a localização dos hailpads.

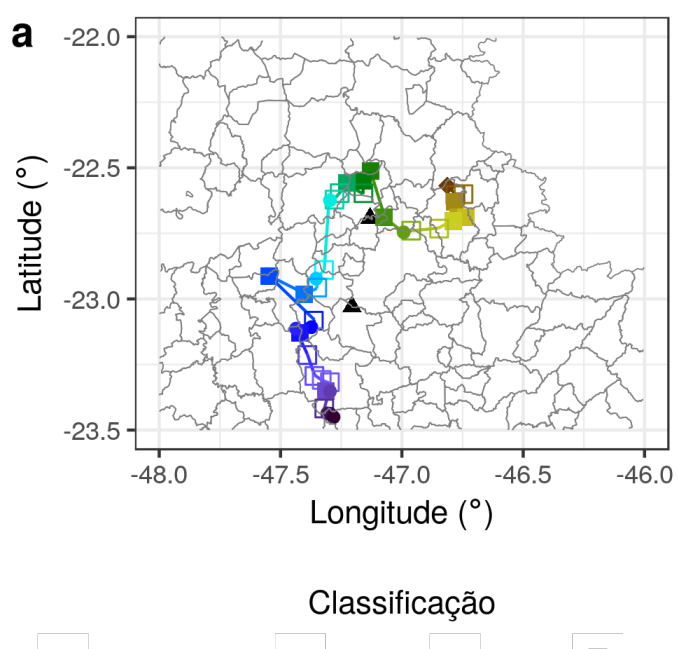

- Continuidade

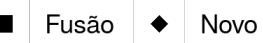

Separação

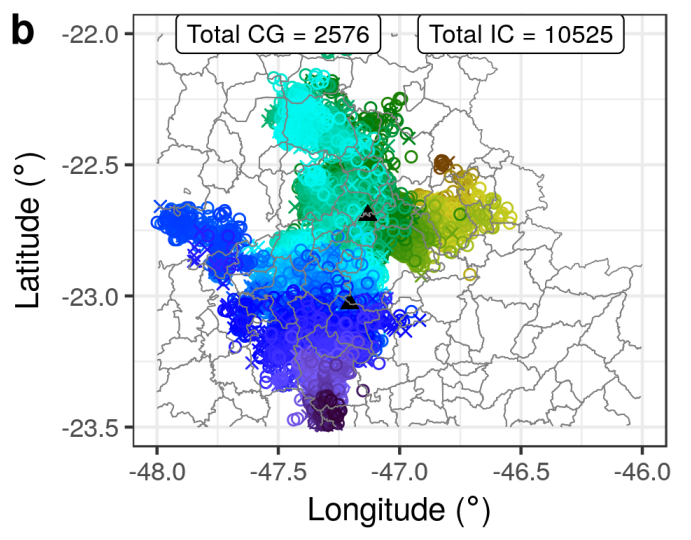

Tipo de Flash

$\times \quad C G \circ \quad$ IC
Hora (UTC)

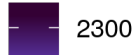

2200

2100

2000

1900

1800

1700

Fonte: Produzido pela autora.

A Figura 24 mostra os campos de refletividade (a) e flashes IC (b) e CG (c) para o caso de 2017-03-14 antes, durante e depois da queda de granizo em Cosmópolis. O núcleo convectivo mais próximo à localização do hailpad está embebido em um sistema multicelular que abrange boa parte do norte da RMC e passa por um processo de fusão com outros núcleos convectivos no período mostrado. A densidade de raios é maior (acima de 60 (10) flashes IC (CG)) ligeiramente à leste (sul) da localização do hailpad antes (depois) da queda de granizo, associado aos núcleos mais intensos (refletividade acima de $60 \mathrm{dBZ}$ ).

Depois da queda de granizo em Cosmópolis, o sistema convectivo se separou em diversos sistemas menores (não mostrado); o maior desses sistemas se intensificou e prosseguiu na direção sul/sudeste (Figura 23a), causando a queda de granizo em Indaiatuba (Figura 25). O núcleo convectivo mais próximo à localização do hailpad moveu-se lentamente no período mostrado, enquanto o resto do sistema à oeste se fundiu com núcleos 
Figura 24 - Campos de refletividade (a) e flashes IC (b) e CG (c) acumulados em 10 minutos do sistema convectivo (delimitado pela linha preta) responsável pela queda de granizo em Cosmópolis em 2017-03-14. O triângulo preto indica a localização do hailpad. Linhas contínuas demarcam os limites dos municípios do Estado de São Paulo.
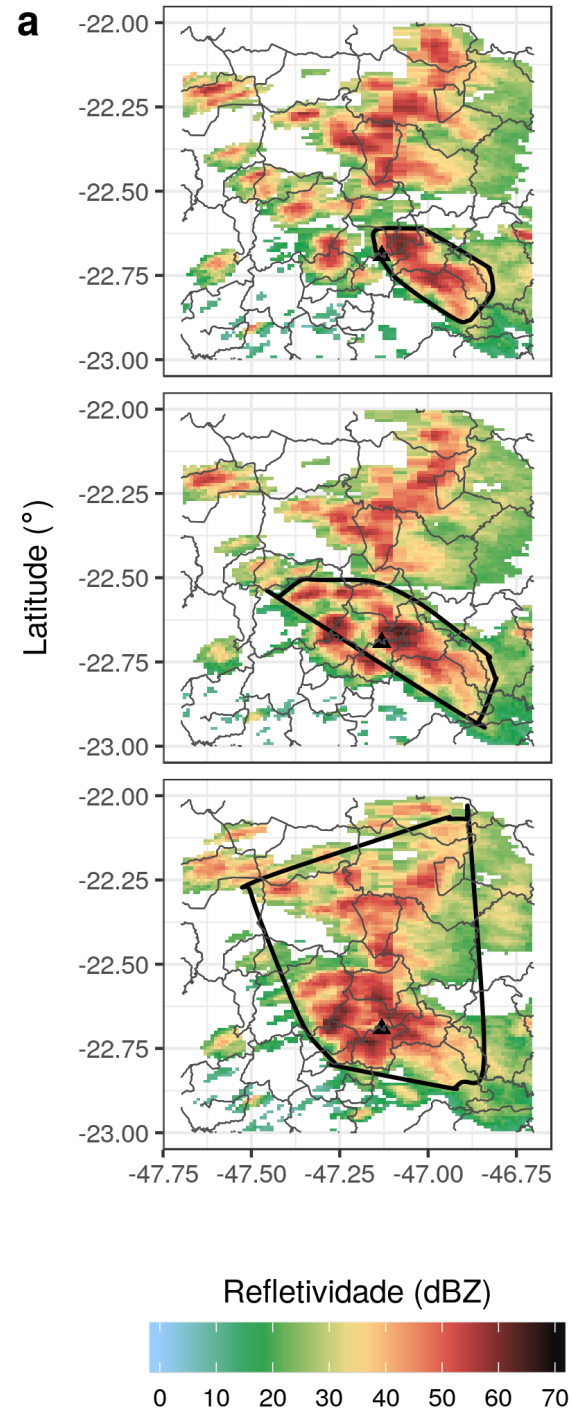
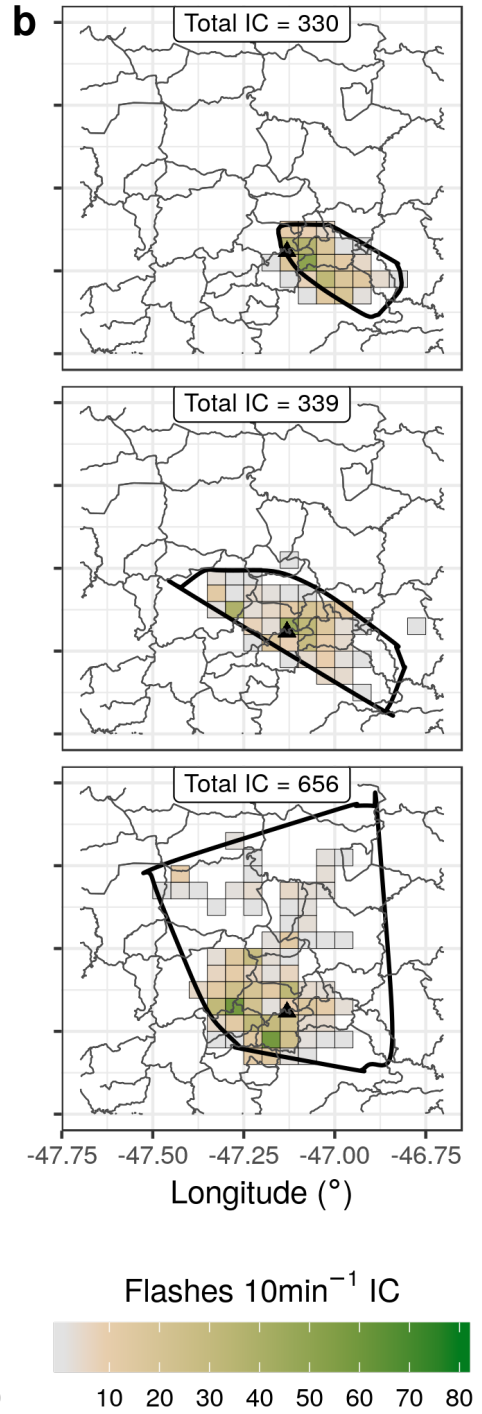
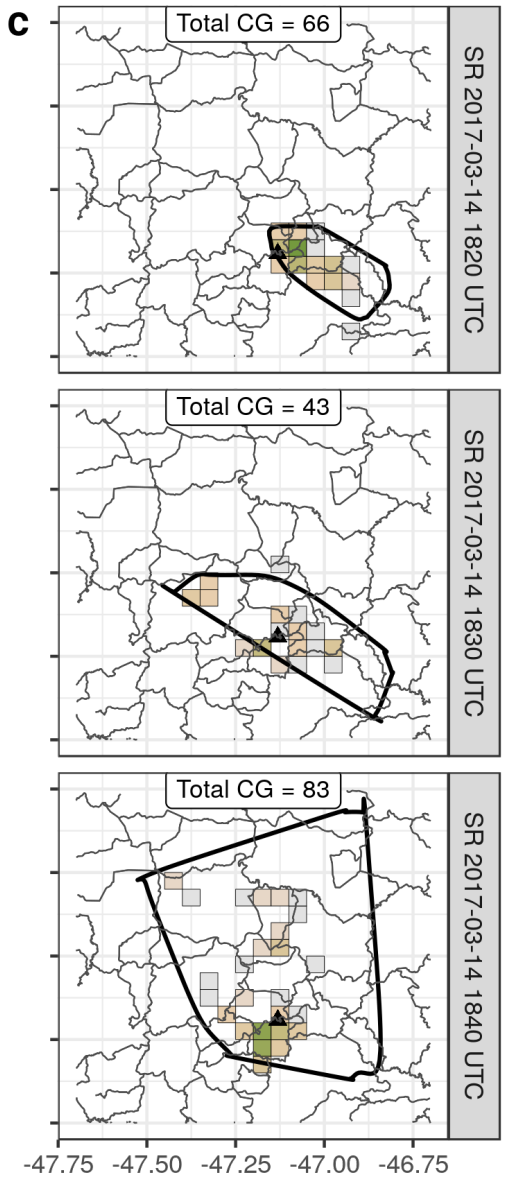

Flashes $10 \mathrm{~min}^{-1} \mathrm{CG}$

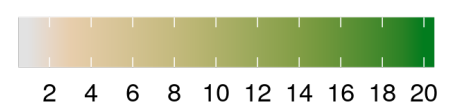

Fonte: Produzido pela autora.

convectivos pequenos. A maior densidade de raios (acima de 40 (10) flashes IC (CG)) está associada ao núcleo mais intenso (refletividade acima de $55 \mathrm{dBZ}$ ) ligeiramente à leste do hailpad; a quantidade de raios aumentou após a queda de granizo em Indaiatuba. 
Figura 25 - Campos de refletividade (CAPPI em $3 \mathrm{~km}$ do radar de São Roque) (a) e flashes IC (b) e CG (c) acumulados em 10 minutos do sistema convectivo (delimitado pela linha preta) responsável pela queda de granizo em Indaiatuba em 201703-14. O triângulo preto indica a localização do hailpad. Linhas contínuas demarcam os limites dos municípios do Estado de São Paulo.
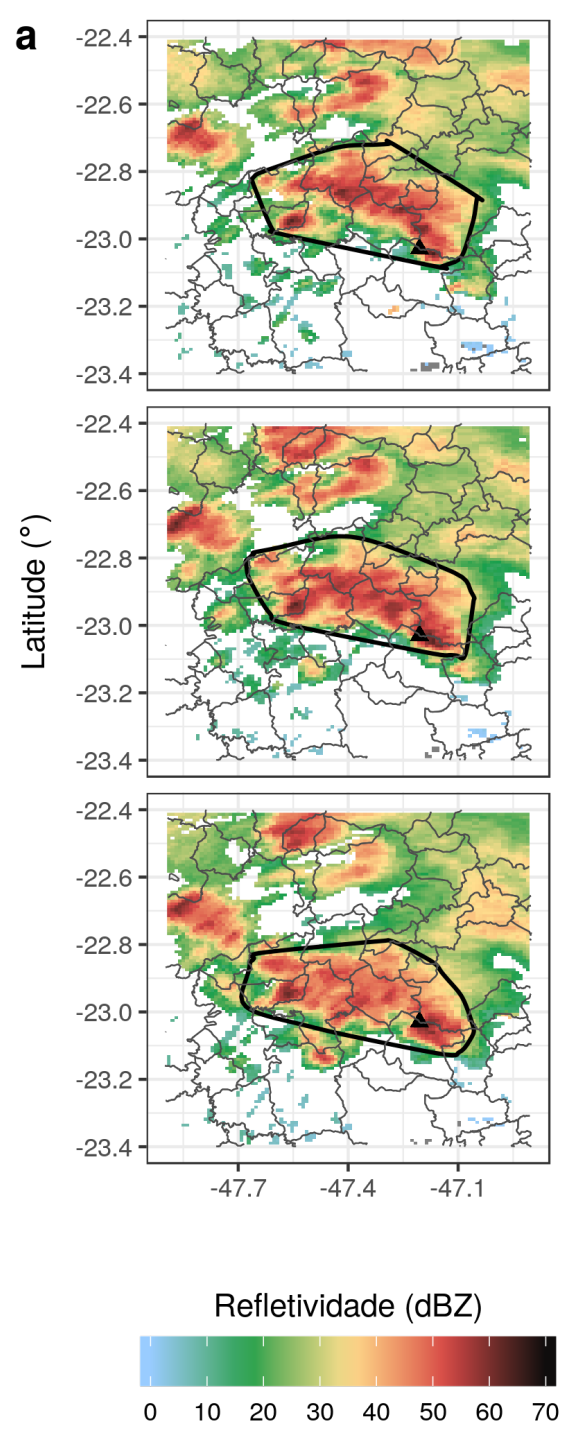
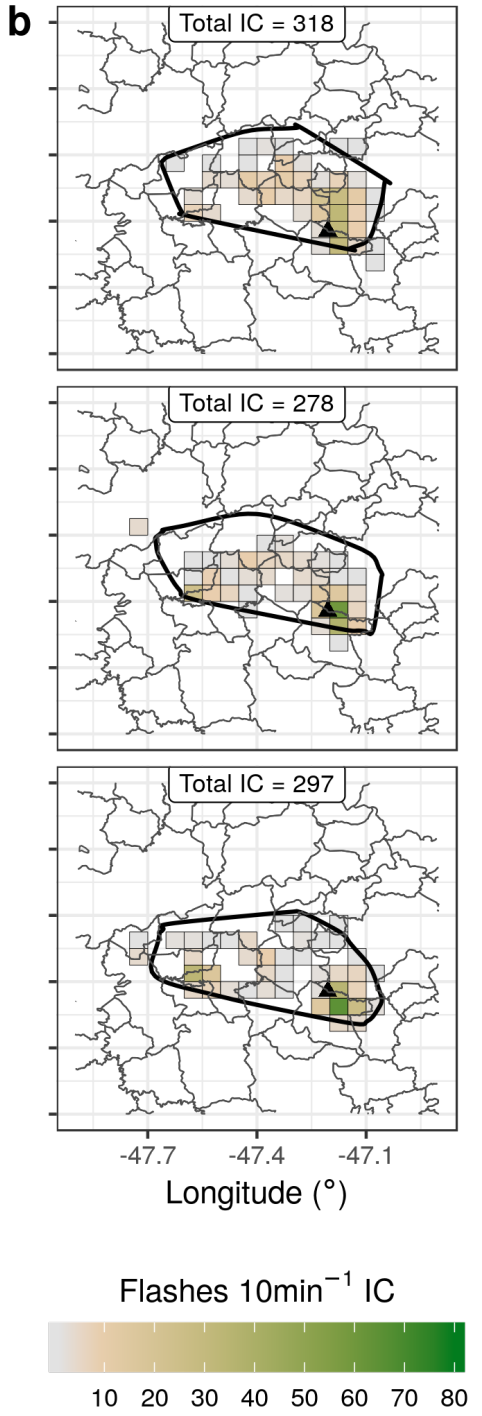
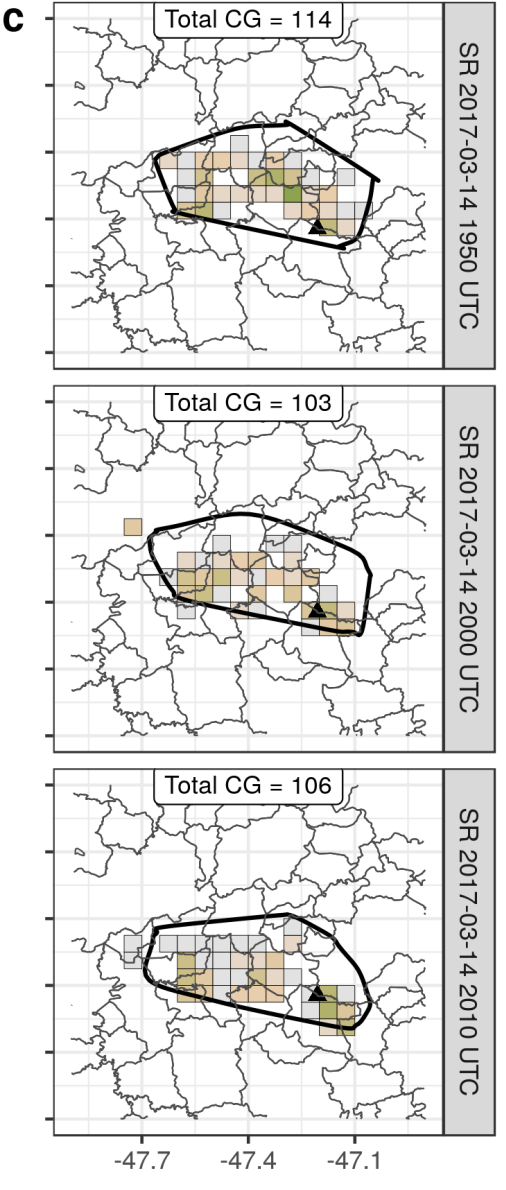

Flashes $10 \mathrm{~min}^{-1} \mathrm{CG}$

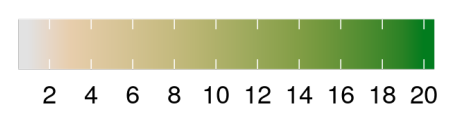

Fonte: Produzido pela autora.

\subsubsection{Microfísica}

A Figura 26 mostra os campos de refletividade e variáveis polarimétricas refletividade diferencial, fase diferencial específica e coeficiente de correlação do radar da FCTH para o caso de 2017-03-14, no momento mais próximo da queda de granizo em Cosmópolis; a Figura 27 mostra a identificação de hidrometeoros e massas de água líquida e gelo calculadas a partir dos campos de radar. O núcleo convectivo que causou a queda de granizo é formado por uma região de refletividade acima de $50 \mathrm{dBZ}$ de cerca de $10 \mathrm{~km}$ de extensão horizontal e vertical (da superfície até a isoterma de $-40{ }^{\circ} \mathrm{C}$ ) (Figura 26a). Os 
valores abaixo de 0,9 de coeficiente de correlação entre a superfície e a isoterma de $0{ }^{\circ} \mathrm{C}$ (Figura 26d) confirmam a presença de granizo ou a coexistência de granizo e chuva em vez de apenas chuva (também associado a altas refletividades) nessa região. Valores negativos de fase diferencial específica acima de $16 \mathrm{~km}$ de altura indicam a presença de gelo vertical. No núcleo convectivo imediatamente à esquerda, observa-se valores relativamente altos de fase diferencial específica (cerca de $1^{\circ} \mathrm{km}^{-1}$ ) logo acima da isoterma de $0{ }^{\circ} \mathrm{C}$, indicando a presença de água líquida superesfriada, associado a refletividade diferencial positiva (entre 1 e $2 d B$ ) até $-40^{\circ} \mathrm{C}$. Esses resultados corroboram com as características de sistemas convectivos eletricamente ativos reportados em outros estudos na região (MATTOS et al., 2016; MATTOS et al., 2017).

Os campos derivados das variáveis polarimétricas são acurados na classificação de granizo no núcleo convectivo responsável pela queda de granizo em Cosmópolis (Figura 27a) e na massa de gelo associada (que chegou a cerca de $15 \mathrm{gm}^{-3}$ abaixo de $2 \mathrm{~km}$, Figura 27c), mas apresenta problemas associados à estratégia do radar. A classificação de hidrometeoros é muito similar ao campo de refletividade (o que é esperado já que o algoritmo dá maior peso à essa variável e à temperatura, vide subseção 3.2.1), com regiões de refletividade acima de $50 \mathrm{dBZ}$ classificadas como granizo, entre 40 e $50 \mathrm{dBZ}$ como graupel de densidade alta (DA) e entre 30 e $40 \mathrm{dBZ}$ como graupel de densidade baixa (DB); para refletividades abaixo de $30 \mathrm{dBZ}$, a classificação de cristais de gelo e agregados ocorre mesmo abaixo da isoterma de $0{ }^{\circ} \mathrm{C}$ (gelo vertical em $1 \mathrm{~km}$ de altura em $22,79^{\circ} \mathrm{S}, 47,24^{\circ} \mathrm{W}$, por exemplo), condição muito difícil de ser encontrada em nuvens frias de tempestades tropicais. O campo de massa de água líquida (Figura 27b) apresenta o mesmo problema, onde é possível observar massa de $1 \mathrm{gm}^{-3}$ acima da isoterma de $-40^{\circ} \mathrm{C}$ no núcleo associado à queda de granizo; mesmo sendo um valor baixo, é difícil encontrar água na forma líquida em regiões com temperaturas tão baixas. A estratégia desse radar (Figura 12a) é essencial para entender esse problema: nessa região (à aproximadamente $160 \mathrm{~km}$ do radar), a primeira elevação faz uma varredura entre 3 e $6 \mathrm{~km}$ de altura, ou seja, entre possivelmente a região de fase quente e mista (acima da isoterma de $0{ }^{\circ} \mathrm{C}$ ) da nuvem, o que prejudica tanto a interpolação de dados volumétricos para uma grade uniforme (pois os níveis abaixo de $3 \mathrm{~km}$ são aproximações do que foi medido em $3 \mathrm{~km}$ ) quanto a identificação de hidrometeoros (pois esses dados interpolados representam uma mistura cada vez maior de hidrometeoros nos níveis mais baixos, tornando a classificação imprecisa). 
Figura 26 - Corte horizontal em $3 \mathrm{~km}$ de altura e vertical entre os pontos A e B de campos do radar da FCTH em 2017-03-14 1827 UTC, no momento mais próximo da queda de granizo em Cosmópolis: Refletividade corrigida (a) e diferencial (b), fase diferencial específica (c) e coeficiente de correlação (d). O 'x' indica a localização do hailpad e as isotermas de 0 e $-40^{\circ} \mathrm{C}$ foram definidas a partir da radiossondagem de SBMT. Linhas contínuas demarcam os limites dos municípios do Estado de São Paulo.

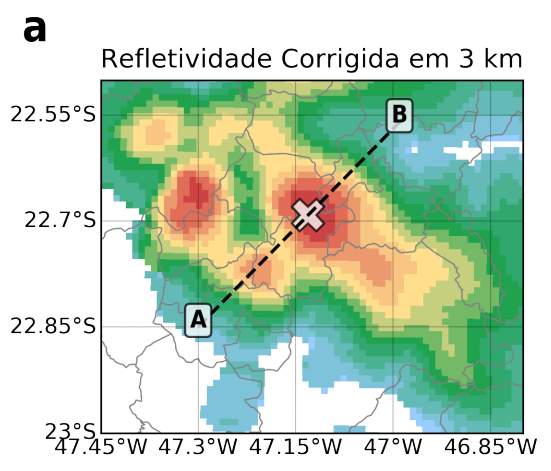

FCTH 2017-03-14 1827 UTC

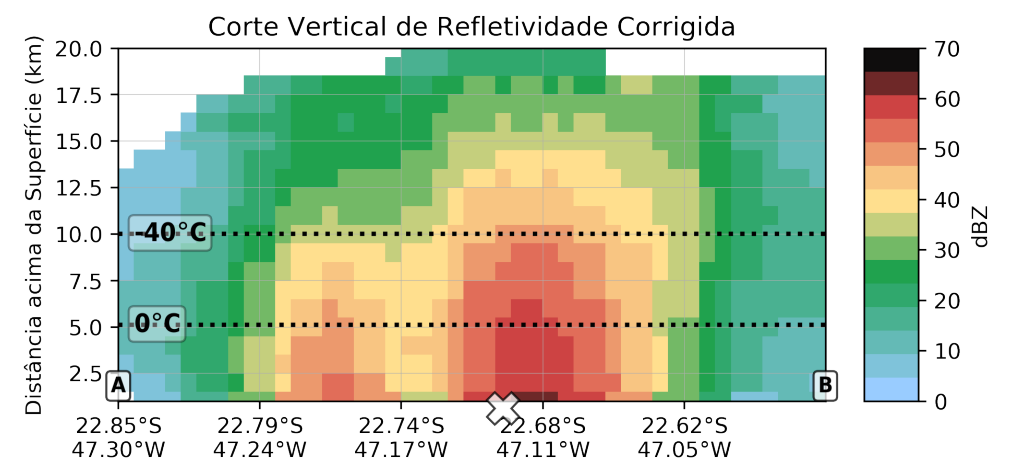

b

\section{FCTH 2017-03-14 1827 UTC}
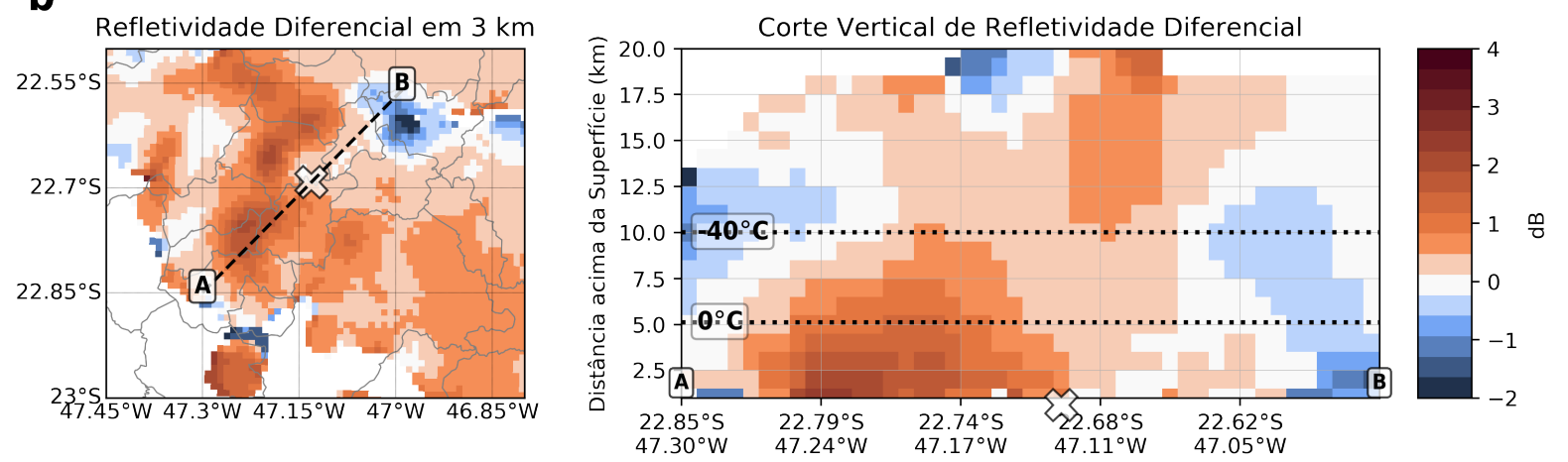

c

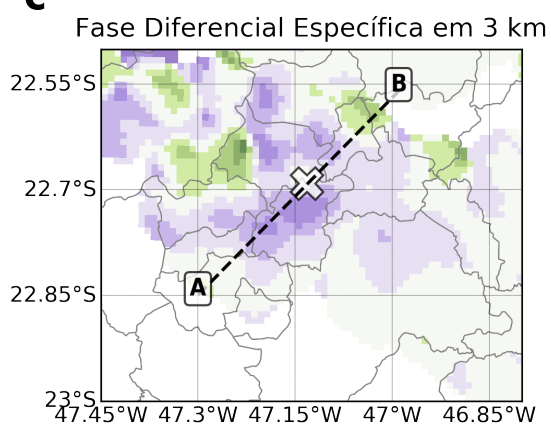

d

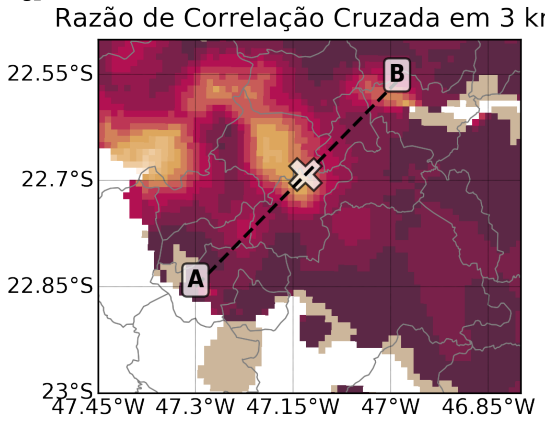

\section{FCTH 2017-03-14 1827 UTC}

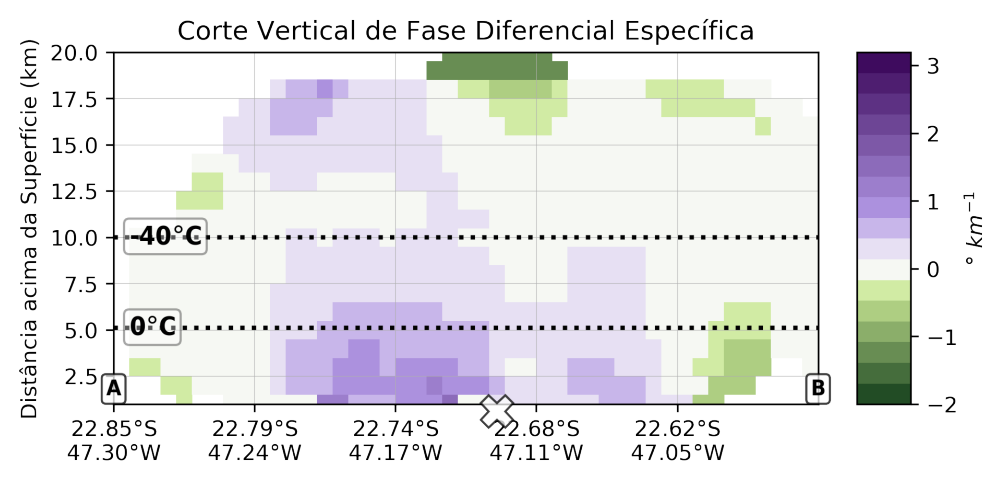

FCTH 2017-03-14 1827 UTC

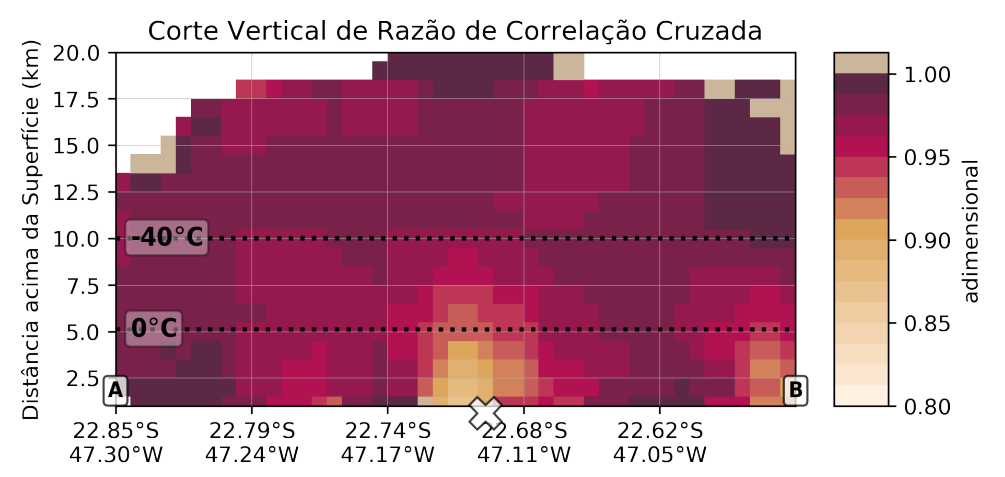

Fonte: Produzido pela autora. 
Figura 27 - Corte horizontal em $3 \mathrm{~km}$ de altura e vertical entre os pontos A e B de campos derivados do radar da FCTH em 2017-03-14 1827 UTC, no momento mais próximo da queda de granizo em Cosmópolis: Identificação de hidrometeoros (a) e massas de água líquida (b) e gelo (c). O 'x' indica a localização do hailpad e as isotermas de $0 \mathrm{e}-40^{\circ} \mathrm{C}$ foram definidas a partir da radiossondagem de SBMT. Linhas contínuas demarcam os limites dos municípios do Estado de São Paulo.

a

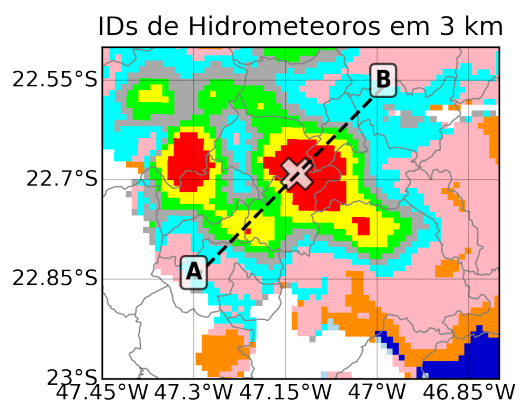

b

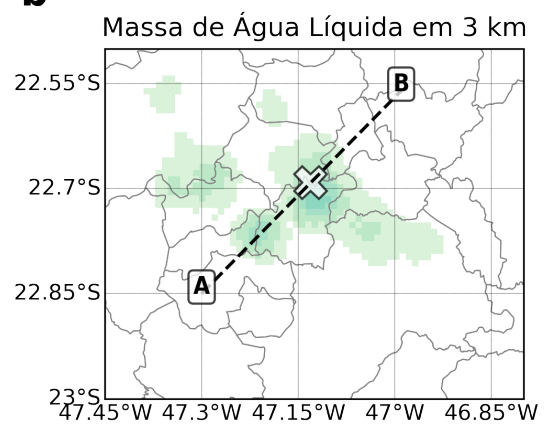

C

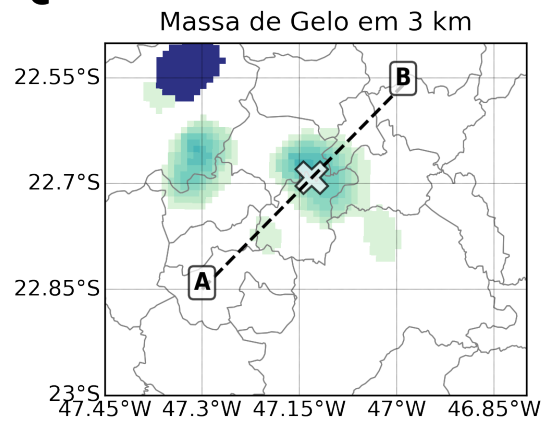

FCTH 2017-03-14 1827 UTC

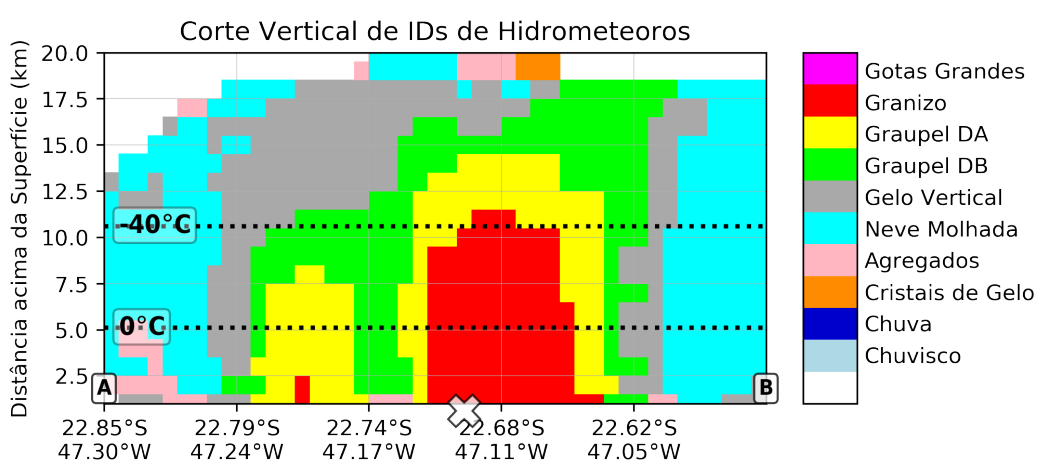

FCTH 2017-03-14 1827 UTC

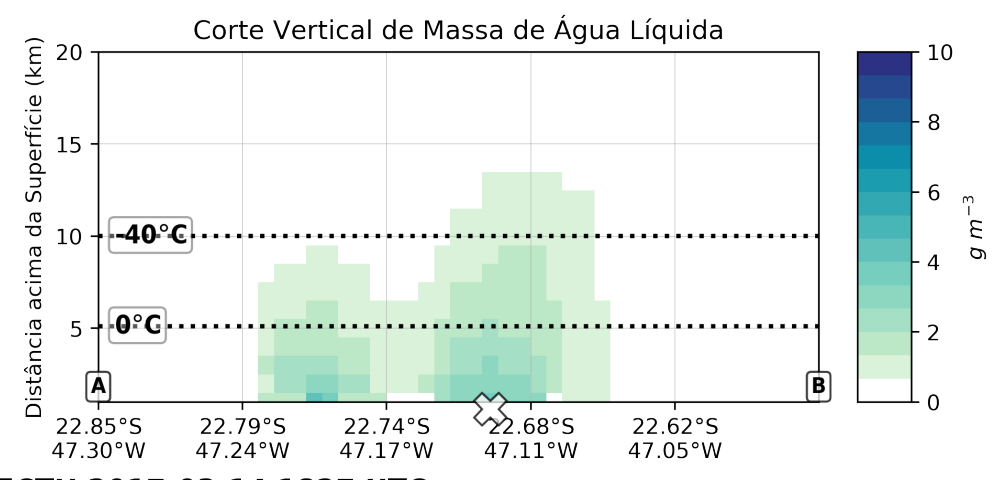

FCTH 2017-03-14 1827 UTC

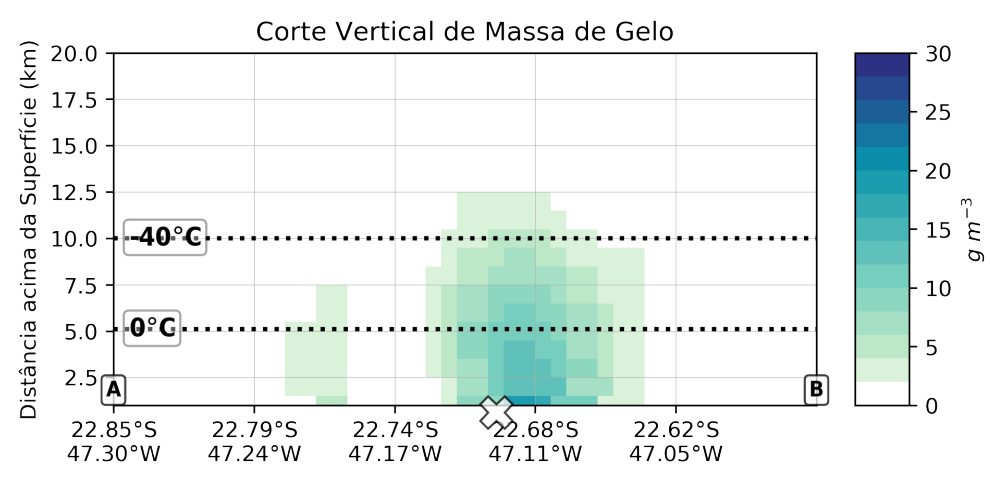

Fonte: Produzido pela autora.

A Figura 28 mostra os campos de refletividade e variáveis polarimétricas do radar da FCTH para o caso de 2017-03-14, no momento mais próximo da queda de granizo em Indaiatuba; a Figura 29 mostra a identificação de hidrometeoros e massas de água líquida e gelo calculadas a partir dos campos de radar. O núcleo convectivo responsável pela queda de granizo não é tão intenso quanto o de Cosmópolis e está embebido em um sistema mais homogêneo que o anterior no oeste da RMC. Este núcleo tem valores de 
refletividade acima de $50 \mathrm{dBZ}$ em cerca de $12 \mathrm{~km}$ de extensão horizontal, da superfície até a isoterma de $-40^{\circ} \mathrm{C}$ (Figura 28a). Os valores de fase diferencial específica acima de $1^{\circ} \mathrm{km}^{-1}$ nessa região, abaixo da isoterma de $0{ }^{\circ} \mathrm{C}$, confirmam a presença de chuva com gotas grandes e granizo (Figura 28c). Valores de refletividade diferencial positivo (até $1 \mathrm{dBZ}$ ) até $7,5 \mathrm{~km}$ de altura indicam a presença de água líquida superresfriada. Valores negativos de refletividade diferencial e fase diferencial específica acima de $16 \mathrm{~km}$ de altura sobre o núcleo convectivo indicam a presença de gelo vertical.

A classificação de hidrometeoros do sistema convectivo que causou queda de granizo em Indaiatuba (Figura 29a) novamente é muito similar ao campo de refletividade, com granizo e gotas grandes próximo à superfície e granizo até a isoterma de $-40{ }^{\circ} \mathrm{C}$, na mesma região de refletividade acima de $50 \mathrm{dBZ}$; há também problemas com a identificação de agregados e cristais de gelo abaixo da isoterma de $0^{\circ} \mathrm{C}$, associados à refletividades abaixo de $30 \mathrm{dBZ}$ (próximo aos pontos A e B, por exemplo, há uma camada de agregados até $4 \mathrm{~km}$ de altura). Em relação à massa de água líquida (Figura 29b), ela ficou limitada ao núcleo convectivo, com concentrações de até $5 \mathrm{gm}^{-3}$ abaixo da isoterma de $-40{ }^{\circ} \mathrm{C}$; a massa de gelo (Figura 29c) também ficou limitada ao núcleo convectivo, com concentrações de até $15 \mathrm{gm}^{-3}$ próximo à superfície.

Em ambos os casos, as massas de água líquida e principalmente gelo observadas dentro da região de fase mista do núcleo convectivo (Figura 27b,c e Figura 29b,c) explica a densidade alta de raios observada durante a queda de granizo (Figura 24, Figura 25), considerando que a colisão entre hidrometeoros de gelo na presença de água líquida é o principal mecanismo de eletrificação de tempestades (seção 2.1). 
Figura 28 - Corte horizontal em $3 \mathrm{~km}$ de altura e vertical entre os pontos A e B de campos do radar da FCTH em 2017-03-14 1957 UTC, no momento mais próximo da queda de granizo em Indaiatuba: Refletividade corrigida (a) e diferencial (b), fase diferencial específica (c) e coeficiente de correlação (d). O 'x' indica a localização do hailpad e as isotermas de 0 e $-40^{\circ} \mathrm{C}$ foram definidas a partir da radiossondagem de SBMT. Linhas contínuas demarcam os limites dos municípios do Estado de São Paulo.

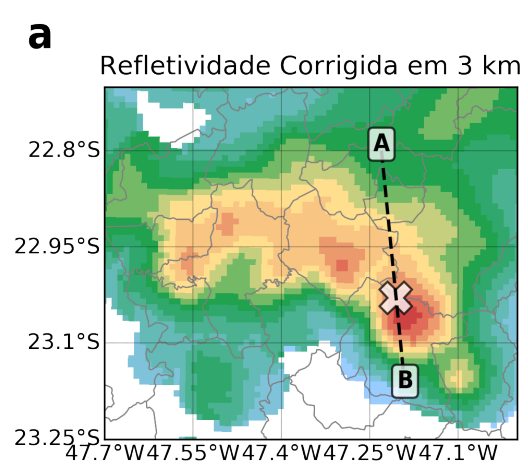

b

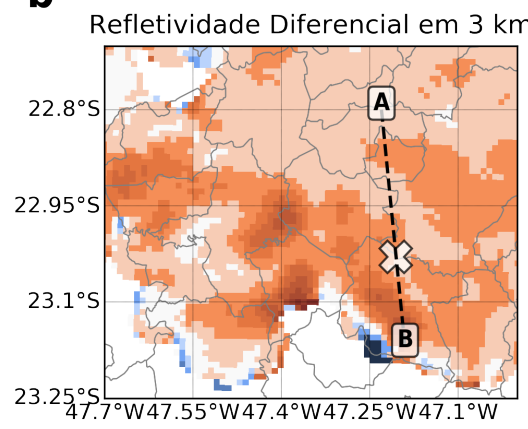

C

C Fase Diferencial Específica em $3 \mathrm{~km}$

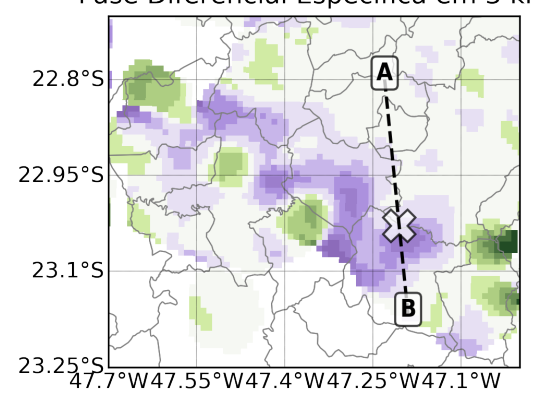

d

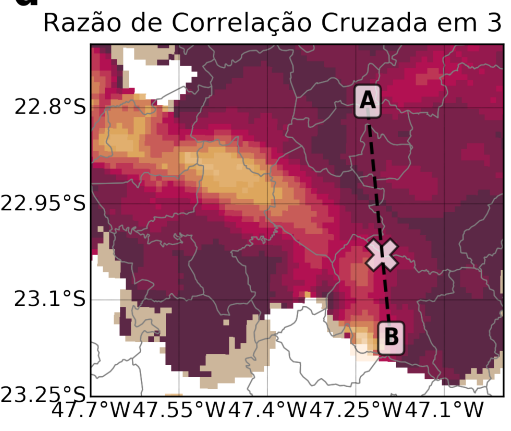

\section{FCTH 2017-03-14 1957 UTC}

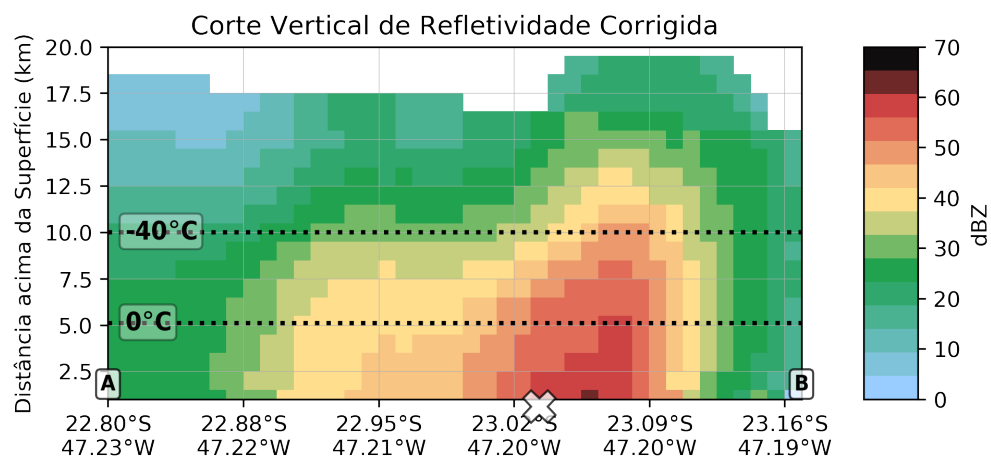

FCTH 2017-03-14 1957 UTC

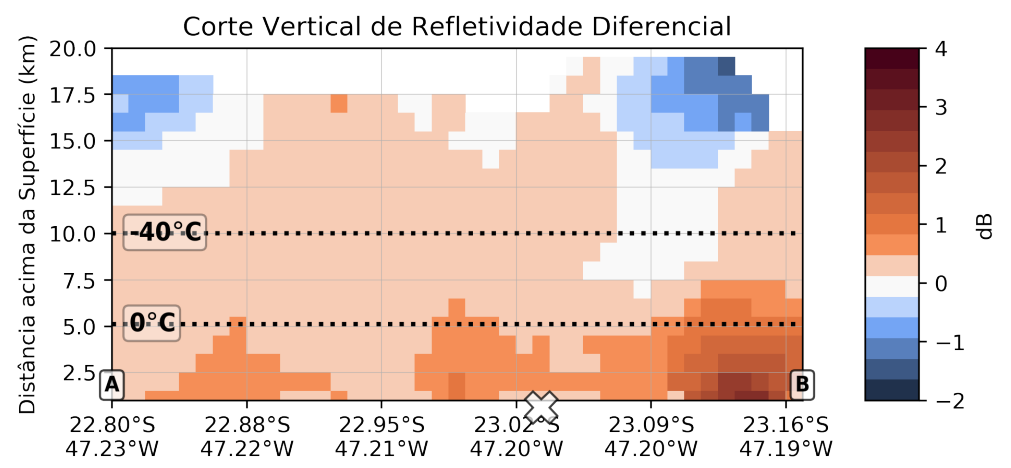

FCTH 2017-03-14 1957 UTC

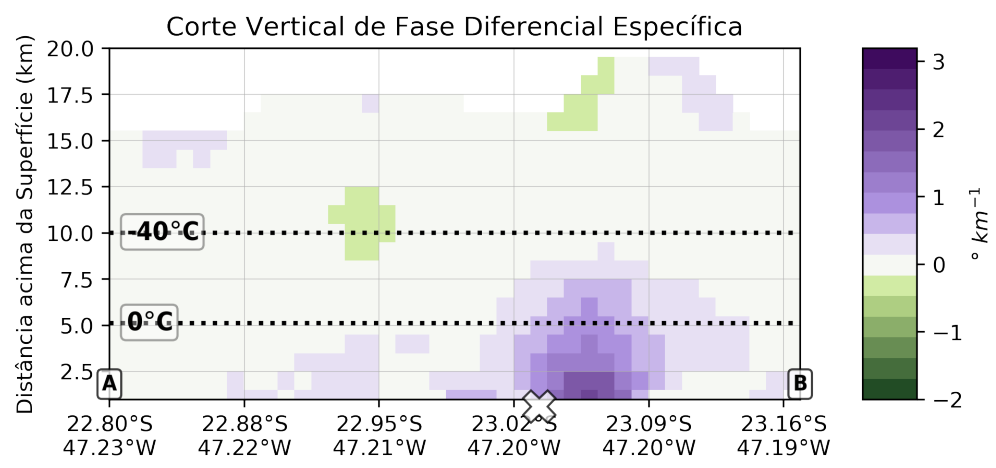

\section{FCTH 2017-03-14 1957 UTC}

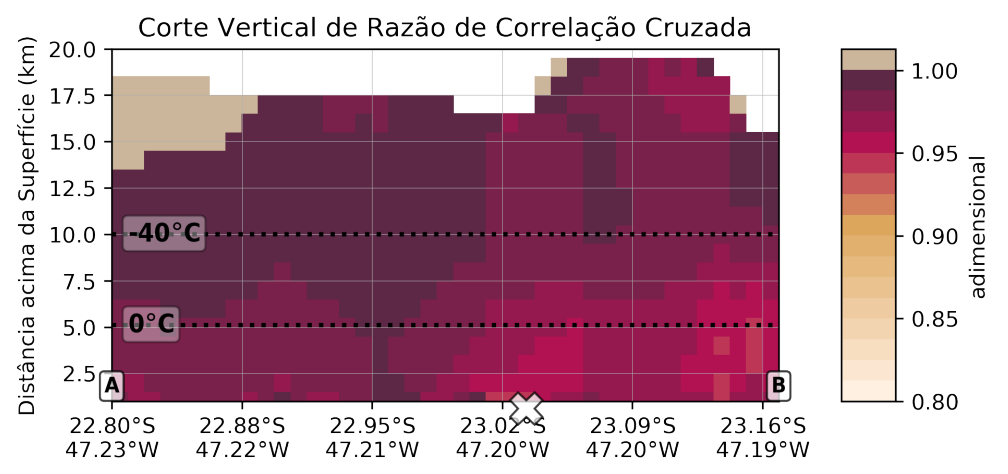

Fonte: Produzido pela autora. 
Figura 29 - Corte horizontal em $3 \mathrm{~km}$ de altura e vertical entre os pontos A e B de campos derivados do radar da FCTH em 2017-03-14 1957 UTC, no momento mais próximo da queda de granizo em Indaiatuba: Identificação de hidrometeoros (a) e massas de água líquida (b) e gelo (c). O 'x' indica a localização do hailpad e as isotermas de 0 e $-40^{\circ} \mathrm{C}$ foram definidas a partir da radiossondagem de SBMT. Linhas contínuas demarcam os limites dos municípios do Estado de São Paulo.
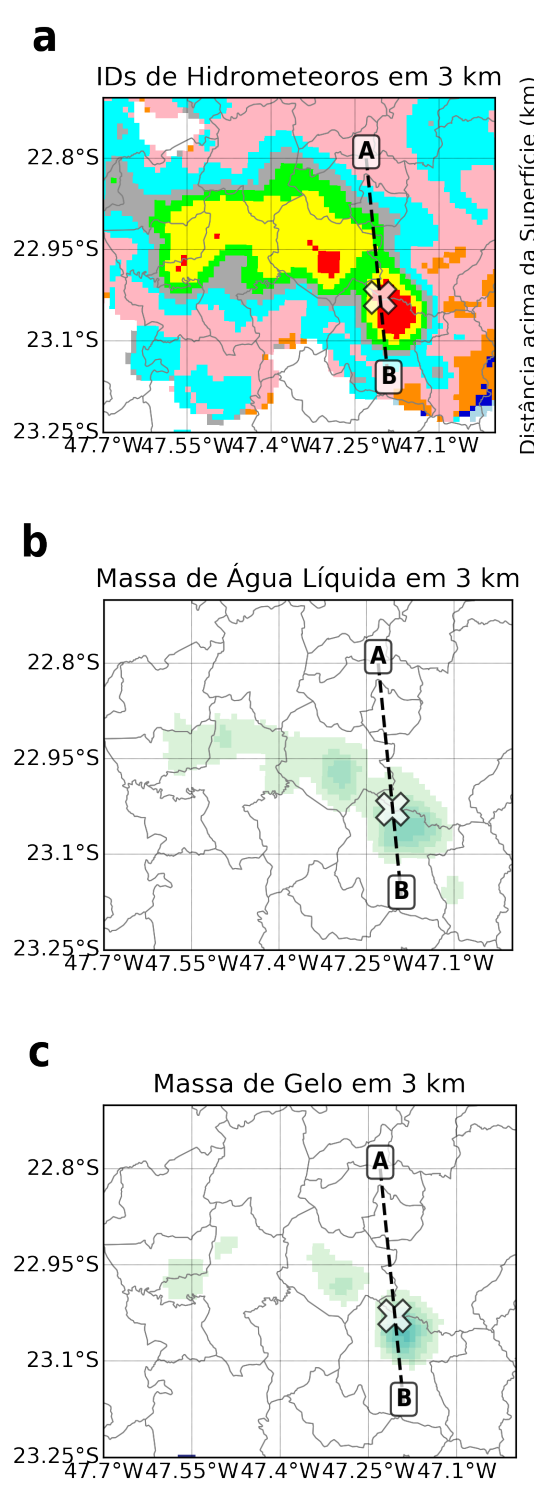

FCTH 2017-03-14 1957 UTC

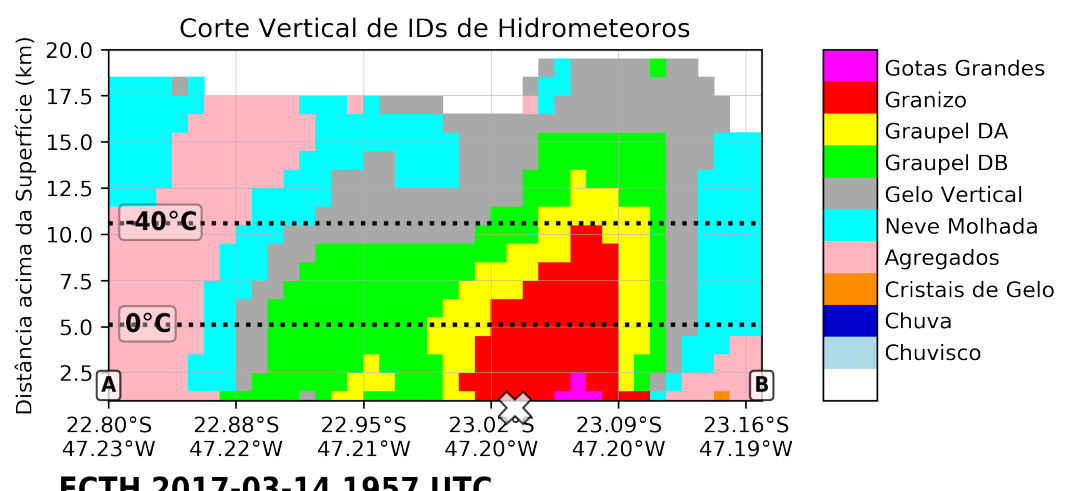

FCTH 2017-03-14 1957 UTC

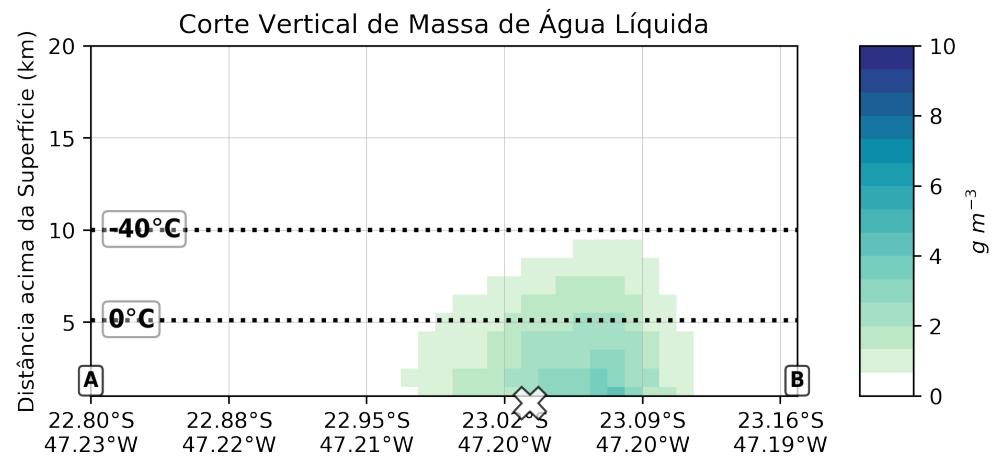

FCTH 2017-03-14 1957 UTC

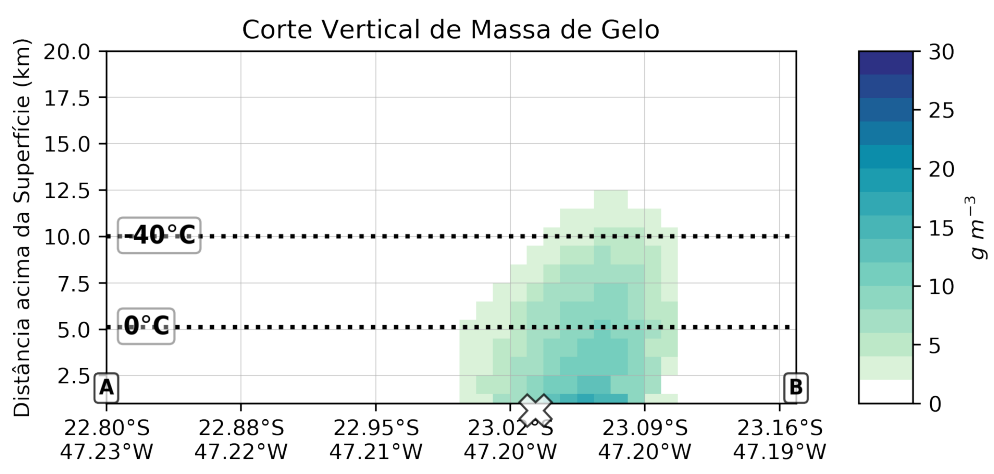

Fonte: Produzido pela autora.

\subsubsection{Cinemática}

A Figura 30 mostra os campos de refletividade combinada e velocidade do vento derivado por Dual-Doppler usando a combinação dos radares de São Roque e FCTH para o caso de 2017-03-14, no momento mais próximo da queda de granizo em Cosmópolis. O sistema convectivo responsável pelo evento apresenta diversos núcleos convectivos com 
refletividade acima de $40 \mathrm{dBZ}$, sendo que o mais intenso deles está mais próximo à localização do hailpad. Dez minutos antes da queda de granizo (1820 UTC - Figura 30a), esse núcleo principal tem cerca de $10 \mathrm{~km}$ de extensão horizontal e $15 \mathrm{~km}$ de altura, com refletividades acima de $50 \mathrm{dBZ}$ até $12 \mathrm{~km}$ de altura. Uma região de corrente ascendente de $30 \mathrm{~ms}^{-1}$ encontra-se acima da isoterma de $-40^{\circ} \mathrm{C}$, com um escoamento ascendente entre 3 e $19 \mathrm{~km}$ de altura, divergência no topo, e um escoamento descendente menos intenso entre 5 e 12 km. Às 1830 UTC (Figura 30b), o núcleo convectivo menos intenso à sudoeste do núcleo principal se intensifica e eles começam a se juntar. A região de corrente ascendente enfraquece (ainda assim com velocidades de cerca de $20 \mathrm{~ms}^{-1}$ ) com a mesma extensão vertical, mas a intensificação do núcleo convectivo menor expande o escoamento ascendente horizontalmente, com um escoamento descendente ainda menos intenso fora do sistema convectivo. Próximo à localização do hailpad (Figura 30b), a corrente ascendente é fraca (praticamente nula em alguns pontos) abaixo da isoterma de $0^{\circ} \mathrm{C}$, o que pode indicar a precipitação de hidrometeoros, incluindo granizo pequeno, como observado pelo hailpad (Tabela 6).

A Figura 31 mostra os campos de refletividade combinada e velocidade do vento derivada por Dual-Doppler para o caso de 2017-03-14, quando houve queda de granizo em Indaiatuba. Esta nova célula convectiva também possui um núcleo principal com refletividades acima de $40 \mathrm{dBZ}$, mas agora com maior extensão horizontal (cerca de $60 \mathrm{~km}$ na direção noroeste-sudeste) e alguns picos de refletividade (acima de $55 \mathrm{dBZ}$ ) distintos, incluindo um próximo à localização do hailpad (Figura 31a, painel da esquerda). Esse pico próximo ao hailpad é associado a um núcleo de $15 \mathrm{~km}$ de altura, com refletividade acima de $50 \mathrm{dBZ}$ até $12 \mathrm{~km}$ de altura. Entre 1950 (Figura 31a) e 2000 UTC (Figura 31b), esse núcleo enfraquece (refletividade máxima e extensão vertical diminuem) ao mesmo tempo em que a área convectiva expande horizontalmente ao fundir com um sistema menor à oeste. Antes da queda de granizo (Figura 31a), algumas regiões de corrente ascendente de até $15 \mathrm{~ms}^{-1}$ estão localizadas entre as isotermas de 0 e $-40^{\circ} \mathrm{C}$ associadas com os picos de refletividade (55 a $60 \mathrm{dBZ}$ ), mas o escoamento ascendente não é tão intenso quanto no momento anterior, mostrando um escoamento horizontal acima de $15 \mathrm{~km}$ e algumas regiões de correntes descendentes (de até $5 \mathrm{~ms}^{-1}$ ); o escoamento descendente principal ocorre fora do núcleo convectivo. Dez minutos depois (Figura 31b), a região de corrente ascendente principal $\left(23,07^{\circ} \mathrm{S}, 47,20^{\circ} \mathrm{W}\right)$ se intensifica, com velocidade de até $25 \mathrm{~ms}^{-1}$ ao longo de um escoamento ascendente bem definido entre 2 e $12 \mathrm{~km}$ de altura; acima dessa região, a corrente descendente é mais fraca e o escoamento descendente principal ocorre fora do núcleo convectivo. Próximo à localização do hailpad, a corrente ascendente é mais fraca entre as isotermas de 0 e $-40^{\circ} \mathrm{C}$ e praticamente nula abaixo dessa região, indicando a precipitação de hidrometeoros, incluindo chuva e granizo pequeno, como observado pelo hailpad (Tabela 6).

Em ambos os casos, o intenso movimento ascendente de hidrometeoros dentro 
Figura 30 - Corte horizontal em $3 \mathrm{~km}$ de altura e vertical entre os pontos A e B de refletividade e velocidade do vento (correntes ascendentes e descendentes máximas no painel da esquerda, escoamento no painel da direita) derivado por Multi-Doppler em 2017-03-14 às 1820 (a) e 1830 UTC (b), no momento mais próximo da queda de granizo em Cosmópolis. O 'x' indica a localização do hailpad e as isotermas de 0 e $-40^{\circ} \mathrm{C}$ foram definidas a partir da radiossondagem de SBMT. Linhas contínuas demarcam os limites dos municípios do Estado de São Paulo.
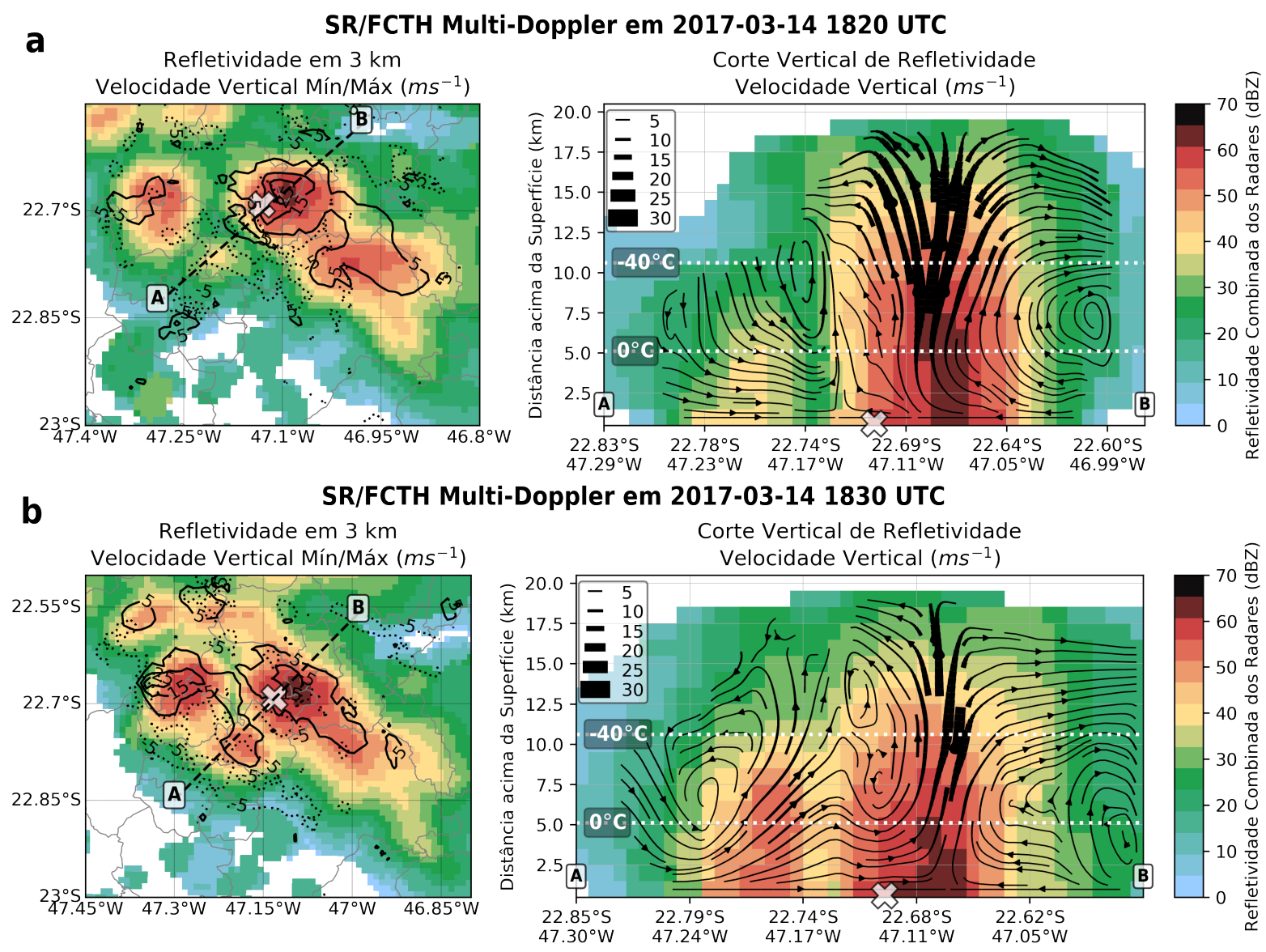

Fonte: Produzido pela autora.

da região de fase mista antes (Figura 30a) ou durante (Figura 31a) a queda de granizo contribui para a alta densidade de raios na região (Figura 24, Figura 25), pois promove maior colisão entre hidrometeoros e consequentemente aumenta a transferência de cargas (seção 2.1). 
Figura 31 - Corte horizontal em $3 \mathrm{~km}$ de altura e vertical entre os pontos A e B de refletividade e velocidade do vento (correntes ascendentes e descendentes máximas no painel da esquerda, escoamento no painel da direita) derivado por Multi-Doppler em 2017-03-14 às 1950 (a) e 2000 UTC (b), no momento mais próximo da queda de granizo em Indaiatuba. O 'x' indica a localização do hailpad e as isotermas de 0 e $-40^{\circ} \mathrm{C}$ foram definidas a partir da radiossondagem de SBMT. Linhas contínuas demarcam os limites dos municípios do Estado de São Paulo.
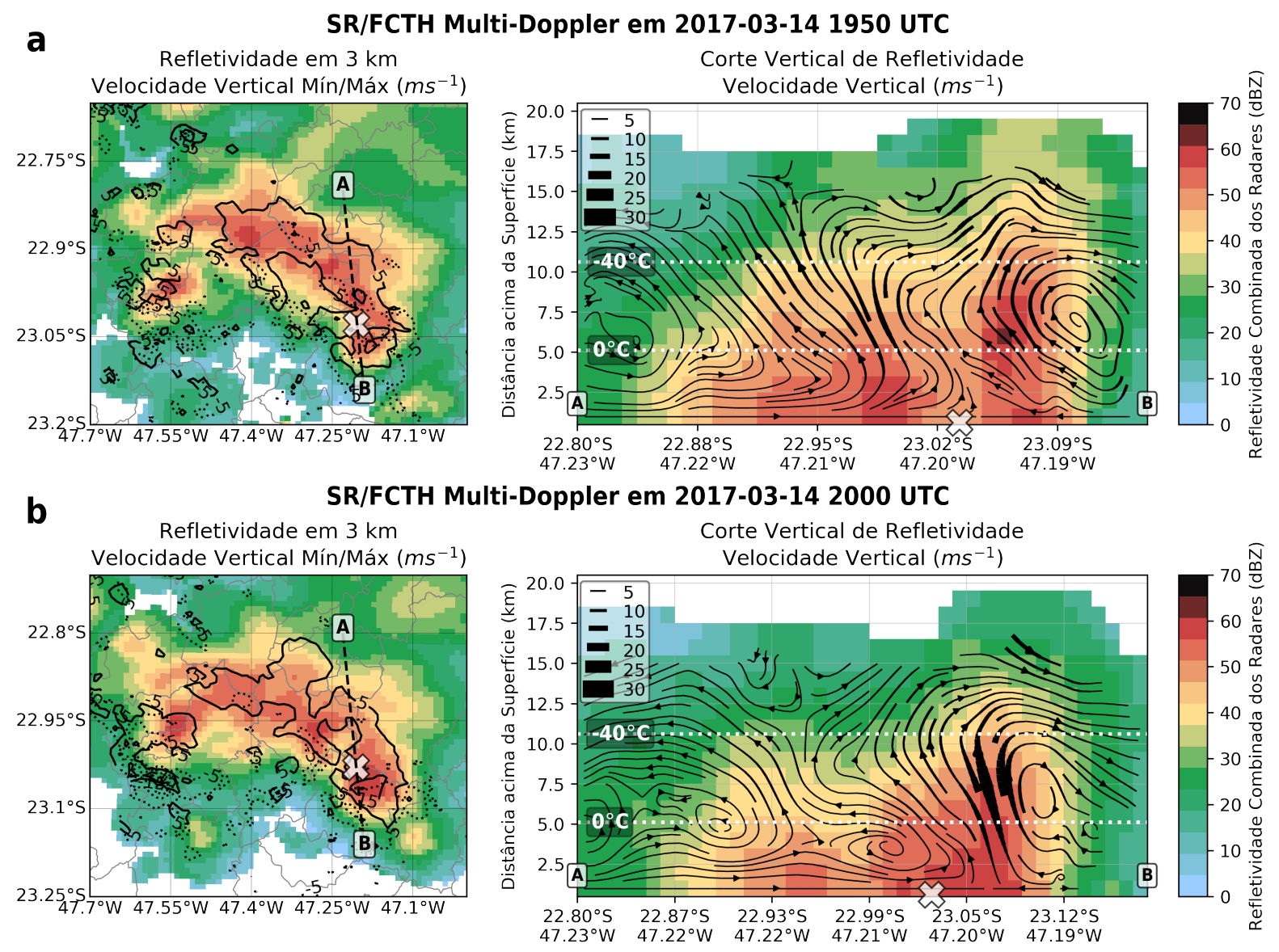

Fonte: Produzido pela autora.

\subsubsection{Caso de 2017-11-15}

\subsubsection{Ambiente Sinótico e Termodinâmico}

Diferentemente do caso anterior, o caso de 2017-11-15 não apresentou condições sinóticas favoráveis para convecção intensa. Mesmo com a Zona de Convergência do Atlântico Sul (ZCAS) localizada à norte do estado de São Paulo em fase de desconfiguração, a subsidência na região se manteve durante o dia: às 1200 UTC, a radiossondagem (Figura 33) mostra uma camada seca acima de $750 \mathrm{hPa}$, com baixo cisalhamento do vento e CAPE nulo, condição similar ao resto do estado (Figuras 32a e 32b); às 1800 UTC (Figura 32c), o CAPE aumenta, mas ainda é baixo (entre 0 e $1000 \mathrm{~J} \mathrm{~kg}^{-1}$ ), com um pouco de cisalhamento entre 1000 e 500 hPa (até 5 nós). Ainda assim, as imagens de satélite mos- 
tram pequenos sistemas convectivos espalhados pelo centro-norte do estado se formando às 1800 (Figura 34a) e 2100 UTC (Figura 34b), com topos de nuvem de até $-60{ }^{\circ} \mathrm{C}$ de temperatura de brilho, incluindo o sistema que causou queda de granizo em Indaiatuba.

Figura 32 - Campos da reanálise do ERA5 em 2017-11-15: Pressão ao nível médio do mar, espessura entre 1000 e $500 h P a$ e velocidade do vento em $250 h P a$ às 1200 UTC (a); altura geopotencial em $850 \mathrm{hPa}$, cisalhamento do vento entre 1000 e $500 h P a$ e CAPE em superfície às 1200 UTC (b) e 1800 UTC, no domínio do estado de São Paulo (c).

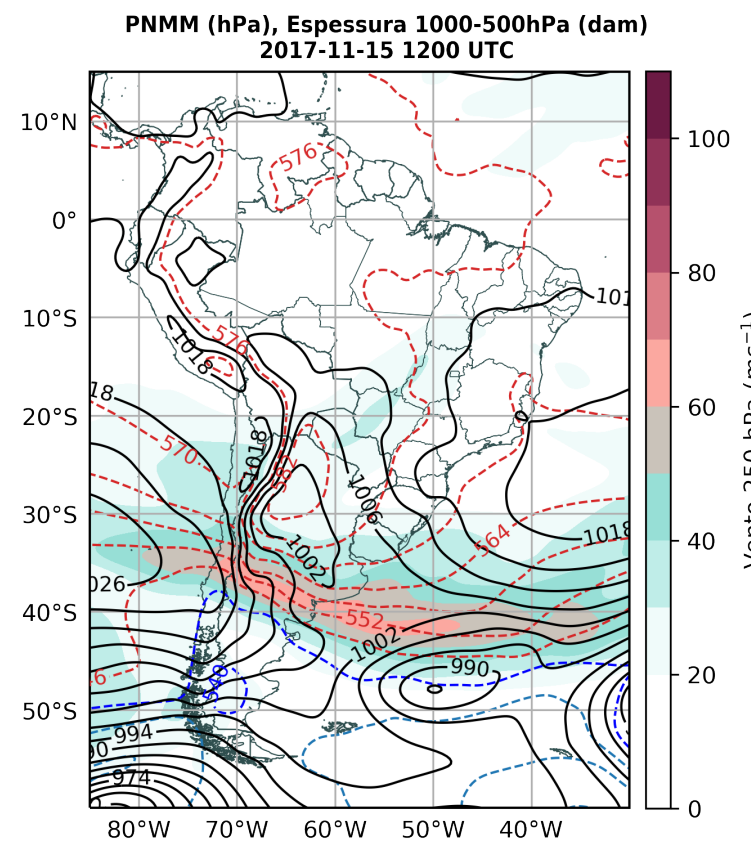

(a)

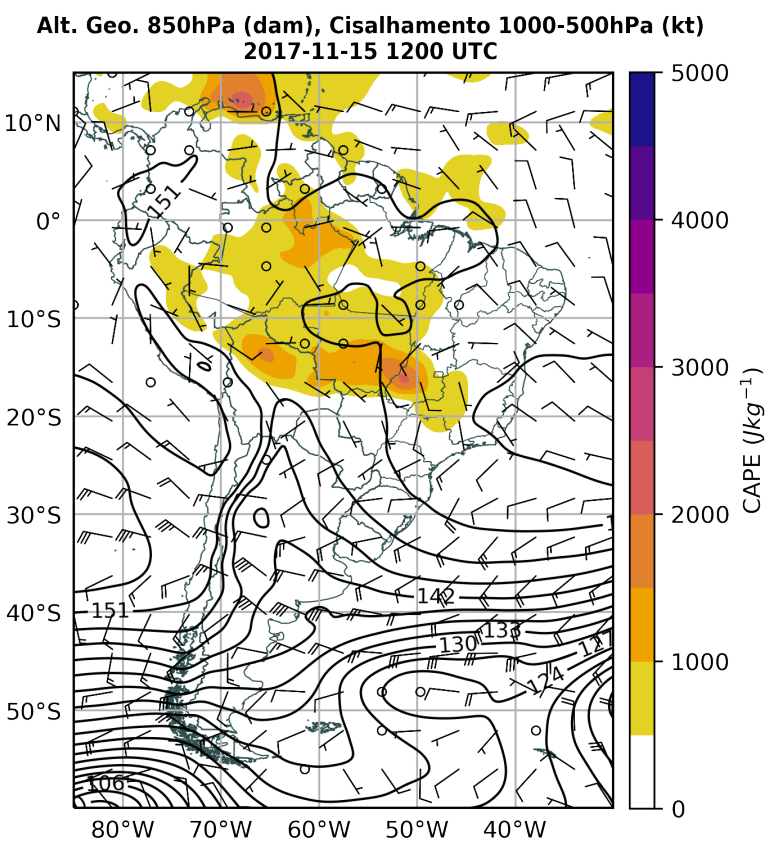

(b)

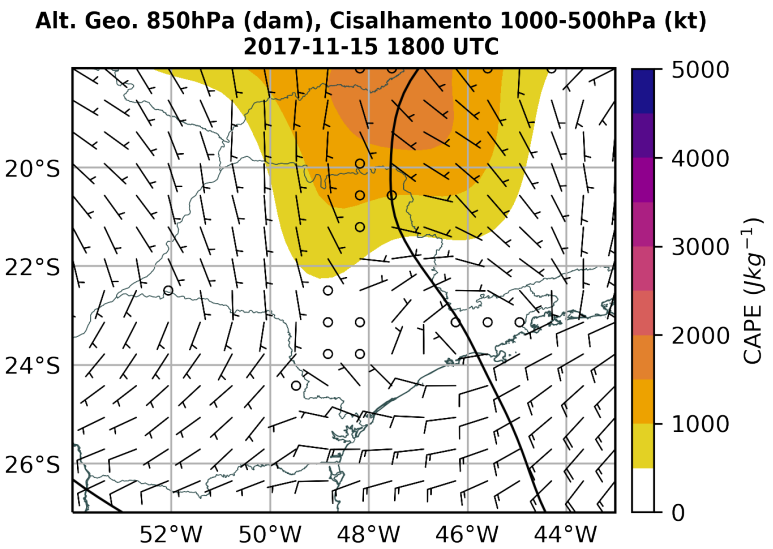

(c)

Fonte: Produzido pela autora. 
Figura 33 - Plotagem Skew-T Log-P da radiossondagem do Campo de Marte (SP) com hodógrafa do vento e índices CAPE e CIN em 2017-11-15 1200 UTC.

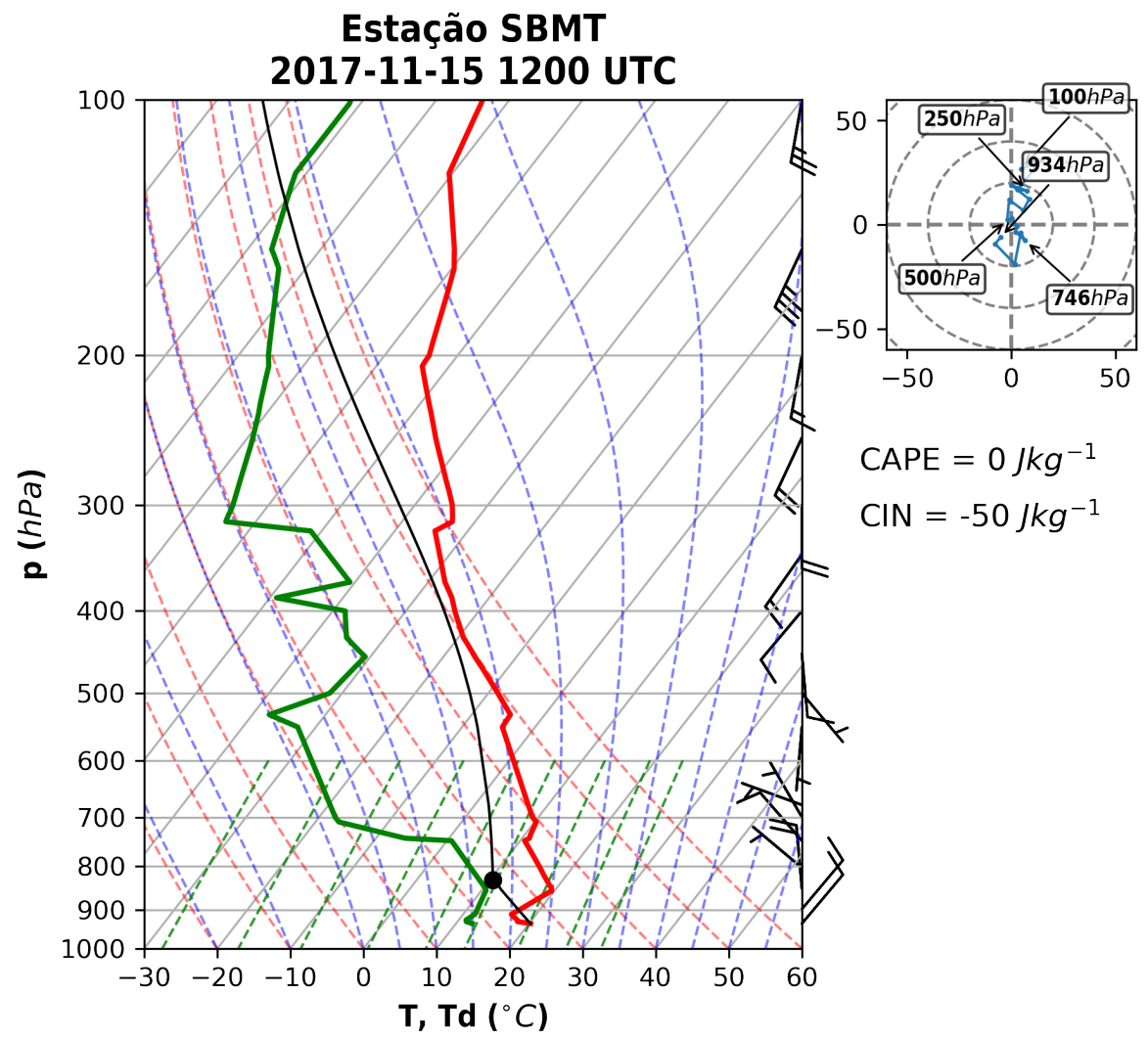

Fonte: Produzido pela autora.

Figura 34 - Imagem de satélite do canal 13 do GOES-16 mostrando a temperatura de brilho do topo das nuvens no estado de São Paulo em 2017-11-15 1800 (a) e $2100 \mathrm{UTC}(\mathrm{b})$.

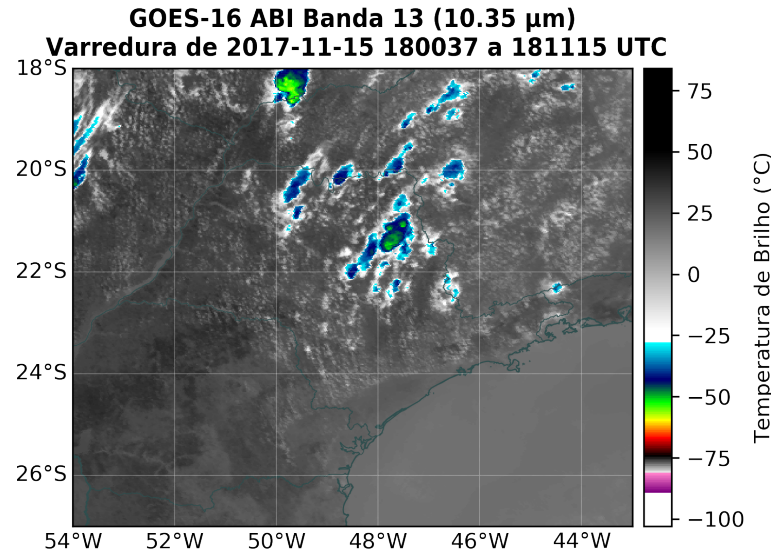

(a)

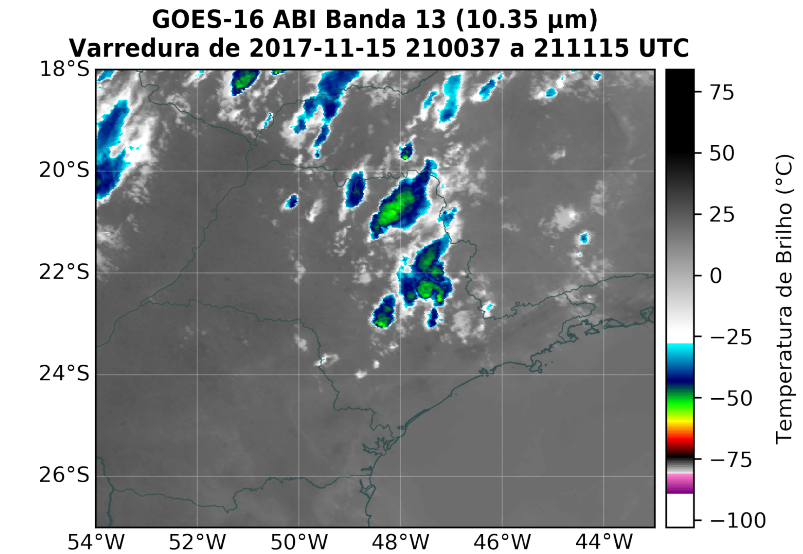

(b)

Fonte: Produzido pela autora. 


\subsubsection{Eletrificação}

A Figura 35 mostra a localização do sistema convectivo ao longo do ciclo de vida e dos flashes associados a ele. Diferentemente do caso de 2017-03-14, já foi mostrado (Figura 19, Tabela 6) que o ciclo de vida desse sistema foi bem mais curto $(2,2 h)$ com baixa atividade elétrica (taxa máxima de 3 (2) flashesmin $^{-1}$ IC (CG)) logo antes (depois, considerando apenas raios CG) da queda de granizo em Indaiatuba. O sistema passou por algumas cidades da RMC, sofrendo poucas fusões e separações (por ser um sistema pequeno e isolado). Boa parte dos flashes (principalmente IC) ocorreram no sudoeste de Campinas e Indaiatuba, onde ocorreu a queda de granizo; em todo o ciclo de vida, cerca de $30 \%$ dos flashes foram CG (20, com 46 flashes IC), proporção maior do que no caso de 2017-03-14.

Figura 35 - Rastreamento (a) e localização dos flashes IC e CG (b) do sistema convectivo responsável pela queda de granizo em Indaiatuba em 2017-11-15. Os triângulos pretos indicam a localização do hailpad. Linhas contínuas demarcam os limites dos municípios do Estado de São Paulo.

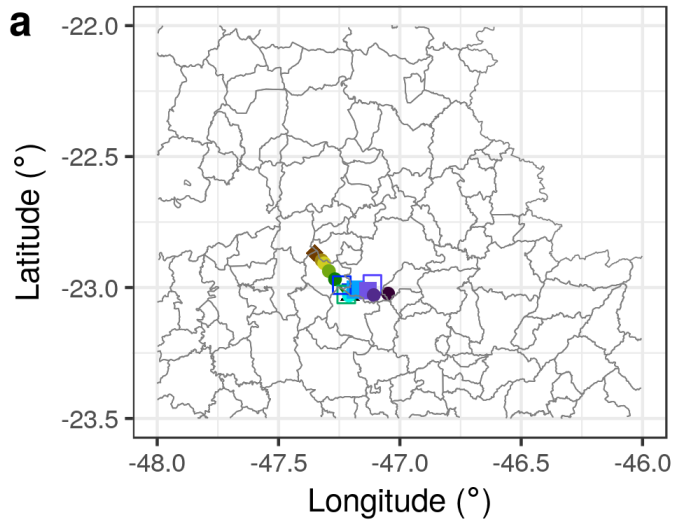

Classificação

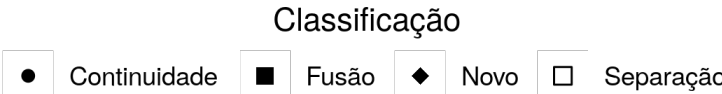

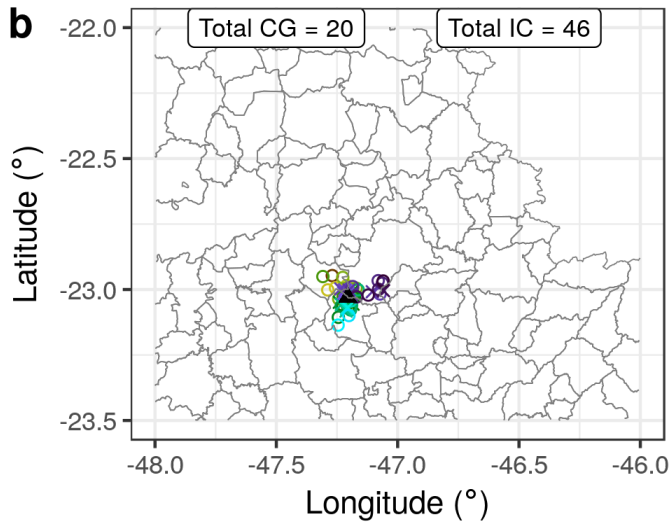

Tipo de Flash

$\times \quad C G \circ I C$
Hora (UTC)

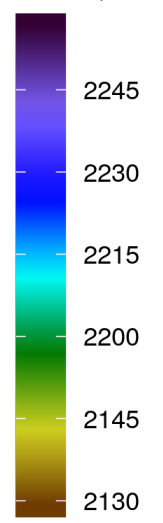

Fonte: Produzido pela autora.

A Figura 36 mostra os campos de refletividade (a) e flashes IC (b) e CG (c) para o caso de 2017-11-15 antes, durante e depois da queda de granizo em Indaiatuba. O núcleo convectivo mais próximo à localização do hailpad está embebido em um sistema multicelular que abrange algumas cidades do oeste e sudoeste da RMC e passa por um processo de separação durante a queda de granizo. A densidade de raios (de até 4 (2) flashes IC (CG)) está concentrada neste núcleo convectivo intenso (refletividade acima de $60 d B Z$ ), no entorno da localização do hailpad. 
Figura 36 - Campos de refletividade (CAPPI em $3 k m$ do radar de São Roque) (a) e flashes IC (b) e CG (c) acumulados em 10 minutos do sistema convectivo (delimitado pela linha preta) responsável pela queda de granizo em Indaiatuba em 201711-15. O triângulo preto indica a localização do hailpad. Linhas contínuas demarcam os limites dos municípios do Estado de São Paulo.

a
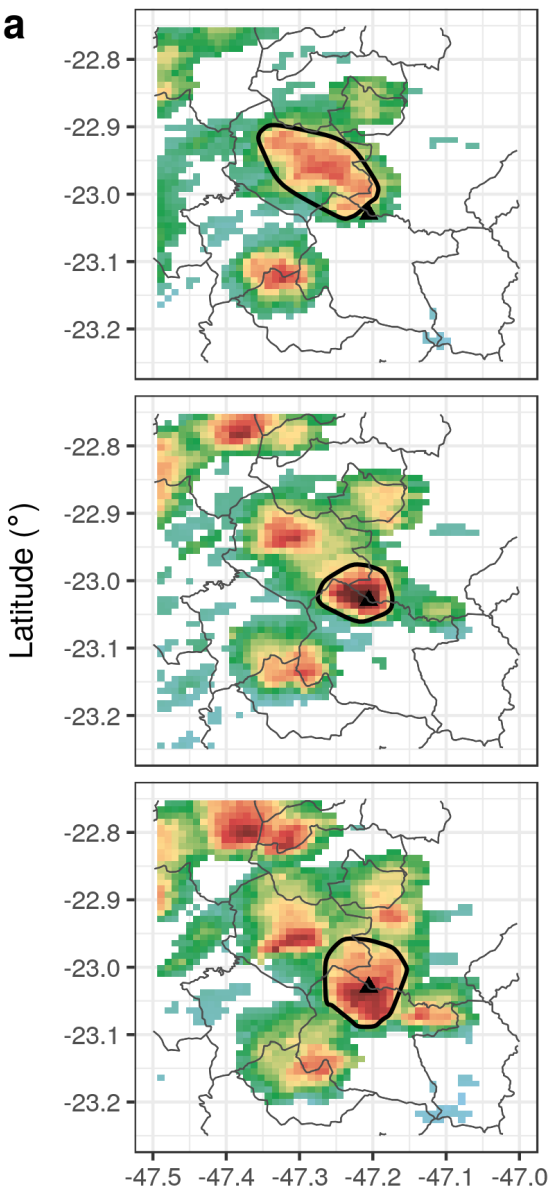

Refletividade (dBZ)

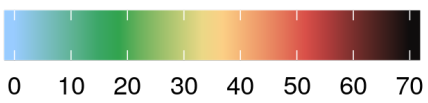

b
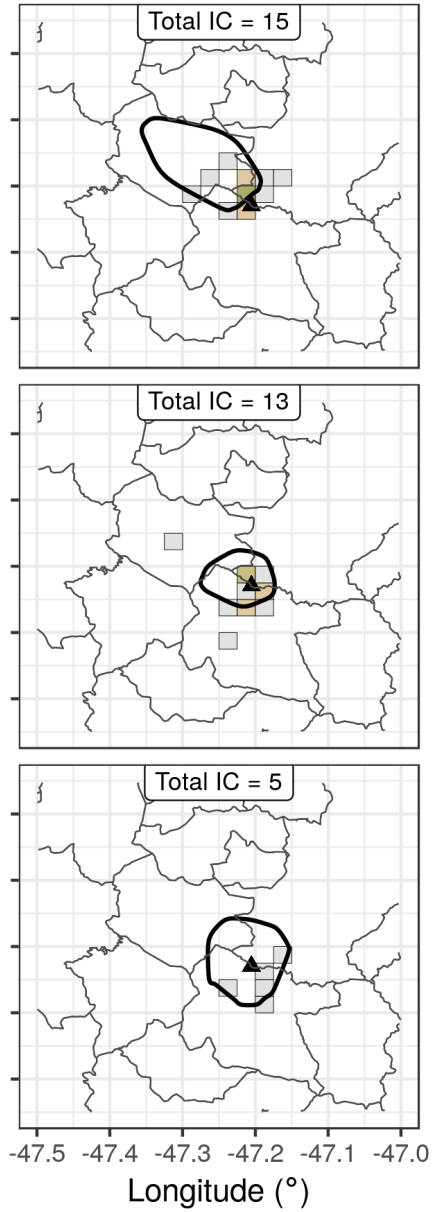

Longitude $\left({ }^{\circ}\right)$

Flashes $10 \mathrm{~min}^{-1} \mathrm{IC}$

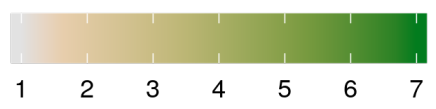

C
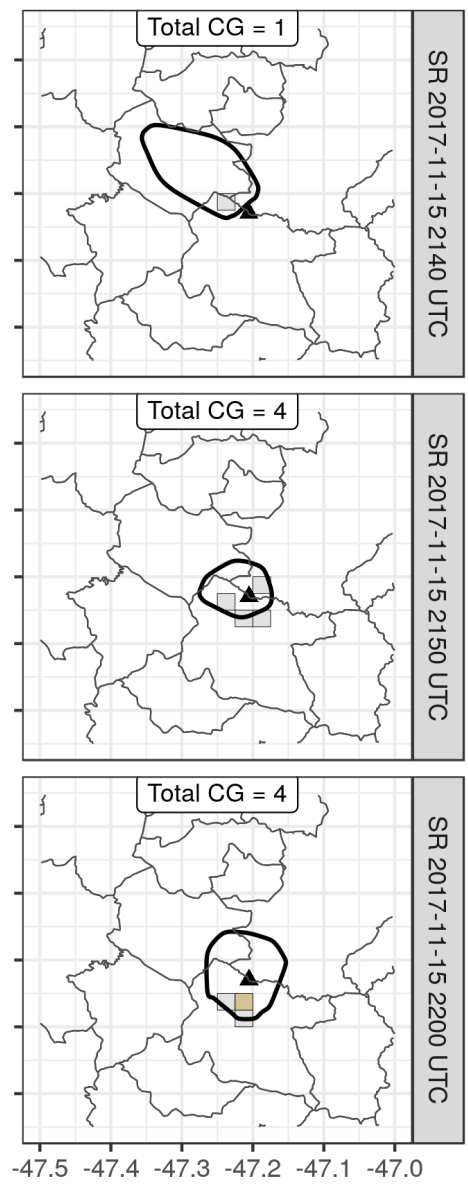

Flashes $10 \mathrm{~min}^{-1} \mathrm{CG}$

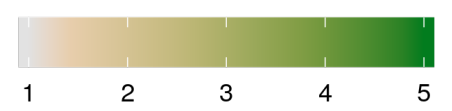

Fonte: Produzido pela autora.

\subsubsection{Microfísica}

A Figura 37 mostra os campos de refletividade e variáveis polarimétricas refletividade diferencial, fase diferencial específica e coeficiente de correlação do radar da FCTH para o caso de 2017-11-15, no momento mais próximo da queda de granizo em Indaiatuba; a Figura 38 mostra a identificação de hidrometeoros e massas de água líquida e gelo calculadas a partir dos campos de radar. O núcleo convectivo responsável pela queda de granizo é formado por uma região de refletividades acima de $50 \mathrm{dBZ}$ com cerca de $8 \mathrm{~km}$ de extensão horizontal e $10 \mathrm{~km}$ de extensão vertical (entre $1 \mathrm{~km}$ de altura e a isoterma 
de $-40^{\circ} \mathrm{C}$ ) (Figura 37a). Entre a superfície e a isoterma de $0^{\circ} \mathrm{C}$ observa-se refletividades acima de $60 \mathrm{dBZ}$ na localização do hailpad, o que indica a presença de granizo ou chuva misturada com granizo - a refletividade diferencial (Figura 37b) confirma isso, com valores entre 0 e $1 d B Z$ nessa região. Logo acima de $0^{\circ} C$, a refletividade diferencial é positiva $(0,5 \mathrm{~dB})$, também indicando presença de água líquida superesfriada, porém com gotas menores que no caso anterior.

A identificação de hidrometeoros no núcleo convectivo responsável pela queda de granizo (Figura 38a) novamente é similar ao campo de refletividade, classificando como granizo a região de refletividades acima de $50 \mathrm{dBZ}$, graupel de densidade alta (DA) entre 40 e $50 d B Z$ e graupel de densidade baixa (DB) entre 30 e $40 d B Z$. O problema está em regiões com refletividade abaixo de $30 \mathrm{dBZ}$, que são classificadas como cristais de gelo ou agregados mesmo abaixo da isoterma de $0^{\circ} \mathrm{C}$ (em $23,03^{\circ} \mathrm{S}, 47,17^{\circ} \mathrm{W}$, por exemplo, há cristais de gelo em $1 \mathrm{~km}$ de altura. As variáveis polarimétricas indicam a presença de graupel), condição muito difícil de ser encontrada em nuvens frias de tempestades tropicais. Assim como no caso de 2017-03-14, a estratégia do radar influencia os resultados encontrados, já que a região está à aproximadamente $140 \mathrm{~km}$ do radar (portanto, a primeira elevação faz varreduras entre aproximadamente 2,5 e 4,5 $\mathrm{km}$ de altura, contribuindo para a mistura de hidrometeoros).

Há uma concentração significativa de massa de água líquida (cerca de $6 \mathrm{gm}^{-3}$, Figura 38b) em $1 \mathrm{~km}$ de altura dentro do núcleo convectivo, extendendo-se até $7,5 \mathrm{~km}$. A massa de gelo (Figura 38c), por outro lado, chega a concentrações muito mais altas $\left(30 \mathrm{gm}^{-3}\right)$ na mesma região, chegando a $12,5 \mathrm{~km}$ de altura; essa alta concentração reforça a intensidade da queda de granizo observada no hailpad (Tabela 6).

Mesmo com a alta massa de gelo dentro da região de fase mista do núcleo convectivo, a baixa massa de água líquida pode ter contribuído para a baixa densidade de raios observada na região (Figura 36), já que o conteúdo de água líquida determina a espessura da camada quase-líquida dos hidrometeoros de gelo e é a troca de massa dessa camada durante colisões que carrega eletricamente os hidrometeoros e consequentemente a tempestade (seção 2.1). 
Figura 37 - Corte horizontal em $3 \mathrm{~km}$ de altura e vertical entre os pontos A e B de campos do radar da FCTH em 2017-11-15 2150 UTC, no momento mais próximo da queda de granizo em Indaiatuba: Refletividade corrigida (a) e diferencial (b), fase diferencial específica (c) e coeficiente de correlação (d). O 'x' indica a localização do hailpad e as isotermas de 0 e $-40^{\circ} \mathrm{C}$ foram definidas a partir da radiossondagem de SBMT. Linhas contínuas demarcam os limites dos municípios do Estado de São Paulo.

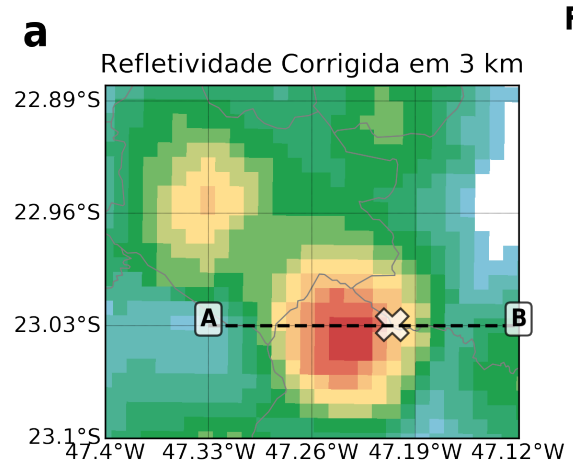

\section{FCTH 2017-11-15 2150 UTC}

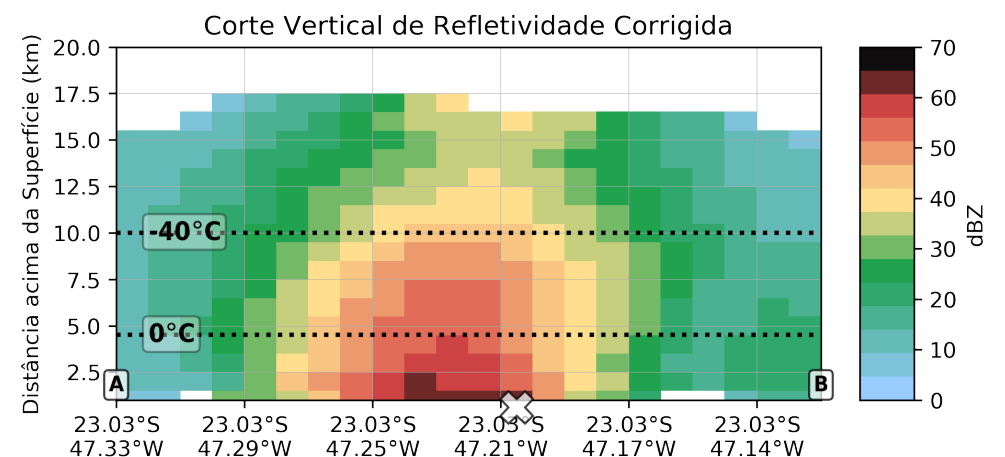

b

\section{FCTH 2017-11-15 2150 UTC}
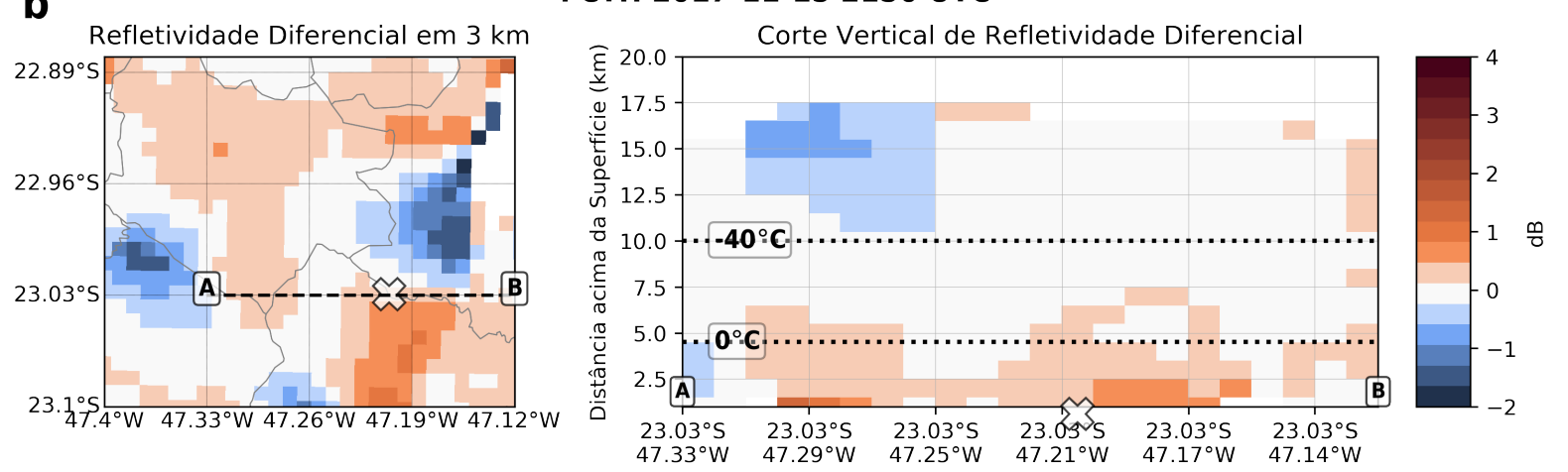

C

\section{FCTH 2017-11-15 2150 UTC}
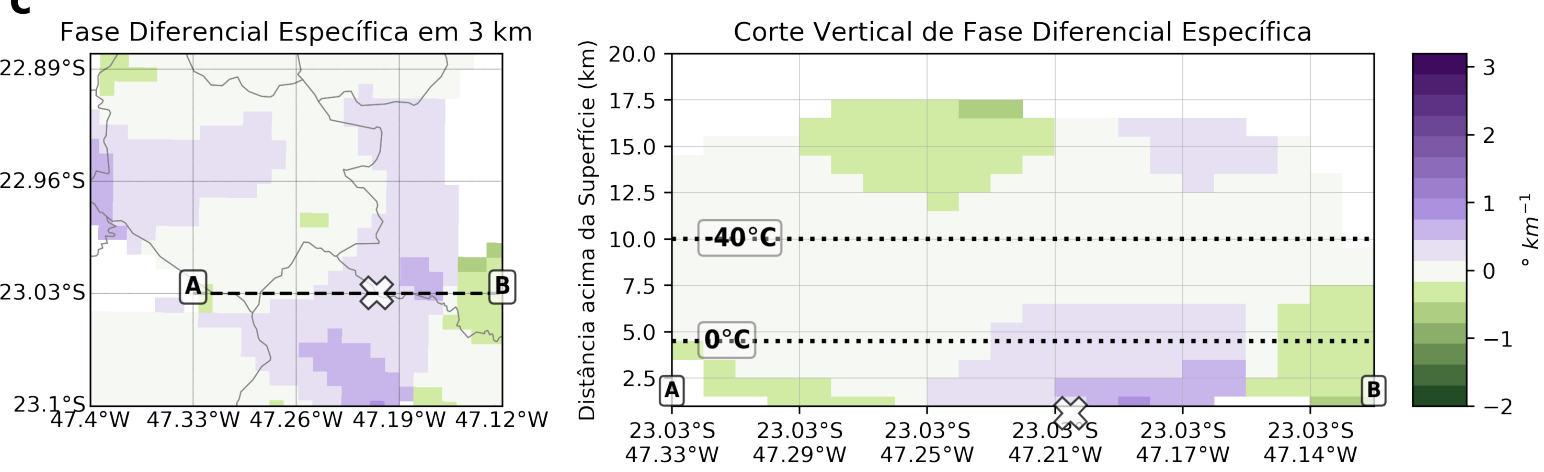

d

\section{FCTH 2017-11-15 2150 UTC}
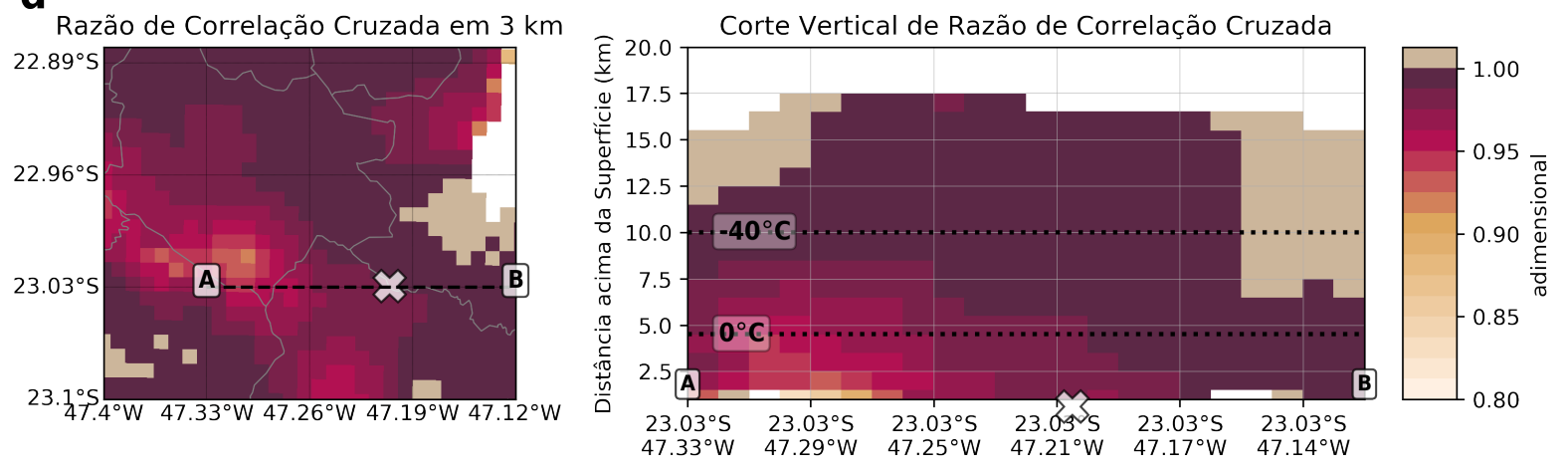

Fonte: Produzido pela autora. 
Figura 38 - Corte horizontal em $3 \mathrm{~km}$ de altura e vertical entre os pontos A e B de campos derivados do radar da FCTH em 2017-11-15 2150 UTC, no momento mais próximo da queda de granizo em Indaiatuba: Identificação de hidrometeoros (a) e massas de água líquida (b) e gelo (c). O 'x' indica a localização do hailpad e as isotermas de 0 e $-40^{\circ} \mathrm{C}$ foram definidas a partir da radiossondagem de SBMT. Linhas contínuas demarcam os limites dos municípios do Estado de São Paulo.

a

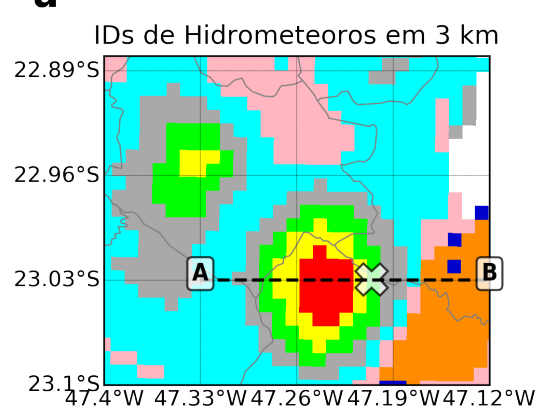

b

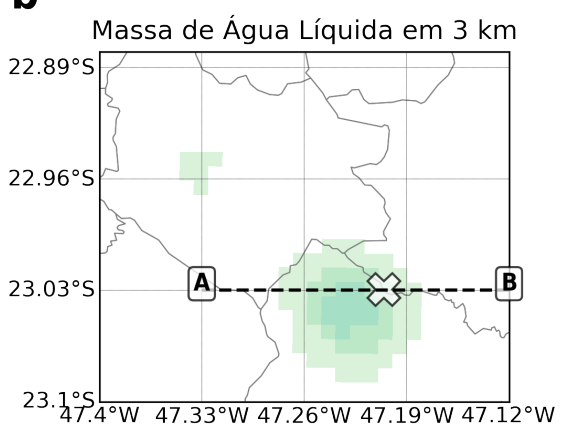

c

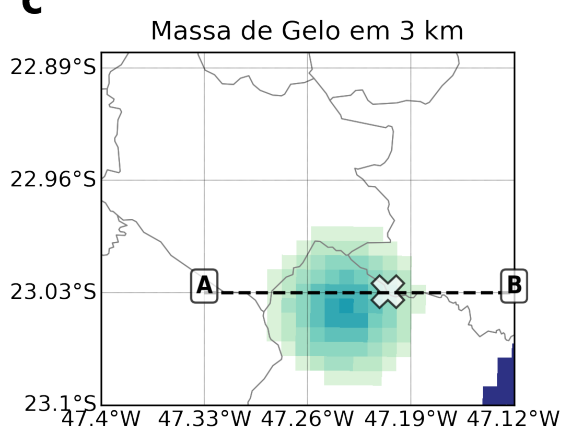

FCTH 2017-11-15 2150 UTC

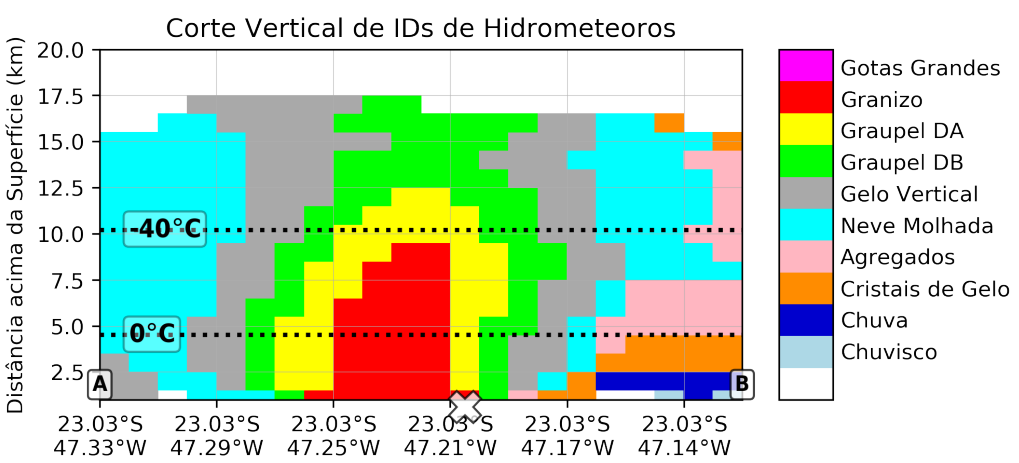

FCTH 2017-11-15 2150 UTC

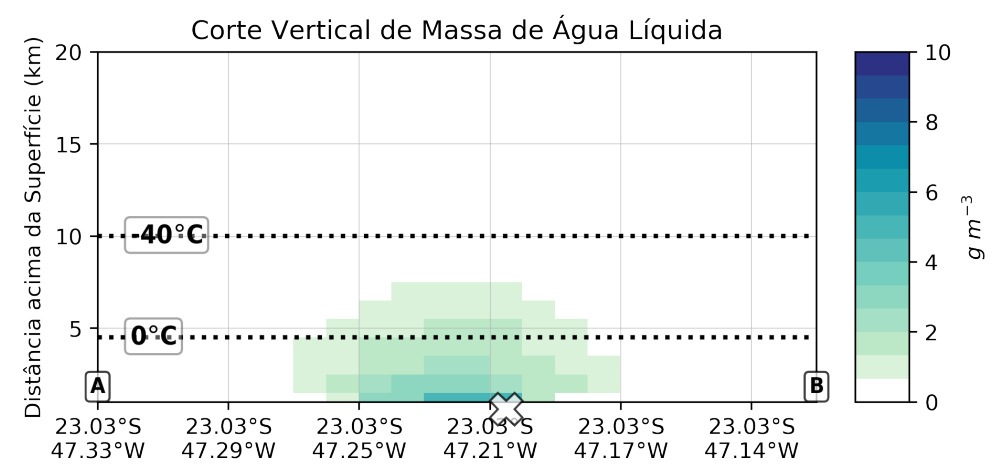

FCTH 2017-11-15 2150 UTC

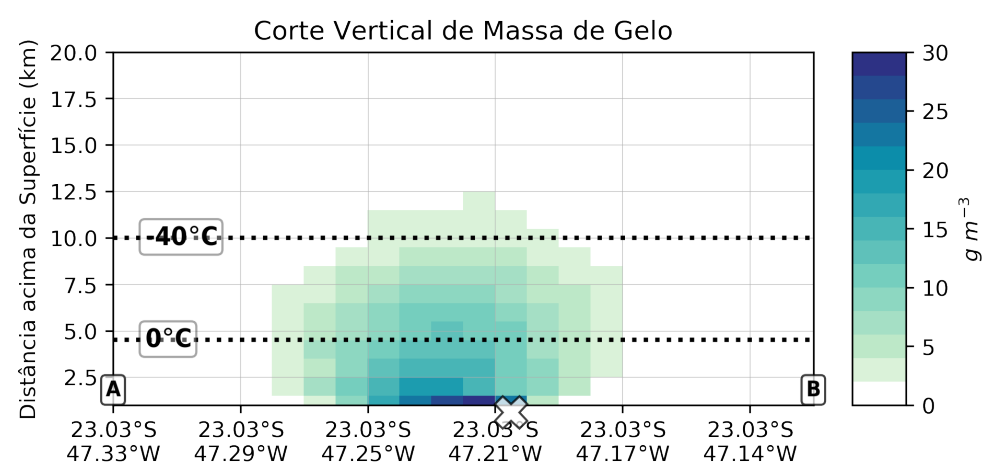

Fonte: Produzido pela autora.

\subsubsection{Cinemática}

A Figura 39 mostra os campos de refletividade combinada e velocidade do vento derivado por Multi-Doppler usando a combinação dos radares de São Roque, FCTH e XPOL, para o caso de 2017-11-15, no momento mais próximo da queda de granizo em Indaiatuba. O sistema convectivo responsável pelo evento mostra um núcleo isolado de 
refletividade acima de $40 d B Z$ que se separa entre 2140 (Figura 39a) e 2150 UTC (Figura 39b), sendo que o núcleo mais intenso é localizado próximo ao hailpad. Esse núcleo tem $15 \mathrm{~km}$ de extensão vertical, com refletividades próximas a $55 \mathrm{dBZ}$ entre as isotermas de 0 e $-40^{\circ} \mathrm{C}$ (Figura 39a) e acima de $60 \mathrm{dBZ}$ abaixo da isoterma de $0^{\circ} \mathrm{C}$ (Figura 39b), indicando momentos distintos de formação e crescimento de hidrometeoros e subsequente precipitação. Antes da queda de granizo, uma região de corrente ascendente com velocidades de até $20 \mathrm{~ms}^{-1}$ está associada ao núcleo convectivo, com um escoamento ascendente entre 5 e $13 \mathrm{~km}$ de altura, divergência no topo e um escoamento descendente intenso (até $10 \mathrm{~ms}^{-1}$ ) fora do núcleo, além de uma corrente descendente mais fraca dentro do núcleo. Dez minutos depois, a corrente ascendente (descendente) enfraquece (é fortalecida) dentro do núcleo convectivo, com um gradiente intenso (cerca de $5 \mathrm{~ms}^{-1} \mathrm{~km}^{-1}$ ) entre as isotermas de 0 e $-40^{\circ} \mathrm{C}$. Próximo à localização do hailpad, a corrente descendente da isoterma de $0^{\circ} \mathrm{C}$ à superfície e a refletividade de até $70 \mathrm{dBZ}$ próximo à superfície indicam intensa precipitação de hidrometeoros, incluindo chuva e granizos maiores (comparado ao caso de 2017-03-14), como observado pelo hailpad (Tabela 6).

O escoamento de hidrometeoros dentro do núcleo convectivo antes ou durante a queda de granizo mostra uma baixa ascendência e/ou descendência abaixo da região de fase mista, o que não indica um transporte significativo de hidrometeoros na forma líquida para a região de fase mista. Essa observação é compatível com a baixa massa de água líquida estimada na região (Figura 38b) e a baixa densidade de raios do sistema nesse período (Figura 36). 
Figura 39 - Corte horizontal em $3 \mathrm{~km}$ de altura e vertical entre os pontos A e B de refletividade e velocidade do vento (correntes ascendentes e descendentes máximas no painel da esquerda, escoamento no painel da direita) derivado por Multi-Doppler em 2017-11-15 às 2140 (a) e 2150 UTC (b), no momento mais próximo da queda de granizo em Cosmópolis. O 'x' indica a localização do hailpad e as isotermas de 0 e $-40^{\circ} \mathrm{C}$ foram definidas a partir da radiossondagem de SBMT. Linhas contínuas demarcam os limites dos municípios do Estado de São Paulo.
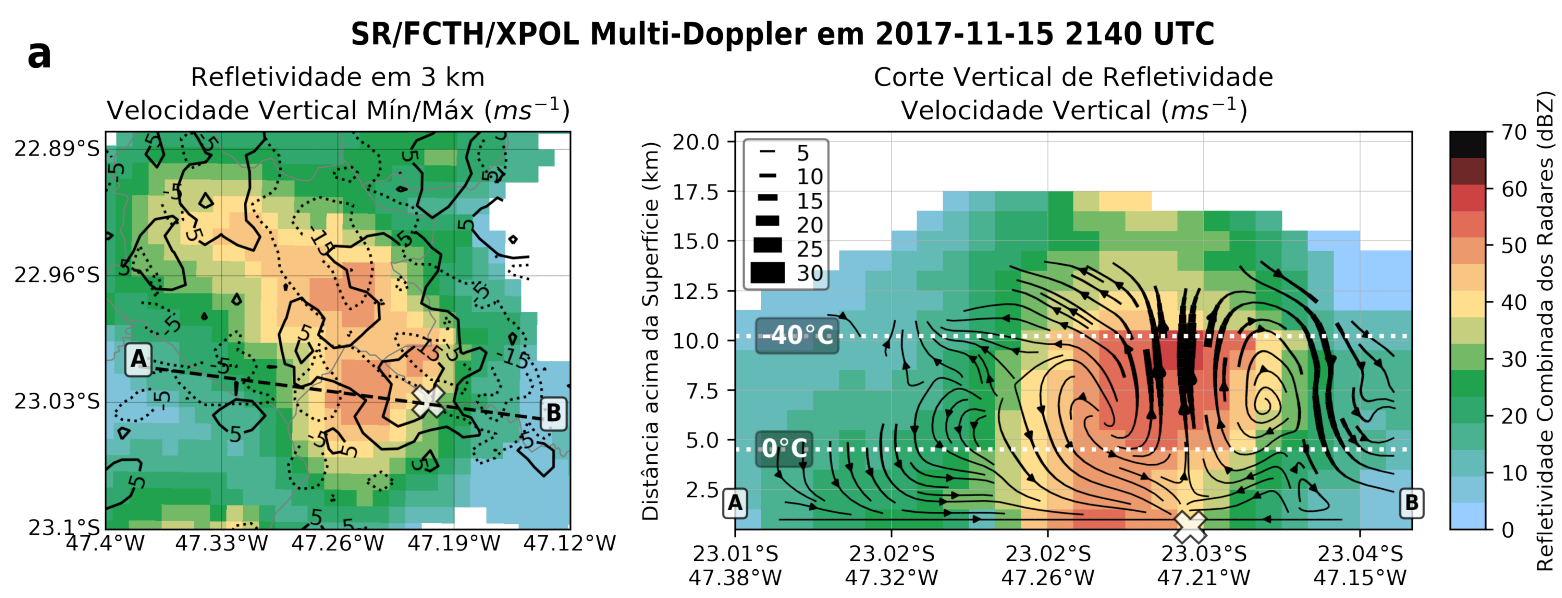

\section{b}

SR/FCTH/XPOL Multi-Doppler em 2017-11-15 2150 UTC
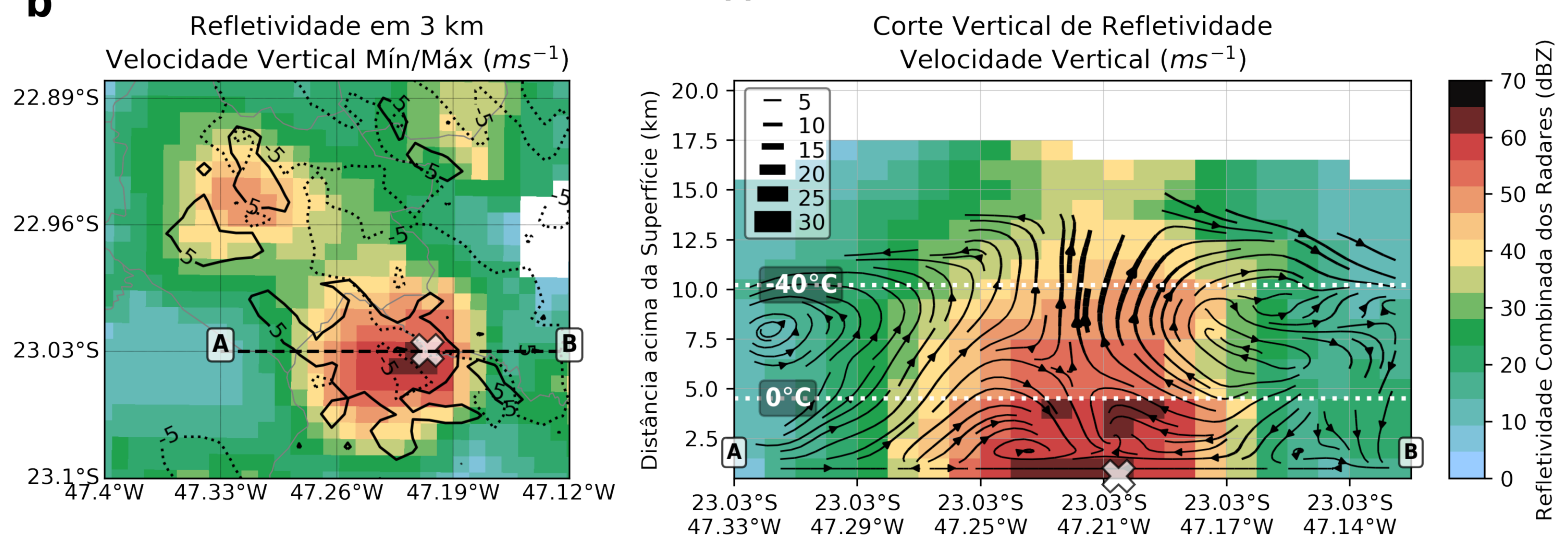

Fonte: Produzido pela autora. 


\section{Conclusões}

Esta dissertação descreveu tempestades tropicais que produziram queda de granizo na Região Metropolitana de Campinas de forma a identificar características físicas determinantes para a formação de granizos precipitáveis. A partir de uma rede de detecção de granizo instalada na região pelo Projeto SOS-CHUVA, cinco casos ocorridos entre 2016 e 2017 foram selecionados. Além da intensidade da queda de granizo inferida pelos registros dos hailpads, três aspectos foram explorados: o ciclo de vida e atividade elétrica através do rastreamento dos sistemas convectivos observados pelo radar Banda-S de São Roque com o algoritmo ForTraCC-Radar e da rede de detecção de raios BrasilDAT, respectivamente; a microfísica das tempestades no momento da queda de granizo através de um algoritmo de identificação de hidrometeoros aplicado ao radar de dupla polarização Banda-S da FCTH e; a cinemática das tempestades antes e durante a queda de granizo através da recuperação de vento tridimensional por Multi-Doppler usando dois ou três radares.

Os casos selecionados mostraram quedas de granizo de baixa intensidade dentro de escalas de intensidade das tempestades de granizo aplicadas no continente europeu. O caso de 2017-11-15 foi o mais intenso, com granizo máximo de 22, $4 \mathrm{~mm}$, enquanto que o caso de 2017-03-14, com o ciclo de vida mais longo $(6,2 h)$ e queda de granizo em duas localidades distintas (Cosmópolis e Indaiatuba), foi o menos intenso, com granizo máximo de $11,8 \mathrm{~mm}$. A baixa atividade elétrica do caso mais intenso, principalmente comparado com o caso menos intenso, motivou o estudo dos aspectos físicos destes dois casos.

O ciclo de vida mais longo do caso de 2017-03-14 se deve a vários processos de fusão e separação com outros sistemas convectivos que se formaram na região durante a tarde e noite. Isso também contribuiu para a alta atividade elétrica, com taxas de até 107 (31) flashes min $^{-1}$ IC (CG) entre a queda de granizo em Cosmópolis e em Indaiatuba. A queda de granizo em Cosmópolis foi associada a um núcleo convectivo intenso embebido em um sistema multicelular, com granizo até $10 \mathrm{~km}$ de altura, massa de gelo de até $15 \mathrm{gm}^{-3}$ e correntes ascendentes de até $30 \mathrm{~ms}^{-1}$ antes do evento; a queda de granizo em Indaiatuba foi associada a um núcleo convectivo (não tão intenso quanto o anterior) dentro de um sistema com poucas células intensas, mas ainda assim com granizo (e chuva) até $10 \mathrm{~km}$ de altura, massa de gelo de até $15 \mathrm{gm}^{-3}$ e correntes ascendentes de até $25 \mathrm{~ms}^{-1}$ durante o evento. Já no caso de 2017-11-15, o sistema convectivo apresentou ciclo de vida mais curto $(2,2 h)$, menor extensão horizontal e total de 46 (20) flashes IC (CG) (quantidade muito menor que no caso de 2017-03-14). A queda de granizo em Indaiatuba foi associada a um núcleo convectivo intenso quase isolado (após separação) com granizo até $11 \mathrm{~km}$ de altura, massa de gelo de $30 \mathrm{gm}^{-3}$ logo abaixo da base da nuvem e correntes ascendentes 
de até $20 \mathrm{~ms}^{-1}$ antes do evento.

Os casos de 2017-03-14 e 2017-11-15 foram de distintas escalas e ciclos de vida, portanto era de se esperar diferenças na intensidade da queda de granizo. Porém, as características microfísicas das tempestades durante o evento foram similares, com uma camada verticalmente extensa de granizo e massa de gelo entre a base e a região de fase mista da nuvem, o que não explica a diferença de tamanho dos granizos entre um caso e outro. A cinemática dessas tempestades possivelmente explica essa diferença: correntes ascendentes intensas (pelo menos $15 \mathrm{~ms}^{-1}$ ) estão presentes dentro da região de fase mista da nuvem principalmente antes da queda de granizo em ambos os casos, o que promove a formação e crescimento de granizo, enquanto que durante a queda de granizo as correntes descendentes são mais intensas no caso de 2017-11-15. Correntes descendentes mais intensas indicam maior precipitação de hidrometeoros, que pode contribuir para a queda de granizos maiores evitando a diminuição de tamanho deles por evaporação abaixo da base da nuvem - a precipitação na forma líquida aumenta a umidade entre a superfície e a base da nuvem, ou seja, aumenta a pressão de vapor (em comparação com os arredores) e consequentemente diminui a taxa de evaporação do granizo. Além disso, o conceito de competição desleal - granizos maiores possuem maior velocidade terminal, o que permite que eles coletem gotículas de nuvem antes dos granizos menores e cresçam ainda mais rápido (KNIGHT; KNIGHT, 2001a) - também possui um papel importante, já que a precipitação fornece mais gotas em uma distância maior para o crescimento do granizo. Assim, mesmo com a baixa atividade elétrica, houve precipitação de granizos maiores no caso de 2017-11-15 possivelmente por contribuição da precipitação na forma líquida.

É importante ressaltar que os resultados mostrados nesta dissertação possuem diversas limitações inerentes à coleta e processamento de dados, listadas a seguir:

a) Distribuição de tamanho de granizo: as medidas manuais das cavidades feitas por dois grupos diferentes sem um consenso sobre a forma de medição mostraram distribuições altamente discrepantes entre si, o que diminuiu a confiabilidade dos resultados derivados dessa medida. O uso de métodos mais sofisticados (manuais ou semi-automáticos) de medição das distribuições de tamanho nos hailpads pode ajudar a evitar este problema;

b) Rastreamento de sistemas convectivos por radar: o algoritmo ForTraCCRadar, por ser uma adaptação de um algoritmo originalmente desenvolvido para imagens de satélite (VILA et al., 2008), apresenta diversas limitações. A principal delas está no limiar de refletividade: não é possível escolher mais de um limiar (ao contrário da versão para satélite), o que obriga o usuário a escolher um limiar mais alto (e rastrear apenas o núcleo convectivo) quando o sistema convectivo não é pequeno e isolado; isso atrapalha a descrição do ciclo de vida do sistema (já que pode 
gerar excesso de separações). Outra limitação está no tratamento de separações e fusões, que pode apresentar falhas quando o limiar de refletividade é alto (acima de $30 \mathrm{dBZ}$ );

c) Identificação de hidrometeoros: o algoritmo Fuzzy Hydrometeor Classificator do pacote CSU_RadarTools (LANG; DOLAN; GUY, 2017) mostrou resultados razoáveis, mas não foi comparado com outros algoritmos para o radar da FCTH, o que é importante para a validação desses resultados. O mesmo se aplica para as estimativas de massas de água líquida e gelo;

d) Recuperação de vento por Multi-Doppler: considerando que esta metodologia foi aplicada de forma inédita aos dados dos radares da FCTH, de São Roque e o XPOL, que possuem estratégias de varredura bem distintas, é preciso interpretar com cautela os resultados obtidos. O próprio algoritmo do pacote MultiDop já possui suas próprias limitações. A ponderação de cada radar dentro da região de boas estimativas apresentou grande sensibilidade: a escala duas vezes menor do radar de São Roque em relação aos demais foi a única escolha que produziu estimativas de velocidade do vento razoáveis (até $30 \mathrm{~ms}^{-1}$ ), pois ponderações maiores geravam ventos fisicamente incompatíveis. A estimativa de vento em regiões de baixas refletividades (até $20 \mathrm{dBZ}$ ) apresentou erros: muitas vezes as velocidades eram muito mais altas do que o esperado; isso também foi observado por outros pesquisadores que usaram esse pacote em radares americanos (Msc. Sarah Stough, UAH, comunicação pessoal, 2019).

A diversidade de casos analisados nesta dissertação mostrou que, assim como em latitudes médias, quedas de granizo podem ocorrer em uma variedade de tempestades tropicais. Casos com ciclo de vida mais longo, constituído por sistemas convectivos multicelulares com alta atividade elétrica, assim como casos com ciclo de vida curto e baixa atividade elétrica, estão associados a queda de granizo. Considerando os dois casos analisados mais detalhadamente, é possível delinear algumas características em comum, como aumento da atividade elétrica antes ou depois do evento, a presença de granizo em uma camada extensa dentro da nuvem e a atuação da corrente ascendente dentro da região de fase mista contribuindo para a formação e crescimento do granizo.

\subsection{Sugestões para Trabalhos Futuros}

O uso de uma rede de detecção de granizo em uma região de transição entre regimes tropical e subtropical para o estudo de tempestades que produzem granizo se mostrou muito importante para identificar e analisar características físicas deste tipo de sistema convectivo. A partir dessa base de dados (constituída por cerca de 10 casos, incluindo 
os 5 casos analisados nesta dissertação), esperamos que outros trabalhos explorem os demais casos não só em relação às suas características físicas mas também comparando parâmetros derivados dos hailpads e de radares e/ou satélites meteorológicos, como por exemplo a energia cinética, de forma a validar estimativas de granizo por radar ou satélite na região ou comparar diretamente a energia cinética calculada com dados de radar. A operacionalização dessa e de possíveis outras redes de hailpads é fundamental para o desenvolvimento de uma climatologia de tempestades de granizo na região.

Outros aspectos relacionados à tempestades de granizo nessa região também podem ser estudados, como a relação entre fluxo de massa de gelo e atividade elétrica para incorporação em modelos numéricos de previsão de tempo e clima e simulações numéricas com modelos de alta resolução e parametrizações de eletrificação com o objetivo de entender os mecanismos e variáveis físicas que controlam a produção de granizo nas tempestades tropicais. 


\section{Referências}

ALBRECHT, R. I. et al. Where are the lightning hotspots on Earth? Bulletin of the American Meteorological Society, v. 97, n. 11, p. BAMS-D-14-00193.1, nov 2016. ISSN 0003-0007. Disponível em: < http://journals.ametsoc.org/doi/10.1175/BAMS-D-1400193.1>. Citado na página 29.

ARMIJO, L. A theory for the Determination of Wind and precipitation velocities with Doppler Radars. Journal of the Atmospheric Sciences, v. 26, n. 3, p. 570-573, may 1969. ISSN 0022-4928. Disponível em: <http://journals.ametsoc.org/doi/abs/10.1175/15200469\%281969\%29026\%3C0570\%3AATFTDO\%3E2.0.CO\%3B2>. Citado na página 31.

BAKER, B. et al. The Influence of Diffusional Growth Rates On the Charge Transfer Accompanying Rebounding Collisions Between Ice Crystals and Soft Hailstones. Quarterly Journal of the Royal Meteorological Society, John Wiley and Sons, Ltd, v. 113, n. 478, p. 1193-1215, jul 1987. ISSN 1477870X. Disponível em: <http://doi.wiley.com/10.1002/qj.49711347807>. Citado na página 26.

BAKER, M. B.; DASH, J. G. Mechanism of charge transfer between colliding ice particles in thunderstorms. Journal of Geophysical Research, John Wiley and Sons, Ltd, v. 99, n. D5, p. 10621-10626, may 1994. ISSN 0148-0227. Disponível em: < http://doi.wiley.com/10.1029/93JD01633http://onlinelibrary.wiley.com/doi/10. 1029/93JD01633/abstracthttp://onlinelibrary.wiley.com/store/10.1029/93JD01633/ asset/jgrd2863.pdf?v=1\&t=insy0wat\&s=721cc6ff8760d7aea7f98eadf068d7a2f8d6df73> . Citado na página 26.

BALDI, M. et al. Hail occurrence in Italy: Towards a national database and climatology. Atmospheric Research, v. 138, p. 268-277, 2014. ISSN 01698095. Disponível em: <https://mail-attachment.googleusercontent.com/ attachment $/ \mathrm{u} / 0 /$ ? ui $=2 \& \mathrm{ik}=2$ def683244\&attid $=0.2 \& \mathrm{th}=15 \mathrm{fa} 0 \mathrm{e} 0393 \mathrm{aa} 213 \mathrm{a} \&$

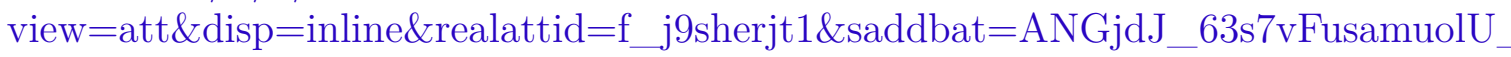
zi7tS2eGbVB2IplYOVKDLutBSaUAaCEzdxjWPhXKSv8JhX7hYq96sSUC32qSr0ab36FGkIQ> . Citado na página 23.

BARNES, G. Severe Local Storms in the Tropics. In: DOSWELL, C. A. (Ed.). Severe Convective Storms. Boston, MA: American Meteorological Society, 2001. p. 359-432. ISBN 978-1-935704-06-5. Disponível em: <https://doi.org/10.1007/978-1-935704-06-5_10>. Citado 2 vezes nas páginas 29 e 30.

BERTHET, C.; DESSENS, J.; SANCHEZ, J. L. Regional and yearly variations of hail frequency and intensity in France. Atmospheric Research, Elsevier, v. 100, n. 4, p. 391-400, jun 2011. ISSN 01698095. Disponível em: < https://www.sciencedirect.com/ science/article/pii/S0169809510002656> . Citado na página 28.

BERTHET, C. et al. Extreme hail day climatology in Southwestern France. Atmospheric Research, Elsevier, v. 123, p. 139-150, apr 2013. ISSN 01698095. Disponível em: <http://www.sciencedirect.com/science/article/pii/S016980951200333X?via\%3Dihub>. Citado 2 vezes nas páginas 23 e 28. 
BRANDES, E. A. Flow in Severe Thunderstorms Observed bu Dual-Doppler Radar. Monthly Weather Review, v. 105, n. 1, p. 113-120, jan 1977. ISSN 0027-0644. Disponível em: <http://journals.ametsoc.org/doi/abs/10.1175/15200493\%281977\%29105\%3C0113\%3AFISTOB\%3E2.0.CO\%3B2http://journals.ametsoc. org/doi/abs/10.1175/1520-0493(1977)105\%3C0113:FISTOB\%3E2.0.CO;2>. Citado na página 32 .

BRINGI, V. N.; CHANDRASEKAR, V. Polarimetric Doppler Radar: Principles and applications. Cambridge University Press, 2001. 636 p. ISBN 9780521623841. Disponível em: <https://books.google.com.br/books?hl=pt-BR\&lr=\&id=KvJvfP9t5Y8C\&oi=fnd\& $\mathrm{pg}=$ PR11\&ots $=$ XworR82NzS\&sig $=$ crq9heYQXXeQRqcton82nX3LFYY\&redir_esc $=\mathrm{y} \#$ $\mathrm{v}=$ onepage\&q\&f=false $>$. Citado na página 46.

CALHOUN, K. M. et al. Evolution of Lightning Activity and Storm Charge Relative to Dual-Doppler Analysis of a High-Precipitation Supercell Storm. Monthly Weather Review, v. 141, n. 7, p. 2199-2223, jul 2013. ISSN 0027-0644. Disponível em: <http://journals.ametsoc.org/doi/pdf/10.1175/MWR-D-12-00258.1http: //journals.ametsoc.org/doi/abs/10.1175/MWR-D-12-00258.1> . Citado na página 32.

CAREY, L. D.; BUFFALO, K. M. Environmental Control of Cloud-to-Ground Lightning Polarity in Severe Storms. Monthly Weather Review, v. 135, n. 4, p. 1327-1353, apr 2007. ISSN 0027-0644. Disponível em: <http://journals.ametsoc.org/doi/abs/10.1175/ MWR3361.1>. Citado 2 vezes nas páginas 27 e 28.

CAREY, L. D.; RUTLEDGE, S. A. Positive cloud-to-ground lightning in severe hailstorms: a multiparameter radar study. In: International Conference on Radar Meteorology. [S.l.: s.n.], 1995. p. 629-632. Citado 2 vezes nas páginas 27 e 28.

CAREY, L. D.; RUTLEDGE, S. A. Electrical and multiparameter radar observations of a severe hailstorm. Journal of Geophysical Research: Atmospheres, v. 103, n. D12, p. 13979-14000, jun 1998. ISSN 01480227. Disponível em: <http://doi.wiley.com/10.1029/ 97JD02626>. Citado na página 44.

CAREY, L. D.; RUTLEDGE, S. A. The Relationship between Precipitation and Lightning in Tropical Island Convection: A C-Band Polarimetric Radar Study. Monthly Weather Review, v. 128, n. 8, p. 2687-2710, aug 2000. ISSN 0027-0644. Disponível em: <http://journals.ametsoc.org/doi/pdf/10.1175/15200493\%282000\%29128\%3C2687\%3ATRBPAL\%3E2.0.CO\%3B2>. Citado 2 vezes nas páginas 45 e 46.

CAREY, L. D.; RUTLEDGE, S. A. Characteristics of cloud-to-ground lightning in severe and nonsevere storms over the central United States from 19891998. Journal of Geophysical Research, v. 108, n. D15, p. 4483, 2003. ISSN 0148-0227. Disponível em: <http://doi.wiley.com/10.1029/2002JD002951>. Citado 2 vezes nas páginas 27 e 28.

CECIL, D. J.; BLANKENSHIP, C. B. Toward a global climatology of severe hailstorms as estimated by satellite passive microwave imagers. Journal of Climate, v. 25, n. 2, p. 687-703, 2012. ISSN 08948755. Citado 2 vezes nas páginas 29 e 31.

Ceped - Centro Universitário De Estudos E Pesquisas Sobre Desastres. Atlas brasileiro de desastres naturais 1991 a 2010: volume São Paulo. [S.1.], 2013. 94 p. Citado na página 23. 
Changnon Jr., S. A. Hailfall Chracteristics Related to Crop Damage. Journal of Applied Meteorology, v. 10, n. 2, p. 270-274, apr 1971. ISSN 0021-8952. Disponível em: $<$ http://journals.ametsoc.org/doi/abs/10.1175/1520-0450\%281971\%29010\%3C0270\% 3AHCRTCD\%3E2.0.CO\%3B2>. Citado na página 29.

CHONG, M. et al. A Tropical Squall Line Observed during the COPT 81 Experiment in West Africa. Part 1: Kinematic Structure Inferred from Dual-Doppler Radar Data. Monthly Weather Review, v. 115, n. 3, p. 670-694, mar 1987. ISSN 0027-0644. Disponível em: <http://journals.ametsoc.org/doi/abs/10.1175/15200493\%281987\%29115\%3C0670\%3AATSLOD\%3E2.0.CO\%3B2>. Citado na página 32.

CIFELLI, R. et al. An Ensemble Study of Wet Season Convection in Southwest Amazonia: Kinematics and Implications for Diabatic Heating. Journal of Climate, v. 17, n. 24, p. 4692-4707, dec 2004. ISSN 0894-8755. Disponível em: < http: //journals.ametsoc.org/doi/abs/10.1175/JCLI-3236.1>. Citado na página 32.

CIFELLI, R. et al. Radar observations of the kinematic, microphysical, and precipitation characteristics of two MCSs in TRMM LBA. Journal of Geophysical Research D: Atmospheres, v. 107, n. 20, p. 8077, 2002. ISSN 01480227. Disponível em: $<$ http://doi.wiley.com/10.1029/2000JD000264>. Citado 3 vezes nas páginas 32, 45 e 46.

COPERNICUS CLIMATE CHANGE SERVICE. ERA5: Fifth generation of ECMWF atmospheric reanalyses of the global climate. Copernicus Climate Change Service Climate Data Store (CDS), 2017. Disponível em: <https://cds.climate.copernicus.eu/cdsapp\#!/ home>. Citado na página 52.

COURT, A.; GRIFFITHS, J. F. Thunderstorm Climatology. In: KESSLER, E. (Ed.). Thunderstorm Morphology and Dynamics of Thunderstorms: A Social, Scientific, and Technological Documentary. 2nd. ed. Norman: University of Oklahoma Press, 1982. cap. 2, p. 11-52. Citado 2 vezes nas páginas 23 e 29.

CUMMINS, K. L. et al. A combined TOA/MDF Technology Upgrade of the US National Lightning Detection Network. Journal of Geophysical Research - Atmospheres, v. 103, n. D8, p. 9035-9044, 1998. Citado 3 vezes nas páginas 51, 52 e 103.

DAVIES-JONES, R. P. Dual-Doppler Radar Coverage Area as a Function of Measurement Accuracy and Spatial Resolution. Journal of Applied Meteorology and Climatology, v. 18, n. 9, p. 1229-1233, sep 1979. ISSN 0021-8952. Disponível em: $<$ http://journals.ametsoc.org/doi/abs/10.1175/1520-0450-18.9.1229>. Citado 2 vezes nas páginas 33 e 34 .

DECKER, F. W.; CALVIN, L. D. Hailfall of 10 September 1959 Near Medford, Oregon. Bulletin of the American Meteorological Society, American Meteorological Society, v. 42, n. 7, p. 475-480, 1961. ISSN 00030007, 15200477. Disponível em: <https://www.jstor.org/stable/26246366http://www.jstor.org/stable/26246366>. Citado na página 28.

DEIERLING, W. et al. Towards the Relationship between Total Lightning Activity and Downward as well as Upward Ice Mass Fluxes in Thunderstorms. In: Conference on Meteorological Applications of Lightning Data. San Diego, CA: [s.n.], 2005. p. 1-6. Disponível em: <http://citeseerx.ist.psu.edu/viewdoc/summary?doi=10.1.1.572.251>. Citado na página 45. 
DEIERLING, W. et al. The relationship between lightning activity and ice fluxes in thunderstorms. Journal of Geophysical Research Atmospheres, v. 113, n. 15, p. 1-20, 2008. ISSN 01480227. Citado 2 vezes nas páginas 32 e 45.

DESSENS, J. A physical evaluation of a hail suppression project with silver iodide ground burners in southwestern France. 1998. 1588-1599 p. Disponível em: <http://journals.ametsoc.org/doi/abs/10.1175/1520-0450\%281998\%29037\%3C1588\% 3AAPEOAH\%3E2.0.CO\%3B2http://www.scopus.com/inward/record.url?eid=2-s2.00032999489\&partnerID $=40 \&$ md5 $=$ b060cee3ce8b5f3629467dc6cfdb0958 $>$. Citado na página 28.

DESSENS, J.; BERTHET, C.; SANCHEZ, J. L. A point hailfall classification based on hailpad measurements: The ANELFA scale. Atmospheric Research, Elsevier, v. 83, n. 2-4 SPEC. ISS., p. 132-139, feb 2007. ISSN 01698095. Disponível em: <https://www.sciencedirect.com/science/article/pii/S0169809506001281>. Citado 2 vezes nas páginas 38 e 39 .

DESSENS, J.; FRAILE, R. Hailstone size distributions in southwestern France. Atmospheric Research, v. 33, n. 1-4, p. 57-73, jun 1994. ISSN 01698095. Disponível em: <http://linkinghub.elsevier.com/retrieve/pii/0169809594900132>. Citado na página 23.

DOLAN, B.; RUTLEDGE, S. A. A theory-based hydrometeor identification algorithm for X-band polarimetric radars. Journal of Atmospheric and Oceanic Technology, v. 26, n. 10, p. 2071-2088, oct 2009. ISSN 07390572. Disponível em: $<$ http://journals.ametsoc.org/doi/abs/10.1175/2009JTECHA1208.1>. Citado na página 44.

DOLAN, B. A.; RUTLEDGE, S. A. An integrated display and analysis methodology for multivariable radar data. Journal of Applied Meteorology and Climatology, v. 46, n. 8, p. 1196-1213, aug 2007. ISSN 15588424. Disponível em: <http: //journals.ametsoc.org/doi/abs/10.1175/JAM2524.1>. Citado na página 33.

DOVIAK, R. J. et al. Error Estimation in Wind Fields Derived from Dual-Doppler Radar Measurement. Journal of Applied Meteorology, v. 15, n. 8, p. 868-878, aug 1976. ISSN 0021-8952. Disponível em: <http://journals.ametsoc.org/doi/abs/10.1175/15200450\%281976\%29015\%3C0868\%3AEEIWFD\%3E2.0.CO\%3B2http://journals.ametsoc. org/doi/abs/10.1175/1520-0450(1976)015\%3C0868:EEIWFD\%3E2.0.CO;2>. Citado na página 34.

DOVIAK, R. J.; ZRNIC, D. S. Doppler Radar and Weather Observations. 2. ed. Elsevier, 1993. 562 p. ISBN 9780122214226. Disponível em: < https://linkinghub.elsevier.com/ retrieve/pii/C20090223580>. Citado 2 vezes nas páginas 33 e 34.

ECCEL, E. et al. Quantitative hail monitoring in an alpine area: 35-year climatology and links with atmospheric variables. International Journal of Climatology, v. 32, n. 4, p. 503-517, 2012. ISSN 08998418. Citado na página 23.

EMERSIC, C.; SAUNDERS, C. P. Further laboratory investigations into the Relative Diffusional Growth Rate theory of thunderstorm electrification. Atmospheric Research, Elsevier, v. 98, n. 2-4, p. 327-340, nov 2010. ISSN 01698095. Disponível em: <https://www.sciencedirect.com/science/article/pii/S0169809510001869?via\%3Dihub>. Citado na página 26. 
ESTER, M. et al. A Density-Based Algorithm for Discovering Clusters in Large Spatial Databases with Noise. In: 2nd International Conference on Knowledge Discovery and Data Mining (KDD-96). [s.n.], 1996. v. 96, n. 34, p. 226-231. ISBN 1577350049. ISSN 09758887. Disponível em: <www.aaai.org > Citado na página 51.

GATLIN, P. N.; GOODMAN, S. J. A total lightning trending algorithm to identify severe thunderstorms. Journal of Atmospheric and Oceanic Technology, v. 27, n. 1, p. 3-22, jan 2010. ISSN 07390572. Disponível em: <http://journals.ametsoc.org/doi/abs/10.1175/ 2009JTECHA1286.1http://journals.ametsoc.org/doi/pdf/10.1175/2009JTECHA1286. $1>$. Citado na página 28.

GIAIOTTI, D.; NORDIO, S.; STEL, F. The climatology of hail in the plain of Friuli Venezia Giulia. Atmospheric Research, Elsevier, v. 67-68, p. 247-259, jul 2003. ISSN 01698095. Disponível em: <https://www.sciencedirect.com/science/article/pii/ S016980950300084X>. Citado na página 28.

GOLESTANI, Y.; CHANDRASEKAR, V.; BRINGI, V. N. Intercomparison of multiparameter radar measurements. In: 24th Conference on Radar Meteorology. [s.n.], 1989. p. 309-314. Disponível em: <https://scholar.google.com/scholar?q=Golestani\% $2 \mathrm{C}+\mathrm{Y} . \% 2 \mathrm{C}+\mathrm{V} .+$ Chandrasekar $\% 2 \mathrm{C}+$ and $+\mathrm{V} .+\mathrm{N} .+$ Bringi $\% 2 \mathrm{C}+$ Intercomparison + of + multiparameter + radar + measurements $+\& b t n G=\& h l=p t-B R \& a s \_s d t=0 \% 2 \mathrm{C} 5>$. Citado na página 45.

GOODMAN, S. J. et al. Lightning and precipitation history of a microburst-producing storm. Geophysical Research Letters, v. 15, n. 11, p. 1185-1188, oct 1988. ISSN 19448007. Disponível em: <http://onlinelibrary.wiley.com/doi/10.1029/GL015i011p01185/ abstracthttp://onlinelibrary.wiley.com/store/10.1029/GL015i011p01185/asset/ grl4105.pdf? $\mathrm{v}=1 \& \mathrm{t}=$ inswx4us\&s=9d958910f9d5fab99c1b1ced674e5f9b68b6d9f8http: //onlinelibrary.wiley.com/doi/10.1029/GL015i0>. Citado na página 28.

HAND, W. H.; CAPPELLUTI, G. A global hail climatology using the UK Met Office convection diagnosis procedure (CDP) and model analyses. Meteorological Applications, v. 18, n. 4, p. 446-458, dec 2011. ISSN 13504827. Disponível em: $<$ http://doi.wiley.com/10.1002/met.236>. Citado na página 29.

HELMUS, J. J.; COLLIS, S. M. The Python ARM Radar Toolkit ( Py-ART ), a Library for Working with Weather Radar Data in the Python Programming Language. Journal of Open Research Software, Ubiquity Press, v. 4, n. 1, p. e25, jul 2016. ISSN 2049-9647. Disponível em: <http://openresearchsoftware.metajnl.com/articles/10.5334/jors.119/>. Citado 3 vezes nas páginas 40, 42 e 49.

HERMAN, G. R.; NIELSEN, E. R.; SCHUMACHER, R. S. Probabilistic Verification of Storm Prediction Center Convective Outlooks. Weather and Forecasting, v. 33, n. 1, p. 161-184, feb 2018. ISSN 0882-8156. Disponível em: < http://journals.ametsoc.org/doi/ 10.1175/WAF-D-17-0104.1>. Citado na página 23.

HOHL, R.; SCHIESSER, H. H.; ALLER, D. Hailfall: The relationship between radar-derived hail kinetic energy and hail damage to buildings. Atmospheric Research, Elsevier, v. 63, n. 3-4, p. 177-207, aug 2002. ISSN 01698095. Disponível em: < https://www.sciencedirect.com/science/article/pii/S0169809502000595>. Citado na página 29. 
HUBBERT, J. et al. CSU-CHILL Polarimetric Radar Measurements from a Severe Hail Storm in Eastern Colorado. Journal of Applied Meteorology, v. 37, n. 8, p. 749-775, aug 1998. ISSN 0894-8763. Disponível em: <http://journals.ametsoc.org/doi/abs/10. 1175/1520-0450\%281998\%29037\%3C0749\%3ACCPRMF\%3E2.0.CO\%3B2>. Citado na página 32.

HUTCHINS, M. L.; HOLZWORTH, R. H. Thunderstorm characteristics from cluster analysis of lightning. In: XV International Conference on Atmospheric Electricity. [s.n.], 2014. p. 1-3. Disponível em: <http://wwlln.nethttp://www.nssl.noaa.gov/users/mansell/ icae2014/preprints/Hutchins_110.pdf>. Citado na página 51.

HUTCHINS, M. L.; HOLZWORTH, R. H.; BRUNDELL, J. B. Diurnal variation of the global electric circuit from clustered thunderstorms. Journal of Geophysical Research: Space Physics, Wiley-Blackwell, v. 119, n. 1, p. 620-629, jan 2014. ISSN 21699402. Disponível em: <http://doi.wiley.com/10.1002/2013JA019593>. Citado na página 51.

ILIINE, V. M.; MINUZZI, R. B.; ROLIM, J. L. W. Climatologia da precipitação de granizo na região central do estado de Santa Catarina. In: 16ř Congresso Brasileiro de Meteorologia. Belém: [s.n.], 2010. p. 5. Disponível em: <http: //www.sbmet.org.br/cbmet2010/artigos/749_39661.pdf >. Citado na página 28.

JAMES, C. N.; HOUZE, J. A real-time four-dimensional Doppler dealiasing scheme. Journal of Atmospheric and Oceanic Technology, v. 18, n. 10, p. 1674-1683, 2001. ISSN 07390572. Disponível em: <www.map.ethz.ch;>. Citado na página 49.

JAYARATNE, E. R.; SAUNDERS, C. P. R.; HALLETT, J. Laboratory studies of the charging of soft hail during ice crystal interactions. Quarterly Journal of the Royal Meteorological Society, v. 109, n. 461, p. 609-630, jul 1983. ISSN 00359009. Disponível em: <http://onlinelibrary.wiley.com/doi/10.1002/qj.49710946111/abstracthttp:

//onlinelibrary.wiley.com/store/10.1002/qj.49710946111/asset/49710946111_ftp.pdf?v= $1 \& \mathrm{t}=$ inswg7g $8 \& \mathrm{~s}=28 \mathrm{~b} 5 \mathrm{~d} 88 \mathrm{ce} 0 \mathrm{~b} 4 \mathrm{~b} 0 \mathrm{a} 239826690 \mathrm{afeac78b0bdc6416}>$. Citado na página 26.

JIN, H. G. et al. A hail climatology in South Korea. Atmospheric Research, Elsevier, v. 188, p. 90-99, may 2017. ISSN 01698095. Disponível em: <https://mail-attachment. googleusercontent.com/attachment/u/0/?ui=2\&ik=2def683244\&attid=0.1\&th $=$ 15fa0e0393aa213a\&view $=$ att\&disp $=$ inline\&realattid $=f \_j 9$ sherj10\&saddbat $=$ ANGjdJlCZlq7-zYYd-0RDNE7KUAfn-ZzZXWUt61KsV-go9Jxp92gRnVLlEB5CvbOQEXzq_ khf2ZqjbkHEyja_tdz3Z1->. Citado na página 23.

KNIGHT, C. A.; KNIGHT, N. C. The Falling Behavior of Hailstones. Journal of the Atmospheric Sciences, v. 27, n. 4, p. 672-681, jul 1970. ISSN 0022-4928. Disponível em: $<$ http://journals.ametsoc.org/doi/abs/10.1175/1520-0469\%281970\%29027\%3C0672\% 3ATFBOH\%3E2.0.CO\%3B2>. Citado na página 28.

KNIGHT, C. A.; KNIGHT, N. C. Hailstorms. In: DOSWELL, C. A. (Ed.). Severe Convective Storms. Boston, MA: American Meteorological Society, 2001. p. 223-254. ISBN 978-1-935704-06-5. Disponível em: <https://doi.org/10.1007/978-1-935704-06-5_6>. Citado 3 vezes nas páginas 23, 25 e 84 .

KNIGHT, C. A.; KNIGHT, N. C. Hailstorms. In: Severe Convective Storms. Boston, MA: American Meteorological Society, 2001. v. 28, n. 50, p. 223-254. 
Disponível em: <http://link.springer.com/10.1007/978-1-935704-06-5_6http: //journals.ametsoc.org/page/0065-9401-28.50.223>. Citado na página 28.

KNIGHT, C. A.; KNIGHT, N. C. Very large hailstones from Aurora, Nebraska. Bulletin of the American Meteorological Society, American Meteorological Society, v. 86, n. 12, p. 1773-1781, dec 2005. ISSN 00030007. Disponível em: < http: //journals.ametsoc.org/doi/10.1175/BAMS-86-12-1773>. Citado na página 28.

KRIEGEL, H. P. et al. Density-based clustering. Wiley Interdisciplinary Reviews: Data Mining and Knowledge Discovery, John Wiley \& Sons, Ltd, v. 1, n. 3, p. 231-240, may 2011. ISSN 19424787. Disponível em: <http://doi.wiley.com/10.1002/widm.30>. Citado na página 51.

LANG, T.; DOLAN, B.; GUY, N. CSU-Radarmet/CSU_RadarTools: CSU_RadarTools v1.2. 2017. Disponível em: <https://zenodo.org/record/1035908>. Citado 4 vezes nas páginas 42, 44, 46 e 85.

LANG, T. J.; RUTLEDGE, S. A. Relationships between Convective Storm Kinematics, Precipitation, and Lightning. Monthly Weather Review, v. 130, n. 10, p. 2492-2506, oct 2002. ISSN 0027-0644. Disponível em: <http://radarmet.atmos.colostate.edu/steps/http: //journals.ametsoc.org/doi/abs/10.1175/1520-0493\%282002\%29130\%3C2492\% 3ARBCSKP\%3E2.0.CO\%3B2>. Citado na página 32.

LEWIS, E. A.; HARVEY, R. B.; RASMUSSEN, J. E. Hyperbolic direction finding with sferics of transatlantic origin. Journal of Geophysical Research, v. 65, n. 7, p. 1879, jul 1960. ISSN 0148-0227. Disponível em: <http://doi.wiley.com/10.1029/JZ065i007p01879http: //www.agu.org/pubs/crossref/1960/JZ065i007p01879.shtml>. Citado na página 50.

LIU, H.; CHANDRASEKAR, V. Classification of Hydrometeors Based on Polarimetric Radar Measurements: Development of Fuzzy Logic and Neuro-Fuzzy Systems, and In Situ Verification. Journal of Atmospheric and Oceanic Technology, v. 17, n. 2, p. 140-164, feb 2000. ISSN 0739-0572. Disponível em: <http://journals.ametsoc.org/doi/abs/10. 1175/1520-0426\%282000\%29017\%3C0140\%3ACOHBOP\%3E2.0.CO\%3B2>. Citado 2 vezes nas páginas 42 e 44 .

LYONS, W. A. et al. Enhanced Positive Cloud-to-Ground Lightning in Thunderstorms Ingesting Smoke from Fires. Science, v. 282, n. 5386, p. 77-80, 1998. ISSN 1095-9203. Disponível em: <http://science.sciencemag.org/content/282/5386/77.shorthttp: //science.sciencemag.org/content/sci/282/5386/77.full.pdf $>$. Citado 2 vezes nas páginas 27 e 28.

MACGORMAN, D. R.; BURGESS, D. W. Positive Cloud-to-Ground Lightning in Tornadic Storms and Hailstorms. Monthly Weather Review, v. 122, n. 8, p. 1671-1697, aug 1994. ISSN 0027-0644. Disponível em: <http://journals.ametsoc.org/doi/abs/10. 1175/1520-0493\%281994\%29122\%3C1671\%3APCTGLI\%3E2.0.CO\%3B2>. Citado 2 vezes nas páginas 27 e 28 .

MACGORMAN, D. R.; RUST, W. D. The Electrical Nature of Storms. [S.l.]: Oxford University Press, 1998. 422 p. ISBN 0195073371. Citado na página 51.

MACHADO, L. A. T. et al. The CHUVA project: How does convection vary across Brazil? Bulletin of the American Meteorological Society, American Meteorological 
Society, v. 95, n. 9, p. 1365-1380, sep 2014. ISSN 00030007. Disponível em: $<$ http://journals.ametsoc.org/doi/abs/10.1175/BAMS-D-13-00084.1>. Citado na página 23.

MARTINS, J. A. et al. Climatology of destructive hailstorms in Brazil. Atmospheric Research, v. 184, p. 126-138, feb 2017. ISSN 01698095. Disponível em: < http: //linkinghub.elsevier.com/retrieve/pii/S016980951630480X >. Citado 2 vezes nas páginas 23 e 29.

MATTOS, E. V. et al. Polarimetric radar characteristics of storms with and without lightning activity. Journal of Geophysical Research, John Wiley and Sons, Ltd, v. 121, n. 23, p. 14,201-14,220, dec 2016. ISSN 21562202. Disponível em: $<$ http://doi.wiley.com/10.1002/2016JD025142>. Citado na página 65.

MATTOS, E. V. et al. Electrification life cycle of incipient thunderstorms. Journal of Geophysical Research, John Wiley and Sons, Ltd, v. 122, n. 8, p. 4670-4697, apr 2017. ISSN 21562202. Disponível em: <http://doi.wiley.com/10.1002/2016JD025772>. Citado na página 65.

MOLlER, A. R. Severe Local Storms Forecasting. In: Severe Convective Storms. Boston, MA: American Meteorological Society, 2001. p. 433-480. Disponível em: <http://link.springer.com/10.1007/978-1-935704-06-5_11>. Citado na página 23.

MORGAN, G. M.; SUMMERS, P. W. Hailfall and Hailstorm Characteristics.

Thunderstorm Morphology and Dynamics, University of Oklahoma Press Norman, USA, p. 237-257, 1986. Citado na página 31.

MORGAN, G. M.; TOWERY, N. G. On the Role of Strong Winds in Damage to Crops by Hail and Its Estimation with a Simple Instrument. 1976. 891-898 p. Disponível em: <http://journals.ametsoc.org/doi/abs/10.1175/1520-0450\%281976\%29015\%3C0891\% 3AOTROSW\%3E2.0.CO\%3B2>. Citado 2 vezes nas páginas 23 e 29.

MURPHY, M. J.; NAG, A. Cloud lightning performance and climatology of the U.S. based on the upgraded U.S. National Lightning Detection Network. In: Seventh Conference on the Meteorological Applications of Lightning Data. Phoenix, AZ: [s.n.], 2015. Disponível em: <https://ams.confex.com/ams/95Annual/webprogram/Paper262391.html>.

Citado 2 vezes nas páginas 51 e 52 .

NACCARATO, K. P. et al. Evaluation of BrasilDAT relative detection efficiency based on LIS observations and a numeric model. In: 2014 International Conference on Lightning Protection (ICLP). Shanghai: [s.n.], 2014. Disponível em: < http://mtcm21b.sid.inpe.br/col/sid.inpe.br/mtc-m21b/2014/12.17.16.43/doc/Naccarato_ILDC_ 2014_final.pdf?metadatarepository $=\&$ mirror $=$ iconet.com.br/banon $/ 2006 / 11 . \overline{2} 6.21 .31>$. Citado na página 50.

NASCIMENTO, E. L. Previsão de Tempestades Severas utilizando-se Parâmetros Convectivos e Modelos de Mesoescala: Uma Estratégia Operacional adotável no Brasil? Revista Brasileira de Meteorologia, v. 20, n. 1, p. 121-140, 2005. Citado na página 23.

PEREYRA, R. G. et al. A laboratory study of graupel charging. Journal of Geophysical Research Atmospheres, John Wiley and Sons, Ltd, v. 105, n. D16, p. 20803-20812, aug 2000. ISSN 01480227. Disponível em: <http://doi.wiley.com/10.1029/2000JD900244>. Citado na página 26. 
PETERSEN, W. A. et al. Mesoscale and Radar Observations of the Fort Collins Flash Flood of 28 July 1997. Bulletin of the American Meteorological Society, v. 80, n. 2, p. 191-216, feb 1999. ISSN 0003-0007. Disponível em: <http://journals.ametsoc.org/ doi/abs/10.1175/1520-0477\%281999\%29080\%3C0191\%3AMAROOT\%3E2.0.CO\%3B2>. Citado na página 32 .

PINEDA, N. et al. Charge structure analysis of a severe hailstorm with predominantly positive cloud-to-ground lightning. Atmospheric Research, Elsevier, v. 178-179, p. 31-44, sep 2016. ISSN 01698095. Disponível em: <http://www.sciencedirect.com/science/ article/pii/S0169809516300606?_rdoc=1\&_fmt=high\&_origin=gateway\&_docanchor= \&md5=b8429449ccfc9c30159a5f9aeaa92ffb\&dgcid=raven_sd_recommender_emailhttps: //www.sciencedirect.com/science/article/pii/S0169809516300606?via\%25>. Citado 2 vezes nas páginas 27 e 28.

POČAKAL, D.; VEČENAJ, Ž.; ŠTALEC, J. Hail characteristics of different regions in continental part of Croatia based on influence of orography. Atmospheric Research, Elsevier, v. 93, n. 1-3, p. 516-525, jul 2009. ISSN 01698095. Disponível em: $<$ https://www.sciencedirect.com/science/article/pii/S0169809508003049>. Citado na página 28.

POTVIN, C. K. et al. 3DVAR versus Traditional Dual-Doppler Wind Retrievals of a Simulated Supercell Thunderstorm. Monthly Weather Review, 2012. ISSN 0027-0644. Citado na página 32.

POTVIN, C. K.; SHAPIRO, A.; XUE, M. Impact of a vertical vorticity constraint in variational dual-doppler wind analysis: Tests with real and simulated supercell data. Journal of Atmospheric and Oceanic Technology, v. 29, n. 1, p. 32-49, 2012. ISSN 07390572. Citado 3 vezes nas páginas 32, 47 e 49.

PUIG, R. Características da precipitação e atividade elétrica de tempestades severas da Região Metropolitana de São Paulo. Tese (Doutorado) - Universidade de São Paulo, 2017. Citado na página 30.

PYTHON CORE TEAM. Python: A dynamic, open source programming language. [S.l.]: Python Software Foundation, 2018. Citado 2 vezes nas páginas 35 e 53.

R CORE TEAM. R: A Language and Environment for Statistical Computing. Vienna, Austria, 2018. Disponível em: <https://www.r-project.org > . Citado 2 vezes nas páginas 35 e 52.

RAUBER, R. M.; NESBITT, S. W. Radar Meteorology: A First Course. 1. ed. Hoboken, NJ: Wiley-Blackwell, 2018. 488 p. ISBN 978-1-118-43262-4. Citado 3 vezes nas páginas 31,41 e 49.

RAY, P. S. et al. Triple-Doppler Observations of a Convective Storm. 1978. 1201-1212 p. Disponível em: <http://journals.ametsoc.org/doi/abs/10.1175/15200450\%281978\%29017\%3C1201\%3ATDOOAC\%3E2.0.CO\%3B2http://journals.ametsoc. org/doi/abs/10.1175/1520-0450(1978)017\%3C1201:TDOOAC\%3E2.0.CO;2>. Citado na página 32 .

RAY, P. S. et al. Single- and Multiple-Doppler Radar Observations of Tornadic Storms. Monthly Weather Review, v. 108, n. 10, p. 1607-1625, oct 1980. ISSN 
0027-0644. Disponível em: <http://journals.ametsoc.org/doi/abs/10.1175/15200493\%281980\%29108\%3C1607\%3ASAMDRO\%3E2.0.CO\%3B2>. Citado na página 32.

REINKING, R. F. Formation of graupel. Journal of Applied Meteorology, v. 14, n. 5, p. 745-754, aug 1975. ISSN 0021-8952. Disponível em: <http://journals.ametsoc.org/doi/ abs/10.1175/1520-0450\%281975\%29014\%3C0745\%3AFOG\%3E2.0.CO\%3B2>. Citado na página 25.

RINEHART, R. E. Radar for Meteorologists. [S.l.]: Rinehart Publications, 1997. 428 p. ISBN 9780965800211 (pbk.)0̊965800210 (pbk.). Citado na página 32.

RUTLEDGE, S. et al. Early results from TRMM-LBA: kinematic and microphysical characteristics of convection in distinct meteorological regimes. In: IGARSS 2000. IEEE 2000 International Geoscience and Remote Sensing Symposium. Taking the Pulse of the Planet: The Role of Remote Sensing in Managing the Environment. Proceedings (Cat. No.00CH37120). IEEE, 2000. v. 3, p. 1358-1360. ISBN 0-7803-6359-0. Disponível em: $<$ http://ieeexplore.ieee.org/document/858118/>. Citado na página 32.

RYZHKOV, A. V.; ZRNIC, D. S. Comparison of Dual-Polarization Radar Estimators of Rain. 1995. 249-256 p. Disponível em: <http://journals.ametsoc.org/doi/abs/10. 1175/1520-0426\%281995\%29012\%3C0249\%3ACODPRE\%3E2.0.CO\%3B2>. Citado na página 46.

SÁNCHEZ, J. L. et al. Characterization of hailstone size spectra in hailpad networks in France, Spain, and Argentina. Atmospheric Research, Elsevier B.V., v. 93, n. 1-3, p. 641-654, 2009. ISSN 01698095. Disponível em: <http://dx.doi.org/10.1016/j.atmosres. 2008.09.033>. Citado 2 vezes nas páginas 28 e 56.

SÁNCHEZ, J. L. et al. Nowcasting of kinetic energy of hail precipitation using radar. Atmospheric Research, Elsevier, v. 123, p. 48-60, apr 2013. ISSN 01698095. Disponível em: <http://www.sciencedirect.com/science/article/pii/S0169809512002578?via\%3Dihub>. Citado na página 28.

SASSEN, K. Ice Cloud Content from Radar Reflectivity. 1987. 1050-1053 p. Disponível em: <http://journals.ametsoc.org/doi/abs/10.1175/1520-0450\%281987\%29026\%3C1050\% 3AICCFRR\%3E2.0.CO\%3B2http://journals.ametsoc.org/doi/abs/10.1175/15200450(1987)026\%3C1050:ICCFRR\%3E2.0.CO;2> . Citado na página 45.

SAUNDERS, C. P. R. Charge separation mechanisms in clouds. Space Science Reviews, Springer New York, v. 137, n. 1-4, p. 335-353, 2008. ISSN 00386308. Disponível em: <http://link.springer.com/chapter/10.1007/978-0-387-87664-1_22http: //link.springer.com/chapter/10.1007/978-0-387-87664-1_22\#page-1>. Citado na página 26.

SAUNDERS, C. P. R. et al. Laboratory studies of the effect of cloud conditions on graupel/crystal charge transfer in thunderstorm electrification. Quarterly Journal of the Royal Meteorological Society, v. 132, n. 621, p. 2653-2673, oct 2006. ISSN 00359009, 1477870X. Disponível em: <http://doi.wiley.com/10.1256/qj.05.218http: //www.atmo.arizona.edu/students/courselinks/spring07/atmo589/articles/Saunders_ et_al_2006.pdfhttp://doi.wiley.com/10.1256/qj.05.218\%5Cnhttp://www.atmo.arizona. edu/students/courselinks/spring07/atmo589/articles/>. Citado na página 26. 
SCHLEUSENER, R. A. ; JENNINGS, P. C. . An Energy Method for Relative Estimates of Hail Intensity. Bulletin of the American Meteorological Society, v. 41, n. 7, p. 372-376, 1960. Disponível em: <https://dspace.library.colostate.edu/bitstream/handle/10217/ 37628/0001_Bluebook.pdf?sequence=1https:// mountainscholar.org/bitstream/handle/ 10217/37628/0001_Bluebook.pdf?sequence=1>. Citado na página 28.

SCHMID, W.; SCHIESSER, H. H.; WALDVOGEL, A. The Kinetic Energy of Hailfalls. Part IV: Patterns of Hailpad and Radar Data. Journal of Applied Meteorology, v. 31, n. 10, p. 1165-1178, oct 1992. ISSN 0894-8763. Disponível em: <http://journals.ametsoc.org/ doi/abs/10.1175/1520-0450\%281992\%29031\%3C1165\%3ATKEOHP\%3E2.0.CO\%3B2>. Citado na página 28.

SCHULTZ, C. J.; PETERSEN, W. A.; CAREY, L. D. Preliminary development and evaluation of lightning jump algorithms for the real-time detection of severe weather. Journal of Applied Meteorology and Climatology, v. 48, n. 12, p. 2543-2563, dec 2009. ISSN 15588424. Disponível em: < http://journals.ametsoc.org/doi/abs/10.1175/ 2009JAMC2237.1>. Citado na página 28.

SCHultz, C. J.; PETERSEN, W. A.; CAREY, L. D. Lightning and Severe Weather: A Comparison between Total and Cloud-to-Ground Lightning Trends. Weather and Forecasting, v. 26, n. 5, p. 744-755, oct 2011. ISSN 0882-8156. Disponível em: <http://journals.ametsoc.org/doi/abs/10.1175/WAF-D-10-05026.1http: //journals.ametsoc.org/doi/pdf/10.1175/WAF-D-10-05026.1> . Citado na página 28.

SCHUSTER, S. S.; BLONG, R. J.; MCANENEY, K. J. Relationship between radar-derived hail kinetic energy and damage to insured buildings for severe hailstorms in Eastern Australia. Atmospheric Research, Elsevier, v. 81, n. 3, p. 215-235, sep 2006. ISSN 01698095. Disponível em: < https://www.sciencedirect.com/science/article/pii/ S0169809506000056>. Citado na página 29.

SHAPIRO, A.; POTVIN, C. K.; GAO, J. Use of a vertical vorticity equation in variational dual-doppler wind analysis. Journal of Atmospheric and Oceanic Technology, 2009. ISSN 07390572. Citado na página 47.

SIMPSON, G.; ROBINSON, G. D. The Distribution of Electricity in Thunderclouds, II. Proceedings of the Royal Society A: Mathematical, Physical and Engineering Sciences, v. 177, n. 970, p. 281-329, 1941. ISSN 1364-5021. Disponível em: $<$ http://rspa.royalsocietypublishing.org/cgi/doi/10.1098/rspa.1941.0013>. Citado na página 27.

SIMPSON, G.; SCRASE, F. J. The Distribution of Electricity in Thunderclouds. Proceedings of the Royal Society A: Mathematical and Physical Sciences, v. 161, n. 906, p. 309-352, 1937. Disponível em: <http://www-jstor-org.ez67.periodicos.capes.gov.br/ stable/96788?seq=1\#page_scan_tab_contents $>$. Citado na página 27.

SPERLING, V. B. Processos físicos e elétricos das tempestades de granizo na região sul do Brasil. 277 p. Tese (Doutorado) - Instituto Nacional de Pesquisas Espaciais, 2018. Disponível em: < http://urlib.net/8JMKD3MGP3W34P/3QE4KB5>. Citado na página 29.

STRAKA, J. M.; ZRNIĆ, D. S.; RYZHKOV, A. V. Bulk Hydrometeor Classification and Quantification Using Polarimetric Radar Data: Synthesis of Relations. Journal of 
Applied Meteorology, v. 39, n. 8, p. 1341-1372, aug 2000. ISSN 0894-8763. Disponível em: <http://journals.ametsoc.org/doi/abs/10.1175/1520-0450\%282000\%29039\%3C1341\% 3ABHCAQU\%3E2.0.CO\%3B2>. Citado 2 vezes nas páginas 40 e 45.

SVABIK, O. Review of meteorological aspects on hail defense activities in Austria. Theoretical and Applied Climatology, v. 40, n. 4, p. 247-254, 1989. ISSN 0177798X. Disponível em: <https://link.springer.com/content/pdf/10.1007\%2FBF00865975.pdf>. Citado na página 28.

TAKAHASHI, T. Riming Electrification as a Charge Generation Mechanism in Thunderstorms. Journal of the Atmospheric Sciences, v. 35, n. 8, p. 1536-1548, aug 1978. ISSN 0022-4928. Disponível em: <http://journals.ametsoc.org/doi/abs/10.1175/15200469(1978)035\%3C1536:REAACG\%3E2.0.CO;2http://journals.ametsoc.org/doi/pdf/ 10.1175/1520-0469(1978)035\%3C1536:REAACG\%3E2.0.CO;2>. Citado 2 vezes nas páginas 26 e 27.

THOMAZ JÚNIOR, J. C. Sítios Experimentais do Hailpad. Campinas: [s.n.], 2016. 10 p. Disponível em: <http://soschuva.cptec.inpe.br/soschuva/pdf/reunioes/1705/CelsoThomaz-ApresentacaoHailpad_mai2016.pdf $>$. Citado 4 vezes nas páginas 11, 36,37 e 38 .

THOMAZ JÚNIOR, J. C. et al. Desenvolvimento de uma Metodologia para Medidas de Eventos de Granizo (Concepção, Materiais, Correspondência dos Dados e Referência) no Laboratório de Instrumentação Meteorológica (LIM). [S.l.], 2015. 14 p. Citado na página 38.

VEMADO, F.; Pereira Filho, A. J. Severe weather caused by heat island and sea breeze effects in the metropolitan area of são paulo, Brazil. Advances in Meteorology, Hindawi, v. 2016, p. 1-13, dec 2016. ISSN 16879317. Disponível em: <http://www.hindawi.com/journals/amete/2016/8364134/>. Citado na página 23.

Vernessa Himmler Illustration. Weather Cat-O-Mat. 2017. Disponível em: < https: //www.facebook.com/VernessaHimmlerIllustration/photos/a.1067533986699890/ 1335982643188355/>. Citado na página 5.

VILA, D. A. et al. Forecast and Tracking the Evolution of Cloud Clusters (ForTraCC) Using Satellite Infrared Imagery: Methodology and Validation. Weather and Forecasting, v. 23, n. 2, p. 233-245, apr 2008. ISSN 0882-8156. Disponível em: $<$ http://journals.ametsoc.org/doi/abs/10.1175/2007WAF2006121.1>. Citado 3 vezes nas páginas 41, 42 e 84 .

WALDVOGEL, A. et al. The Kinetic Energy of Hailfalls. Part II: Radar and Hailpads. Journal of Applied Meteorology, v. 17, n. 11, p. 1680-1693, nov 1978. ISSN 0021-8952. Disponível em: <http://journals.ametsoc.org/doi/abs/10.1175/1520-0450\% 281978\%29017\%3C1680\%3ATKEOHP\%3E2.0.CO\%3B2https://doi.org/10.1175/15200450(1978)017\%3C1680:TKEOHP\%3E2.0.CO;2>. Citado 2 vezes nas páginas 28 e 29.

WALDVOGEL, A. et al. The Kinetic Energy of Hailfalls. Part I: Hailstone Spectra. Journal of Applied Meteorology, v. 17, n. 4, p. 515-520, apr 1978. ISSN 0021-8952. Disponível em: <http://journals.ametsoc.org/doi/abs/10.1175/15200450\%281978\%29017\%3C0515\%3ATKEOHP\%3E2.0.CO\%3B2>. Citado na página 37. 
WEAVER, J. F.; NELSON, S. P. Multiscale Aspects of Thunderstorm Gust Fronts ant Their Effects on Subsequent Storm Development. Monthly Weather Review, v. 110, n. 7, p. 707-718, jul 1982. ISSN 0027-0644. Disponível em: < http://journals.ametsoc.org/ doi/abs/10.1175/1520-0493\%281982\%29110\%3C0707\%3AMAOTGF\%3E2.0.CO\%3B2>. Citado na página 32.

WEBB, J. D. C.; ELSOM, D. M.; MEADEN, G. T. The TORRO hailstorm intensity scale. J Meteorol, v. 11, p. 337-339, 1986. Citado na página 38.

WILLIAMS, E. R. The tripole structure of thunderstorms. Journal of Geophysical Research: Atmospheres, v. 94, n. D11, p. 13151-13167, sep 1989. ISSN 2156-2202.

Disponível em: <http://onlinelibrary.wiley.com/doi/10.1029/JD094iD11p13151/ abstracthttp://onlinelibrary.wiley.com/doi/10.1029/JD094iD11p13151/abstract; jsessionid=1E8A23A85D1BD6C9640C9F4A0A3CDCDB.f04t01http://onlinelibrary.wiley. com/doi/10.1029/JD094iD11p13151/abstract\%25>. Citado na página 27.

WILLIAMS, E. R. et al. The behavior of total lightning activity in severe Florida thunderstorms. Atmospheric Research, v. 51, n. 3, p. 245-265, jul 1999. ISSN 01698095. Disponível em: <http://www.sciencedirect.com/science/article/pii/S0169809599000113http: //www.sciencedirect.com/science/article/pii/S0169809599000113/pdfft?md5= 89f3411e000bda6c019b13cde2dd8fca\&pid=1-s2.0-S0169809599000113-main.pdf $>$. Citado na página 28.

WILLIAMS, E. R.; ZHANG, R.; RYDOCK, J. Mixed-Phase Microphysics and Cloud Electrification. 1991. 2195-2203 p. Disponível em: < http://journals.ametsoc.org/doi/ abs/10.1175/1520-0469\%281991\%29048\%3C2195\%3AMPMACE\%3E2.0.CO\%3B2http: //journals.ametsoc.org/doi/abs/10.1175/1520-0469(1991)048\%3C2195:MPMACE\%3E2. 0.CO;2>. Citado 2 vezes nas páginas 26 e 27.

WILSON, C. T. R. Investigations on Lightning Discharges and on the Electric Field of Thunderstorms. Philosophical Transactions of the Royal Society of London. Series A, Containing Papers of a Mathematical or Physical Character, v. 221, p. 73-115, 1921. ISSN 0264-3952. Disponível em: <http://www-jstor-org.ez67.periodicos.capes.gov.br/stable/ 91189?.seq=1\#page_scan_tab_contentshttp://www.jstor.org/stable/91189\%5Cnhttp: //www.jstor.org/stable/pdfplus/91189.pdf?acceptTC=true>. Citado na página 27.

WILSON, J. W. et al. Microburst Wind Structure and Evaluation of Doppler Radar for Airport Wind Shear Detection. Journal of Climate and Applied Meteorology, v. 23, n. 6, p. 898-915, jun 1984. ISSN 0733-3021. Disponível em: <http://journals.ametsoc.org/ doi/abs/10.1175/1520-0450\%281984\%29023\%3C0898\%3AMWSAEO\%3E2.0.CO\%3B2>. Citado na página 32 .

WURMAN, J. et al. Dual-Doppler and Single-Doppler Analysis of a Tornadic Storm Undergoing Mergers and Repeated Tornadogenesis. Monthly Weather Review, v. 135, n. 3, p. 736-758, mar 2007. ISSN 0027-0644. Disponível em: <http://journals.ametsoc.org/doi/abs/10.1175/MWR3276.1>. Citado na página 32. 

Anexos 



\section{ANEXO A - Conversão Strokes-Flashes: Teste de Sensibilidade de $\epsilon_{S p c}$}

A distância base entre strokes $\epsilon_{s p c}$ usada no algoritmo DBSCAN para a rede BrasilDAT foi determinada considerando que ela seria mínima (para evitar excesso de agrupamento) desde que o tempo entre strokes e entre flashes apresentasse uma distribuição unimodal centralizada em no máximo $1 \mathrm{~s}$.

A Figura 40 mostra as estatísticas do agrupamento de strokes em flashes para diferentes valores de $\epsilon_{s p c}$ usando a base de dados da rede BrasilDAT . O histograma de tempo entre strokes (a) mostra uma distribuição unimodal centralizada em aproximadamente $0,1 s$ cuja contagem aumenta com $\epsilon_{s p c}$ (já que a quantidade de strokes em um flash também aumenta com $\epsilon_{s p c}$ ); o tempo máximo entre flashes também ligeiramente aumenta com $\epsilon_{s p c}$, ultrapassando o limite de $500 \mathrm{~ms}$ estabelecido por Cummins et al. (1998) para $\epsilon_{s p c}=5 \mathrm{~km}$. O histograma de tempo entre flashes (a) mostra uma distribuição bimodal centralizada em aproximadamente 0,2 e $1 s$ que se torna unimodal centralizada em $1 s$ com o aumento de $\epsilon_{s p c}$. O número máximo de strokes por flash (b) ligeiramente aumenta com $\epsilon_{s p c}$, de 17 para 20 strokes. A distância entre strokes em um flash (c), diretamente influenciada por $\epsilon_{s p c}$, mostra uma distribuição unimodal centralizada próxima a zero, com uma maior quantidade de pontos até o valor de $\epsilon_{s p c}$ escolhido e alguns pontos com até o dobro da distância $\epsilon_{s p c}$; nota-se que, mesmo para $\epsilon_{s p c}=5 \mathrm{~km}(40 \mathrm{c})$, os pontos na distância máxima ainda estão dentro da consideração (b) da subseção 3.3 .1 (strokes subsequentes em um raio máximo de $50 \mathrm{~km}$ ). Dentro das determinações estipuladas, definiu-se que $\epsilon_{s p c}=2,5 \mathrm{~km}$ é a escolha mais adequada. 
Figura 40 - Histogramas de tempo entre strokes e entre flashes (a), número de strokes por flash (b) e distância latitude e longitudinal entre strokes em um flash (c) para diferentes valores de $\epsilon_{\mathrm{spc}}$.
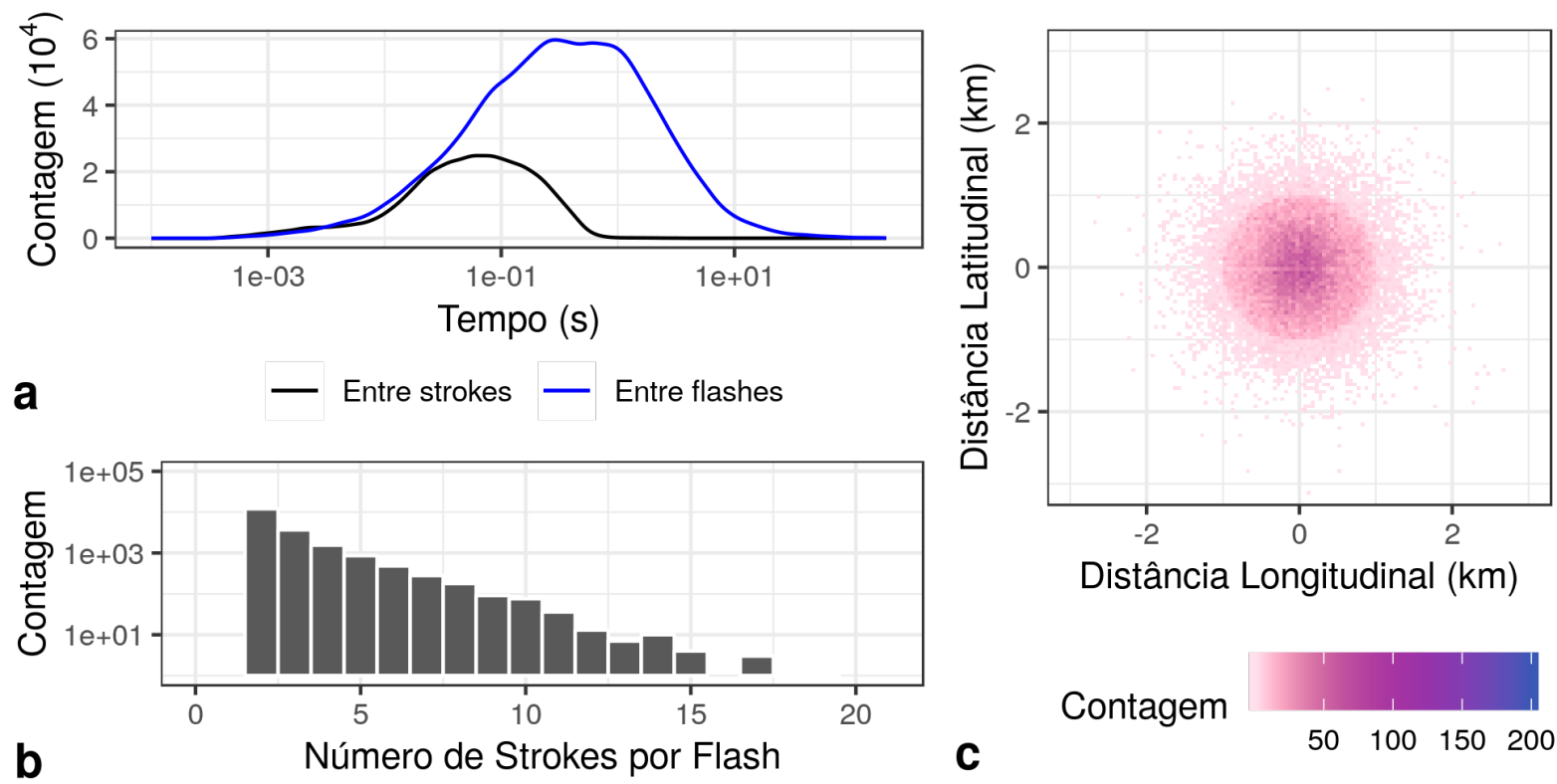

(a) $\epsilon_{\mathrm{spc}}=1 \mathrm{~km}$

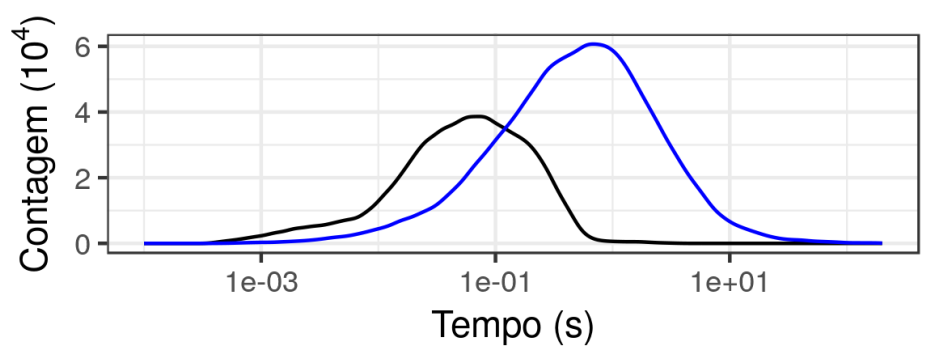

a $\quad$ Entre strokes - Entre flashes

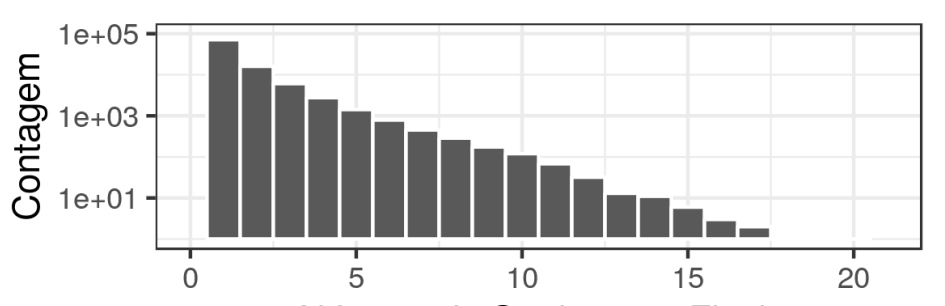

b Número de Strokes por Flash

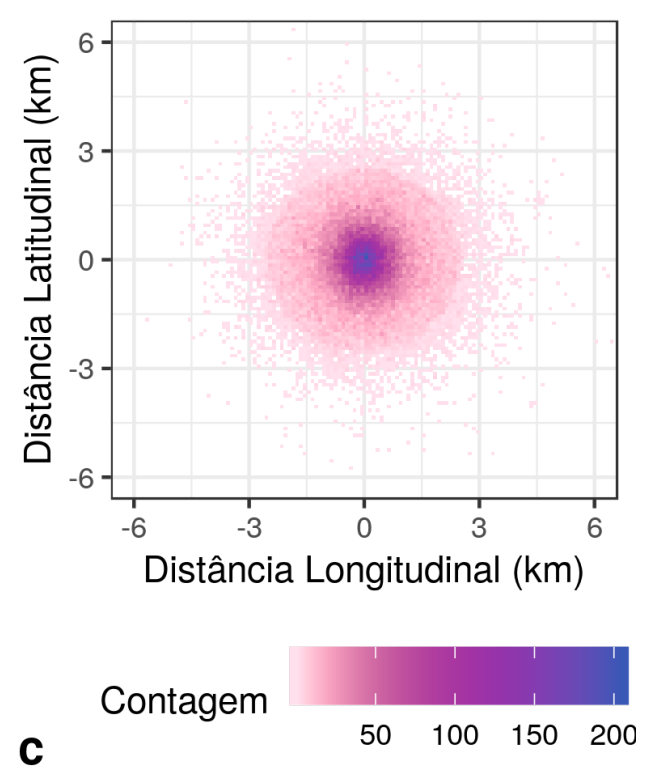

(b) $\epsilon_{\mathrm{spc}}=2,5 \mathrm{~km}$

Fonte: Produzido pela autora. 
Figura 40 - Continuação.
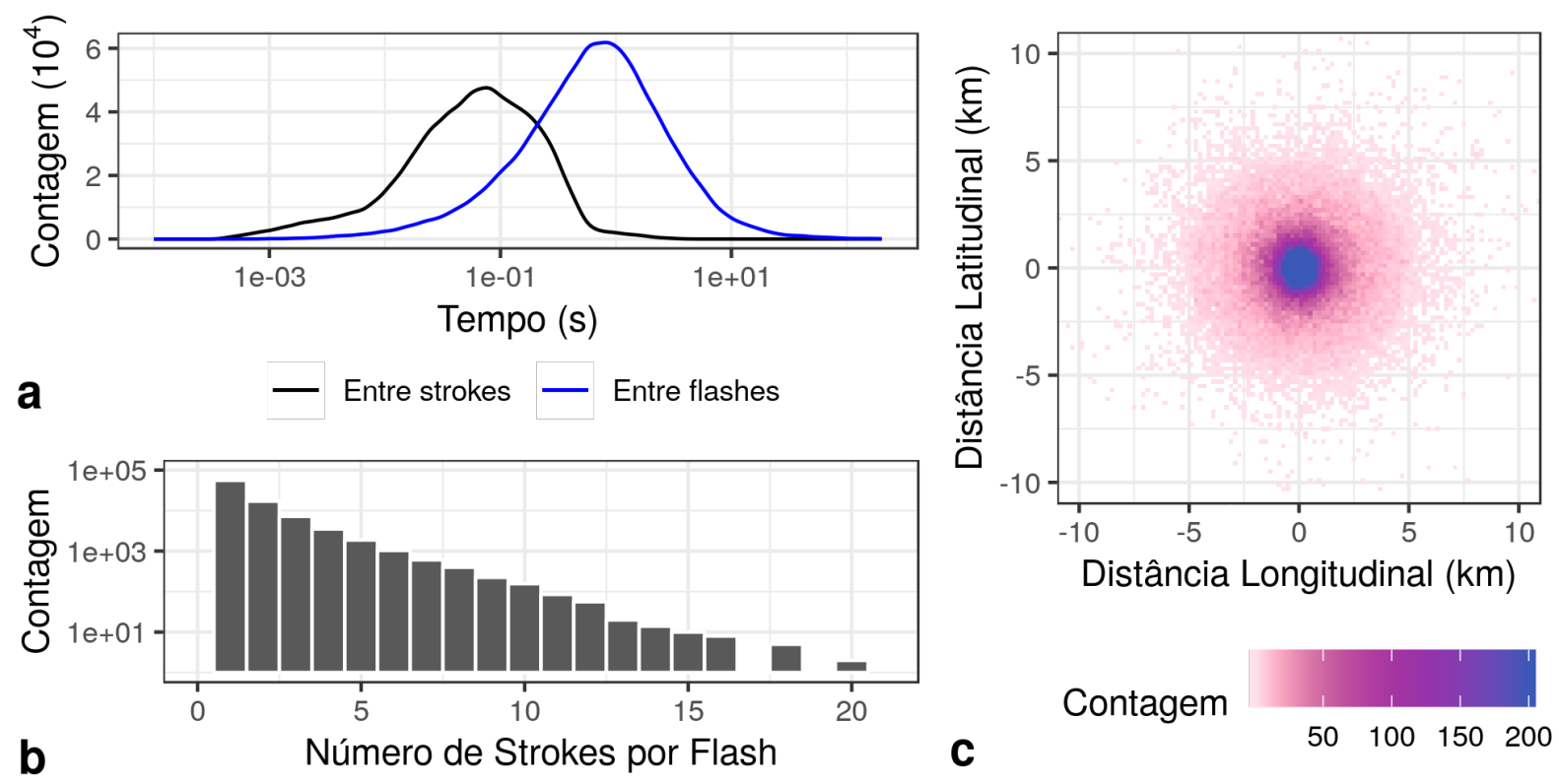

(c) $\epsilon_{\mathrm{spc}}=5 \mathrm{~km}$

Fonte: Produzido pela autora. 